Vinicius Antonio de Oliveira Martins

Verificação Funcional para Circuitos de Transmissão e Recepção de Sinais Mistos

São Paulo 
Vinicius Antonio de Oliveira Martins

Verificação Funcional para Circuitos de Transmissão e Recepção de Sinais Mistos

Dissertação apresentada à Escola Politécnica da Universidade de São Paulo para obtenção do título de Mestre em Ciências no Programa de Engenharia Elétrica.

São Paulo 
Vinicius Antonio de Oliveira Martins

\section{Verificação Funcional para Circuitos de Transmissão e Recepção de Sinais Mistos}

Dissertação apresentada à Escola Politécnica da Universidade de São Paulo para obtenção do título de Mestre em Ciências no Programa de Engenharia Elétrica.

Área de concentração: Microeletrônica

Orientador: Prof. Dr. Wang Jiang Chau

São Paulo 
Este exemplar foi revisado e corrigido em relação à versão original, sob responsabilidade única do autor e com a anuência de seu orientador.

São Paulo, de de

Assinatura do autor:

Assinatura do orientador:

Catalogação-na-publicação

Martins, Vinicius Antonio de Oliveira

Verificação Funcional para Circuitos de Transmissão e Recepção de Sinais Mistos / V. A. O. Martins -- versão corr. -- São Paulo, 2017. $112 \mathrm{p}$.

Dissertação (Mestrado) - Escola Politécnica da Universidade de São Paulo. Departamento de Engenharia de Energia e Automação Elétricas.

1.ENGENHARIA ELÉTRICA 2.CIRCUITOS DIGITAIS 3.CIRCUITOS INTEGRADOS 4.CIRCUITOS DE SINAIS MISTOS 5.VERIFICAÇÃO DE CIRCUITOS INTEGRADOS I.Universidade de São Paulo. Escola Politécnica. Departamento de Engenharia de Energia e Automação Elétricas II.t. 
Dedico este trabalho primeiramente a Deus que iluminou meu caminho durante esta caminhada tornando possível a realização de um sonho.

À minha familia, que me mostrou o valor do trabalho árduo, da perseverança, me deu apoio e sempre me motivou durante toda a minha jornada.

À minha noiva, por acreditar em minha capacidade, por seu apoio incondicional, paciência, amor e compreensão.

Aos meus amigos e professores, que me ajudaram e incentivaram nas mais diversas atividades. 


\section{AGRADECIMENTOS}

Primeiramente, gostaria de agradecer ao meu orientador, Prof. Dr. Wang Jiang Chau, pela oportunidade, apoio, paciência, amizade, pelo incentivo e por ter me motivado durante o desenvolvimento de todo o projeto e desta dissertação de mestrado.

Aos integrantes do Cl-Brasil, pelo fornecimento da infraestrutura e do suporte necessário ao acesso à base de dados utilizada para realizar esta pesquisa. Em especial, ao Prof. Dr. João Antonio Martino e Prof. a Dra. Paula Ghedini Der Agopian, pelo incentivo durante todo o trabalho; ao Jerson Paulo Guex e Everton Jose de Souza, pela ajuda durante a etapa de integração; e ao Fellipe Sola e Walter Santiago Campos Aranda pelo auxílio ao entendimento do comportamento esperado de blocos analógicos.

Aos meus superiores do LSI-TEC (Laboratório de Sistemas Integráveis Tecnológico), por viabilizarem e incentivarem a realização dos meus estudos; aos meus pares de trabalho - e também amigos - do Centro de Treinamento, pelo companheirismo, pelos conselhos e por terem me proporcionado experiências na área de microeletrônica que embasaram minha pesquisa. 
"A menos que modifiquemos a nossa maneira de pensar, não seremos capazes de resolver os problemas causados pela forma como nos acostumamos a ver o mundo".

Albert Einstein 


\section{RESUMO}

Este trabalho propõe o desenvolvimento de uma metodologia para a verificação circuitos integrados de sinais mistos de uso em sistemas de comunicação que operem em modo simplex. Deseja-se aproveitar as características inversas de recepção e transmissão para otimizar o processo de verificação. Para o desenvolvimento desta metodologia de verificação, teve-se como objetivo estudar metodologias de verificação de circuitos integrados de sinais mistos existentes e sua evolução, as quais têm garantido cada vez mais a funcionalidade de circuitos integrados que são compostos por blocos analógicos e digitais.

A metodologia é aplicada a um dos circuitos que compõem um sistema otimizado de transmissão de dados via satélite (Transponder para Satélite). O sistema de transmissão de dados via satélite, foco do trabalho, é composto por receptores, transmissores e conversores analógico digital e um Processador Digital de Sinais Digital Signal Processing (DSP), todos desenvolvidos em hardware. A metodologia de verificação compreende no desenvolvimento de uma estrutura de verificação capaz de estimular os blocos digitais e analógicos com o objetivo de garantir a funcionalidade de cada um dos componentes do IP Transponder. Em uma etapa seguinte, foi possível estimular o IP Transponder de forma integrada, no que se refere aos os blocos digitais e analógicos, assim como os de transmissão e recepção.

Ressalta-se ainda que todo o desenvolvimento foi realizado em alto nível, ou seja, todas as características e propriedades foram observadas utilizando-se somente simuladores para garantir a funcionalidade do circuito integrado de sinais mistos que compõe o IP Transponder para satélite.

Palavras-chaves: Estratégia de Verificação. Verificação de Circuitos de Sinais Mistos. Metodologia de Verificação. 


\begin{abstract}
This work proposes the development of a verification methodology, used during the verification process of a mixed signal integrated circuit, which represents a communication system operating in simplex mode. In order to optimize the verification process, reverse reception and transmission will be used. With the intention of developing our verification methodology, a study on other methodologies used for the verification of mixed signals integrated circuits and the evolution of such methodologies was carried out. The proposed methodology has been applied in an advanced circuit used to establish data transmission by satellite (Transponder for Satellite). The targeted data transmission system is composed by analog receptor and transmitter, analog to digital converters and a digital signal-processing unit, all developed in hardware. The verification methodology consists of two steps: first, the development of a verification structure that are able to stimulate digital and analog blocks in order to guarantee the functionality of each system component. In a following step, the developed verification environment provides the stimulation for all the Transponder IP (digital and analog blocks), and for transmission and reception blocks as well.
\end{abstract}

The verification process development was performed in high level, meaning all the characteristics and properties has been observed using only simulators with the purpose of guarantee the functionality of the mixed signal integrated circuit that composes the satellite Transponder IP.

Keywords: Verification Strategy. Verification of Mixed Signal Circuits. Verification Methodology. 


\section{LISTA DE FIGURAS}

Figura 2.1: Fluxo de Projeto de Circuitos Digitais .............................................. 27

Figura 2.2: Fluxo de Projeto de Circuitos Analógicos............................................. 28

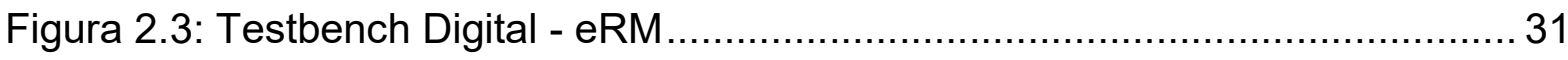

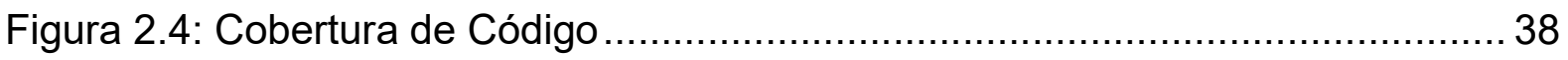

Figura 2.5: Cobertura Funcional................................................................... 39

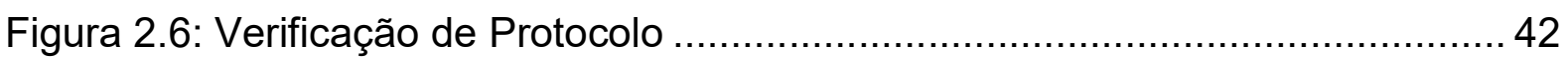

Figura 2.7: Código para Verificação de Protocolo........................................................ 43

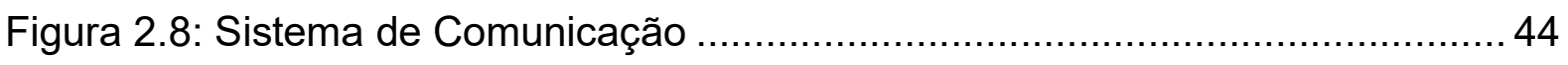

Figura 2.9: Sistema de Comunicação Digital ....................................................... 45

Figura 2.10: Kit de Verificação de Circuitos Sinais Mistos Aplicado ao Bandgap .... 49

Figura 2.11: Diagrama de Blocos do Testbench ............................................... 50

Figura 2.12: Diagrama de Blocos Simplificado de um SoC para um Telefone GSM 51

Figura 2.13: Fluxo de Verificação do Transmissor ................................................ 52

Figura 2.14: fluxo de Verificação do Receptor ......................................................53

Figura 3.1: Arquitetura do Testbench de Circuitos de Sinais Mistos ........................ 57

Figura 3.2: Verificação do Transmissor e Receptor Separadamente ........................ 59

Figura 3.3: Estratégia de Verificação de Circuitos de Sinais Mistos com Modelo .... 61

Figura 4.1: Sistema Brasileiro de Coleta de Dados.............................................. 63

Figura 4.2: Diagrama de Blocos da Arquitetura do Potiguara SoC .......................... 64

Figura 4.3: Diagrama de Blocos da Arquitetura Digital............................................65

Figura 4.4: Diagrama de Blocos da Arquitetura Analógica..................................... 70

Figura 4.5: Diagrama de Blocos da Arquitetura do Potiguara SoC - Modo Fast .... 72

Figura 4.6: Diagrama de Blocos da Arquitetura do Potiguara SoC - Modo Direto... 73

Figura 4.7: Diagrama de Blocos da Arquitetura do Potiguara SoC - Modo Indireto 74 
Figura 4.8: Arquitetura do Testbench para o Receptor

Figura 4.9: Arquitetura do Testbench para o Transmissor ................................. 76

Figura 4.10: Arquitetura do Testbench para a Validação da Integração dos

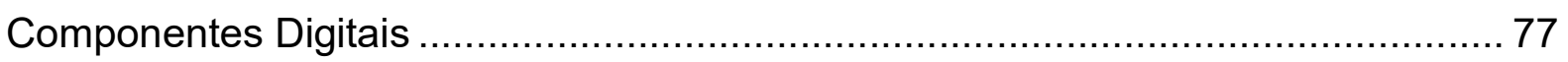

Figura 4.11: Estrutura para Verificação de Blocos Analógicos............................. 78

Figura 4.12: Arquitetura do IP Transponder utilizada durante o Processo de

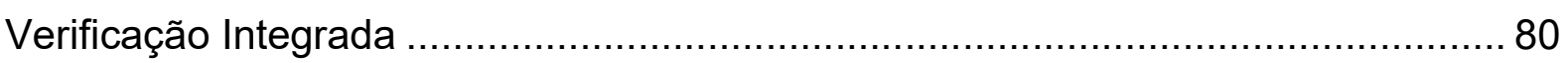

Figura 4.13: Testbench para Validação do IP Transponder ................................ 81

Figura 5.1: Diagrama de Blocos do IP Transponder para Simulação ..................... 83

Figura 5.2: Expects Utilizado na Checagem de Protocolo do Bloco Window........... 89

Figura 5.3: Verificação do Protocolo da Interface ADC-Window ..........................90

Figura 5.4: Geração de Estímulos para Verificação Integrada ............................... 92

Figura 5.5: Características dos Pacotes Gerados ............................................ 93

Figura 5.6: Verilog-AMS do Modelo do Ambiente ............................................. 95

Figura 5.7: Sinais de Entrada e Saída do Modelo de Ambiente ............................96 


\section{LISTA DE TABELAS}

Tabela 2.1: Padrão de codição Manchester............................................................ 47

Tabela 2.2: Principais Especificações do DUV Bandgap .......................................... 48

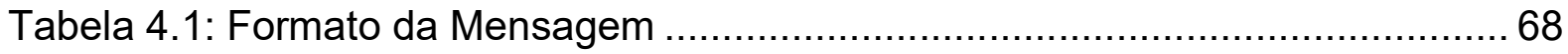

Tabela 4.2: Conteúdo dos Campos da Mensagem Transmitida ............................. 69

Tabela 5.1: Quantidade de Componentes de Cada Testbench .............................. 84

Tabela 5.2: Resultados da Verificação por Bloco Digital......................................... 84

Tabela 5.3: Verificação Integrada do Transmissor e do Receptor ........................... 86 


\section{LISTA DE ABREVIATURA E SIGLAS}

$\begin{array}{ll}\text { ADC } & \text { Analog to Digital Converter } \\ \text { ADE } & \text { Analog Design Environment } \\ \text { AGC } & \text { Automatic Gain Control } \\ \text { AHB } & \text { Advanced High Performance Bus } \\ \text { AM } & \text { Amplitude Modulation } \\ \text { AMS } & \text { Analog Mixed Signal } \\ \text { APB } & \text { Advanced Peripheral Bus } \\ \text { ARM } & \text { ARM Architectures } \\ \text { AVM } & \text { Advanced Verification Methodology } \\ \text { BFM } & \text { Bus Functional Model } \\ \text { CGA } & \text { Calibrated Gain Amplifier } \\ \text { CI } & \text { Circuito Integrado } \\ \text { CMOS } & \text { Complementary metal-oxide-semiconductor } \\ \text { CPS } & \text { Carrier Phase Synchronizer } \\ \text { CRC } & \text { Cyclic Redundancy Check } \\ \text { DAC } & \text { Digital to Analog Converter } \\ \text { DH } & \text { Design House } \\ \text { DRC } & \text { Design Rules Check } \\ \text { DUV } & \text { Design Under Verification } \\ \text { EDA Design Automation }\end{array}$




\begin{tabular}{|c|c|}
\hline eRM & e Reuse Methodology \\
\hline eVC & Electronic Verification Code \\
\hline FFT & Fast Fourier Transform \\
\hline FIFO & First In, First Out \\
\hline FM & Frequency Modulation \\
\hline GSM & Global System Mobile \\
\hline I2C & Inter-Integrated Circuit \\
\hline INPE & Instituto Nacional de Pesquisas Espaciais \\
\hline IP & Intellectual Property \\
\hline LCD & Liquid Crystal Display \\
\hline LNA & Low Noise Amplifier \\
\hline LVS & Layout Versus Schematic \\
\hline MDV & Metric-Driven Verification \\
\hline OVM & Open Verification Methodology \\
\hline PCD & Plataformas de Coleta de Dados \\
\hline PDS & Processador Digital de Sinais \\
\hline PLL & Phase-Locked-Loop \\
\hline PM & Phase Modulation \\
\hline $\mathrm{RF}$ & Radiofrequência \\
\hline RFID & Radio-Frequency Identification \\
\hline RTL & Register Transfer Level \\
\hline
\end{tabular}


$\mathrm{RX}$

Receptor

SBC System Basis Chip

SBCD Sistema Brasileiro de Coleta de Dados

SoC System-on-Chip

SPI Serial Peripheral Interface

SPICE Simulation Program with Integrated Circuit Emphasis

TX Transmissor

UHF Ultra High Frequency

UVM Universal Verification Methodology

VHDL Very-High-Speed Integrated Circuit Hardware Description Language

VMM Verification Methodology Manual 


\section{SUMÁRIO}

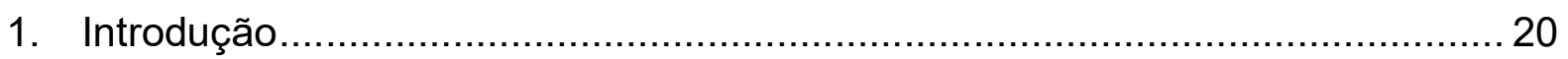

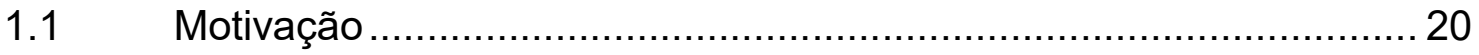

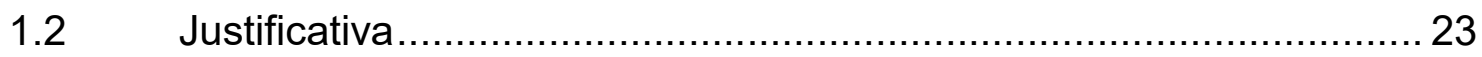

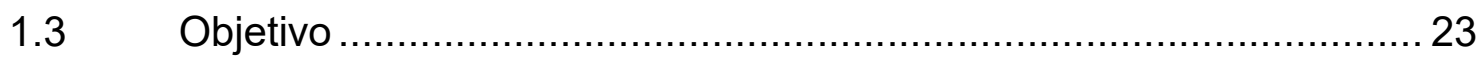

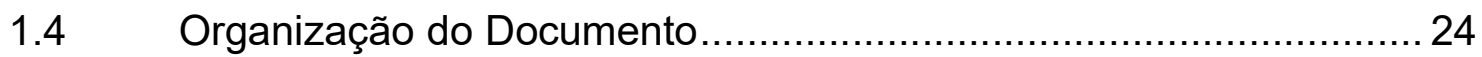

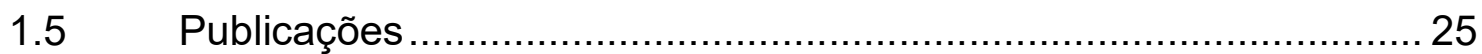

2. Aspectos Teóricos e Trabalhos Correlatos ..................................................... 26

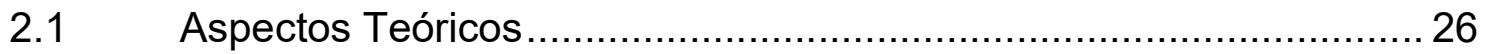

2.1.1 Fluxo de Desenvolvimento de Circuitos Integrados ........................ 26

2.1.1.1 Fluxo de Projeto de Circuitos Digitais.......................................... 26

2.1.1.2 Fluxo de Projeto de Circuitos Analógicos ......................................... 28

2.1.2 Verificação de Circuitos Integrados ………………………….......... 29

2.1.3 Verificação Funcional de Blocos Digitais.......................................... 30

2.1.3.1 Abordagens de Verificação Funcional.............................................. 31

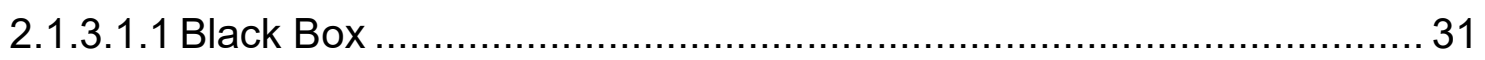

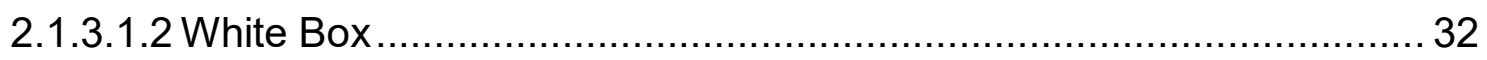

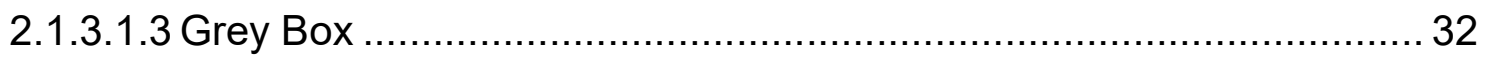

2.1.3.2 Metodologias de verificação Funcional ............................................33

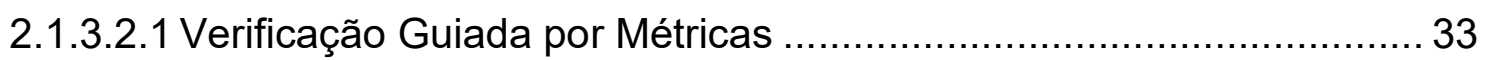

2.1.3.2.2 Metodologia de Reuso com e language ....................................... 34

2.1.3.3 Métricas de Verificação ............................................................... 37

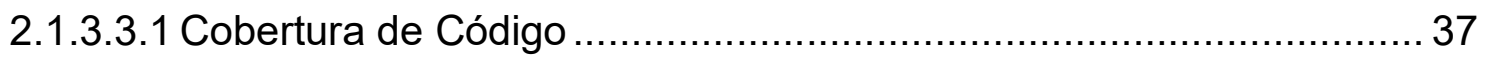

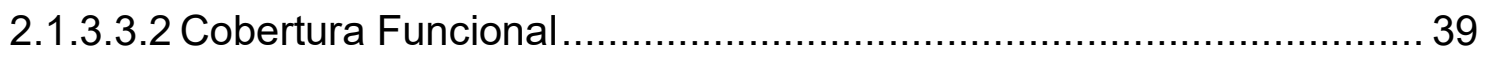

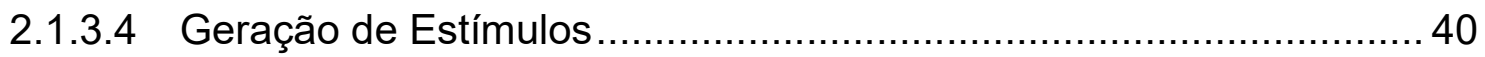


2.1.4 Verificação de Blocos Analógicos ………….................................. 40

2.1.5 Verificação de Protocolo de Interface.............................................. 41

2.1.6 Verificação Mixed-signal ou de interação analógico-digital ................ 43

2.1.7 Sistemas de Comunicação............................................................ 44

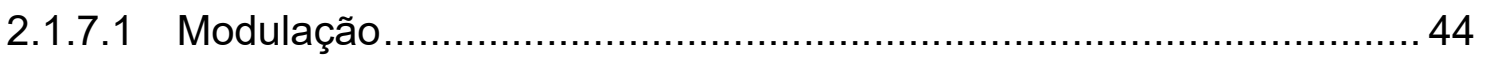

2.1.7.2 Sistema de Comunicação Digital..................................................... 45

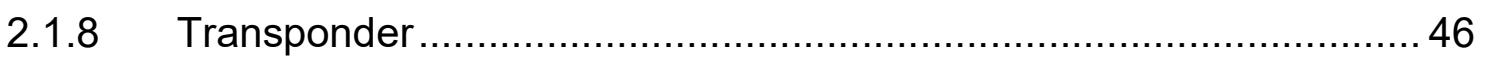

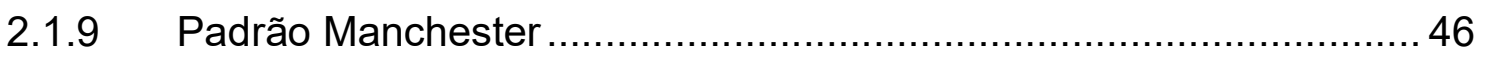

$2.2 \quad$ Trabalhos Correlatos .............................................................. 47

2.2.1 Kit de Verificação de Circuitos Integrados de Sinais Mistos............... 47

2.2.2 Estímulo Pseudoaleatório e a Cobertura Funcional na Verificação de

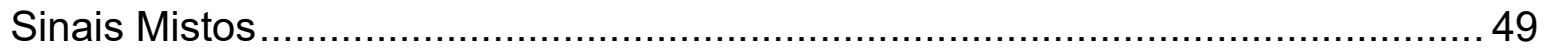

2.2.3 Implementação da Verificação de Processadores RF Digitais ...........51

3. Verificação Integrada de Circuitos de Comunicação ....................................... 54

3.1 Verificação de Circuitos de Sinais Mistos......................................... 54

3.1.1 A Integração e a Simulação da Interface Analógica-Digital................ 54

3.1.2 Modelagem de Circuitos de Sinais Mistos para Simulação................ 55

3.1.3 Modelo Comportamental de Blocos Analógicos …........................... 56

3.1.4 Verificação de Circuitos de Sinais Mistos Utilizando Modelos .......... 56

3.1.5 Desafios da Verificação de Circuitos de Sinais Mistos ...................... 58

3.2 Estratégia de Verificação de Circuitos Integrados de Sinais Mistos para

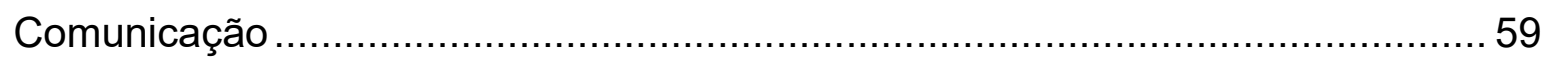

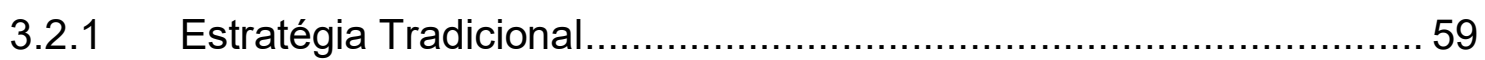

3.2.2 Estratégia de Verificação Integrada para Circuitos de Comunicação 60 4. Aplicação da Metodologia de Verificação de Circuitos de Sinais Mistos a um Transponder 62

4.1 Sistema Brasileiro de Coleta de Dados 62 
4.1.1 Arquitetura do Sistema Potiguara e do IP Transponder ...................63

4.1.2 Arquitetura Digital do Transponder........................................... 64

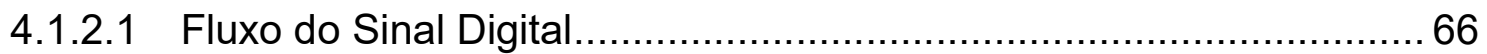

4.1.2.2 Estrutura da Informação Enviada pela PCD ..................................6 68

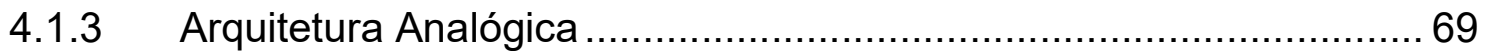

4.1.3.1 Fluxo de Sinal Analógico .......................................................... 70

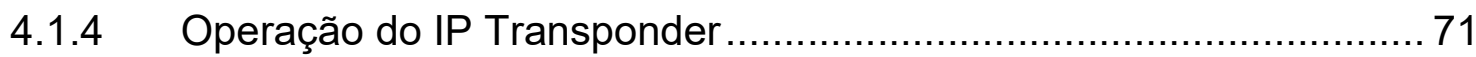

4.1.4.1 Modo Fast .............................................................................. 71

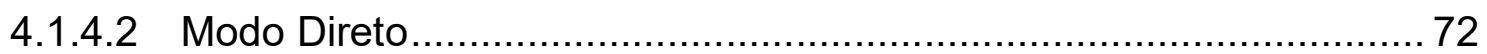

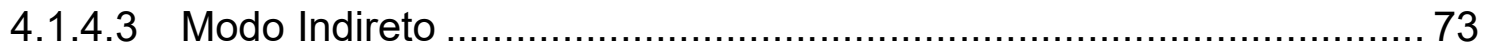

4.2 Verificação do IP Transponder - Componentes Digitais ...................74

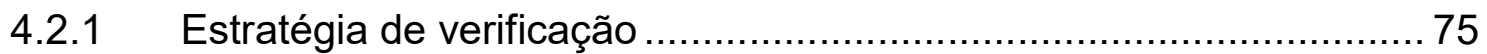

4.2.2 Verificação dos Blocos Digitais ................................................ 75

4.2.3 Verificação do Receptor e Transmissor Digital............................... 75

4.3 Verificação da Integração dos Componentes Digitais do IP

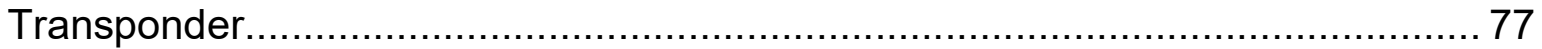

4.4 Verificação do IP Transponder - Componentes Analógicos e Interface

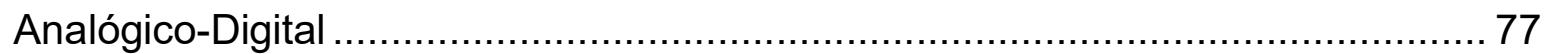

4.5 Verificação Integrada do IP Transponder .................................. 79

4.5.1 Estratégia de Verificação do IP Transponder ............................... 79

4.5.2 Modelo do Ambiente ............................................................ 80

4.5.3 Arquitetura do Testbench Integrada ....................................... 81

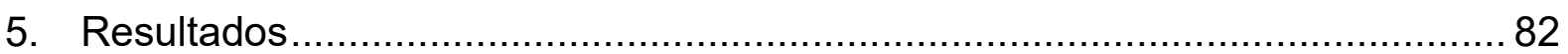

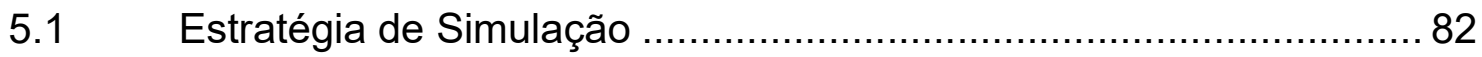

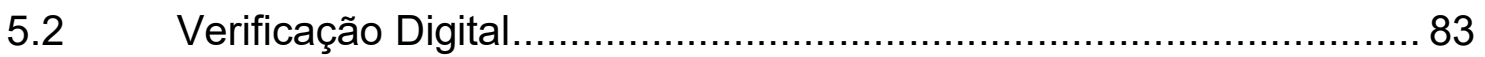

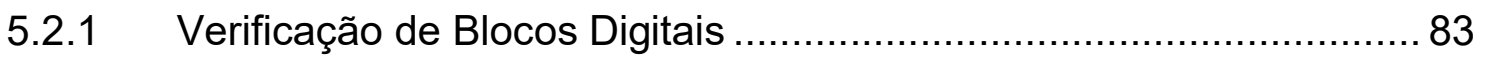

5.2.2 Verificação dos Blocos Digitais Transmissor e Receptor ................... 85 


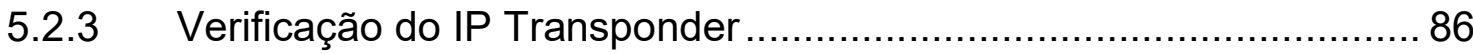

5.3 Verificação da Comunicação entre Interfaces .................................. 87

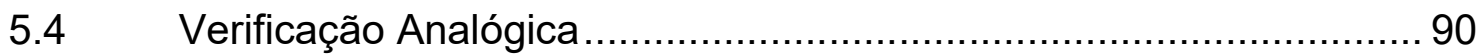

5.5 Verificação do IP Transponder Integrado .......................................... 91

5.5.1 Geração dos Pacotes para Verificação Integrada .............................. 91

5.5.2 Simulação e Deteç̧ão de Erros ...................................................... 93

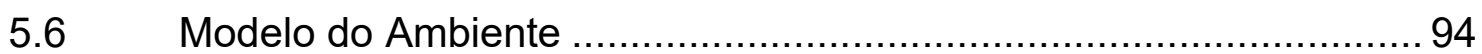

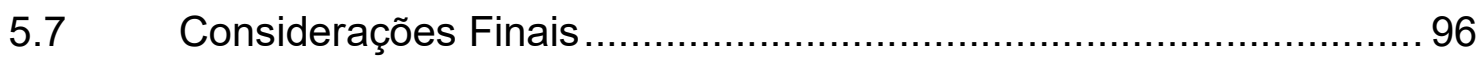

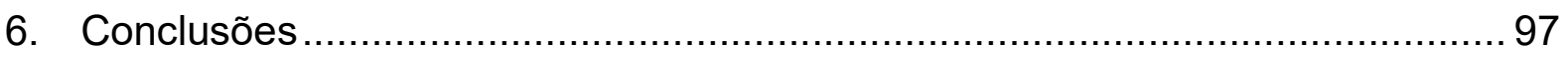

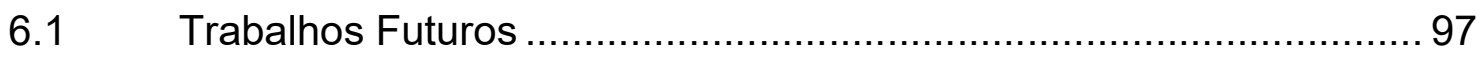

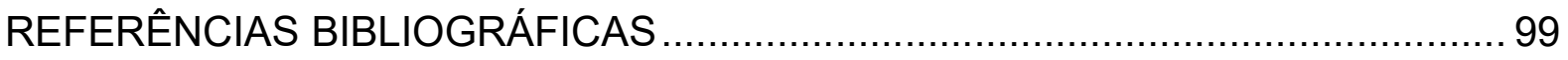

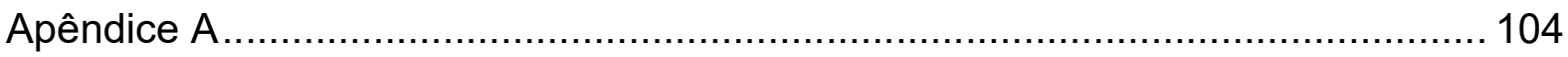




\section{Introdução}

O desenvolvimento da indústria de semicondutores tem como desdobramento a criação de circuitos integrados (Cl's) cada vez menores, mais rápidos, com menor consumo de potência, além de possibilitar a integração de circuitos analógicos e digitais no mesmo die. Assim, a indústria de semicondutores, que utiliza largamente transistores CMOS (Complementary metal-oxide-semiconductor), tem a possibilidade de criar circuitos integrados compostos por estruturas digitais, de sinais mistos (AMS) e de radiofrequência (RF) de alta performance e confiabilidade.

A utilização da tecnologia CMOS deve-se, principalmente, a duas características que são a alta densidade de integração de componentes em uma mesma pastilha de silício (die) e o baixo consumo de potência, possibilitando a criação de Cl's de alta complexidade com dimensões reduzidas.

Atualmente os sistemas-em-chip (Systems-on-chip - SoC) são circuito de complexidade elevada e contém uma grande variedade de blocos com diversas funcionalidades. Somando-se isto à necessidade de se ter um produto competitivo e disponível no mercado em tempo hábil (time to maket), empresas estão encontrando no reuso de Intellectual Property (IP) uma maneira interessante de se obter um produto que alcance as exigências comerciais. Normalmente, os IP são adquiridos de empresas parceiras ou terceirizadas que já realizaram previamente uma verificação funcional sobre o bloco ou conjunto de blocos. A verificação funcional é responsável por garantir a funcionalidade definida na especificação (RASHMI et al., 2015; IEEE, 2016).

De acordo com (FOSTER, 2015), de 60 a 70\% do tempo e recursos gastos no processo de desenvolvimento de um circuito integrado são utilizados durante o processo de verificação, seja ele funcional, formal ou de equivalência lógica.

\subsection{Motivação}

Com a criação de circuitos integrados de sinais mistos, surge a necessidade de se validar o funcionamento conjunto dos domínios discreto e contínuo, ou seja, da verificação da "comunicação" existente entre circuitos analógicos e digitais. O projeto 
em separado dos dois domínios é considerado por muitos como uma fonte importante de erros, os quais, normalmente, não são detectados antes da fabricação (DELORME, 2014; MARTINS et al., 2016;MARTINS et al., 2017). Pouco tem sido feito efetivamente neste âmbito, apesar de que diferentes desenvolvedoras de ferramentas têm focado em criar auxílios computacionais capazes de simular circuitos de sinais mistos (RASHMI et al., 2015).

A importância de se desenvolver uma técnica de verificação de circuitos de sinais mistos está focada na possibilidade de estabelecer uma garantia quando se trata de comunicação eficiente e válida entre circuitos analógicos e circuitos digitais. Isto elimina uma potencial fonte de erros, uma vez que ao longo do desenvolvimento de um projeto cada equipe (digital e analógica) desenvolve separadamente seus projetos havendo pouca ou quase nenhuma interação entre elas.

A escolha da estratégia de verificação funcional de circuitos integrados de sinais mistos junto ao modelo de arquitetura do testbench, também denominado por ambiente de verificação, é um aspecto estritamente dependente da aplicação, motivo pelo qual se faz necessário elaborar um planejamento e monitoramento da estratégia de verificação, o que traz grandes desafios. Dentre os vários desafios existentes, um dos maiores é o ponto de inserção de estímulos, cujas características devem ser bem conhecidas e definidas. Outro desafio é a eficiência da verificação, para garantir o correto funcionamento do circuito dentro das especificações funcionais, deixando-o livre de erros.

Até uma década atrás, em geral, o nível de interação entre estruturas analógicas e digitais não era elevado, o que justificava uma abordagem de dividir para conquistar quando se trata de verificação funcional. Grande parte das metodologias de verificação para sinais mistos baseava-se então naquelas especificadas para sistemas digitais (GLASSER, 2009; MENTORGRAPHICS, 2009; AGGARWAL, 2012; SHETTY e MAHMOODI, 2012; MEALE e ROSENBERG, 2013; INITIATIVE, 2014; SHVARTZ, 2014; IEEE, 2016), a fim de criar uma metodologia sólida e eficaz para o processo de verificação de circuitos desta natureza.

Existiram poucas propostas com técnicas específicas para circuitos integrados mistos, como, por exemplo, o trabalho proposto por Bonfini et al. (BONFINI et al., 
2006) que desenvolveram e aplicaram um kit para verificação de circuitos com poucos transistores (não mais que dez, no seus exemplos), não ficando claro se ela serviria para circuitos de maior complexidade; além disso, não houve, por parte dos autores, preocupação com os aspectos da conversão analógico digital, como por exemplo a quantidade de bits utilizados para conversão.

Atualmente, o projeto de circuitos de sinais mistos conta com um aumento significativo na interação entre os blocos digitais e analógicos dentro de sistemas complexos, tornando necessária a verificação integrada das partes digitais e analógicas para garantir o seu correto funcionamento. Dentro desta visão, lliuţă e Ţepuş (ILIUŢ̌̆ e ŢEPUŞ, 2014) propuseram uma forma de mensurar a qualidade dos estímulos aplicados porém não se preocuparam com a verificação de circuitos integrados de maior complexidade.

Uma área particular de aplicações em sinais mistos é a de comunicação, onde blocos transmissores e receptores têm sinais semelhantes em suas entradas e saídas, permitindo-se aproveitar tais características; pode-se criar uma estrutura de verificação capaz de garantir o correto funcionamento de todo o sistema através de um loop entre o transmissor e o receptor, aproveitando o sinal do transmissor para estimular o receptor. Ainda assim, as formas de verificação são ainda estanques, como, por exemplo, o trabalho de Muhammad et al. (MUHAMMAD et al., 2007), que propuseram uma verificação para um sistema complexo de comunicação, focando separadamente os blocos transmissor e receptor. Este tratamento em separado pode trazer dificuldades na conversão analógico digital e propagar erros de quantização para o modelo de referência.

A verificação em separado dos domínios de transmissão e recepção implica na complexa manipulação de estímulos analógicos e na não simulação em conjunto de todo o SoC. Além disso, estão presentes os problemas de amostragem dos sinais analógicos que podem ser inseridos durante este processo, dificultando a criação de um testbench com um modelo de referência que expresse exatamente o resultado esperado em função de um estímulo de entrada.

A criação do loop entre o transmissor e receptor apresenta como vantagem a manipulação apenas de estímulos digitais, sistematizando uma metodologia de 
verificação de circuitos de sinais mistos, esta que não é bem definida atualmente. Ao se manipular sinais analógicos em geração e monitoração de dados, conversores analógico digitais são necessários na amostragem de sinais analógicos, com a inserção de erros de quantização no sinal amostrado. Com isto, propaga-se o erro para dentro do testbench e, consequentemente, para o modelo de referência, dificultando a verificação dos dados obtidos pelos monitores.

\subsection{Justificativa}

No segmento de criação de Cl's, o Brasil, atualmente conta com uma cadeia de produção completa, iniciando pela formação de mão-de obra qualificada nos Centros de Treinamento localizados em Porto Alegre e São Paulo, passando pelas Designs Houses (DH's), que são responsáveis pela elaboração de projetos. O ciclo de desenvolvimento é concluído nas fábricas (foundry) que são encarregadas pela fabricação dos chips projetados pelas DH's. Atualmente o Brasil possui duas fábricas, ainda não totalmente operacionais, CEITEC (CEITEC, 2014) e UNITEC (UNITEC, 2014), localizadas respectivamente em Porto Alegre - RS e em Belo Horizonte - MG.

No Brasil, até meados de 2016, existiam 14 DH's ${ }^{1}$, sendo que várias delas, como, por exemplo, UNITEC, Chipus (CHIPUS, 2008) e Instituto Eldorado (ELDORADO, 1999) trabalham ainda diretamente com projeto de circuitos integrados e que, com o grande crescimento da interação analógico digital, necessitam de realizar uma verificação de sinais mistos a nível de sistema. É fundamental que as DH's encontrem as possíveis falhas utilizando técnicas de verificação de circuitos integrados de sinais mistos antes que o SoC passe pelo custoso processo de fabricação.

\subsection{Objetivo}

Baseado na discussão apresentada nas seções anteriores, definimos como objetivo geral deste trabalho o desenvolvimento e a sistematização de uma metodologia para verificação de um circuito integrado composto por blocos analógicos e digitais. Dentro deste escopo geral, definimos os seguintes objetivos específicos:

\footnotetext{
1 Com a crise de financiamento no Brasil entre 2016 e 2017, algumas DH's estão saindo de operação.
} 
- Entender métodos correntes de verificação de circuitos em sinais mistos complexos.

- Desenvolver alternativas integradas dos domínios analógico-digital e transmissãorecepção para melhorar a eficiência do processo de verificação, particularmente para sistemas de comunicação envolvendo transmissor e receptor (transponder).

- Desenvolver a verificação de um circuito de sinais mistos da área de comunicação como estudo de caso: estabelecer um plano de verificação, criar o testbench e validar os circuitos de sinais mistos através de verificações funcionais.

- Realizar simulação de todo o circuito garantido a funcionalidade de todo o Transponder.

- Realizar a verificação da interface existente entre o mundo analógico e o mundo digital, fonte de erros durante a concepção de circuitos integrados compostos por blocos digitais e analógicos.

- Obter resultados de cobertura funcional e de código, que possam evidenciar que as metodologias adotadas e aplicadas permitam obter uma validação confiável do IP Transponder.

\subsection{Organização do Documento}

O presente documento apresenta o trabalho de pesquisa e está assim dividido:

Inicialmente, no Capítulo 2, apresenta-se os aspectos teóricos, fruto de revisão bibliográfica realizada sobre a criação de circuitos integrados analógicos e digitais e uma visão detalhada da verificação de circuitos integrados. Inclui-se uma abordagem básica sobre sistemas de comunicações, focando em Transponders que é o objeto principal de estudo deste trabalho. Ainda neste capitulo, descreveu-se alguns trabalhos correlatos aplicados a verificação de circuitos integrados de sinais mistos que foram obtidas no processo de pesquisa bibliográfica feita sobre a literatura técnica.

No Capítulo 3 há uma sistematização das metodologias existentes a serem utilizadas para a verificação de circuitos integrados de sinais mistos aplicada a circuitos de comunicação utilizado no modo simplex. Inclui-se neste capítulo a nossa proposta de uma verificação integrada entre recepção e transmissão. 
O Capítulo 4 irá descrever o SoC Potiguara que contém o IP Transponder, caso de estudo desta dissertação, e descreve a aplicação da metodologia de verificação de circuitos integrados de sinais mistos aplicada ao IP Transponder.

No Capítulo 5, os resultados da verificação do IP Transponder são apresentados, focando na cobertura funcional e de código e também reportando erros encontrados durante o processo de verificação.

No Capítulo 0, as conclusões são apresentadas, assim como algumas sugestões detectadas para trabalhos futuros.

Finalmente são apresentadas as referências bibliográficas utilizadas durante esta pesquisa.

\subsection{Publicações}

Durante este trabalho foram alcançadas as seguintes publicações em anais de eventos:

- WCAS-2016 (Belo Horizonte, MG) - Study Case of Mixed Verification Flow to cope Analog Mixed Signal Mismatch Integration

- LATS-2017 (Bogotá, Colômbia) - Mixed Signal Verification to Avoid Integration Mismatch in Complex SoCs

- Seminatec-2017 (São Paulo, SP) - Verifying the Interface between a Digital Windowing Block and a Sigma-Delta Analog to Digital Converter

- Seminatec-2017 (São Paulo, SP) - Verification Challenges in Analog-Digital Interfaces 


\section{Aspectos Teóricos e Trabalhos Correlatos}

Neste capítulo serão abordados fundamentos teóricos importantes para o desenvolvimento deste trabalho, focando-se principalmente nas duas bases deste projeto: verificação de circuitos integrados digitais e verificação de circuitos integrados de sinais mistos. Além disso, será feita uma breve revisão de sistemas de comunicação voltado para transponder.

Ainda neste capítulo serão apresentados alguns trabalhos relacionados a verificação de circuitos integrados de sinais mistos.

\subsection{Aspectos Teóricos}

\subsubsection{Fluxo de Desenvolvimento de Circuitos Integrados}

Um fluxo de projeto é definido como uma sequência de etapas e procedimentos que permite que os projetistas consigam avançar desde a especificação até a implementação física do circuito(WEST e HARRIS, 2005).

A criação de Cls deve seguir um fluxo estabelecido para auxiliar e facilitar o seu desenvolvimento, sendo que, atualmente existem dois fluxos consolidados, o digital e o analógico. Paralelamente ao fluxo de síntese de um circuito, o fluxo de verificação também é seguido.

\subsubsection{Fluxo de Projeto de Circuitos Digitais}

Um fluxo típico de projeto digital é ilustrado na Figura 2.1, sendo dividido em duas grandes fases: a de Front End e a de Back End. Cada fase é composta de várias etapas de síntese para as quais, os projetistas contam com o auxílio de ferramentas de Automação de Projeto Eletrônico (em inglês, Electronic Design Automation, EDA), tornando o desenvolvimento de projeto mais eficiente.

Seguindo-se a Figura 2.1, a primeira etapa de síntese na fase de Front End, é a especificação das suas funções e das suas condições de operação. Esta fase é crítica, pois, quando mal executada, implicará em retrabalho de parte ou de todo o projeto, acarretando aumento no custo global do trabalho final. (MAMMANA, 1987). Em seguida, baseando-se nas especificações e no comportamento do sistema, é possível dividi-lo, escolher as opções para as suas subdivisões, e também as 
arquiteturas de implementação internas de cada subdivisão (CARVALHO, 2016); nesta etapa, é definido o uso de processadores, memórias, entre outros componentes. Após a definição da microarquitetura, segue-se a etapa de descrição de RTL (Register Transfer Level), onde o projetista elabora a descrição de hardware utilizando alguma linguagem apropriada, como por exemplo, Verilog (IEEE, 2006), SystemC (IEEE, 2012b), SystemVerilog (IEEE, 2012a) e VHDL (IEEE, 2009) (VeryHigh-Speed Integrated Circuit Hardware Description Language).

Figura 2.1: Fluxo de Projeto de Circuitos Digitais

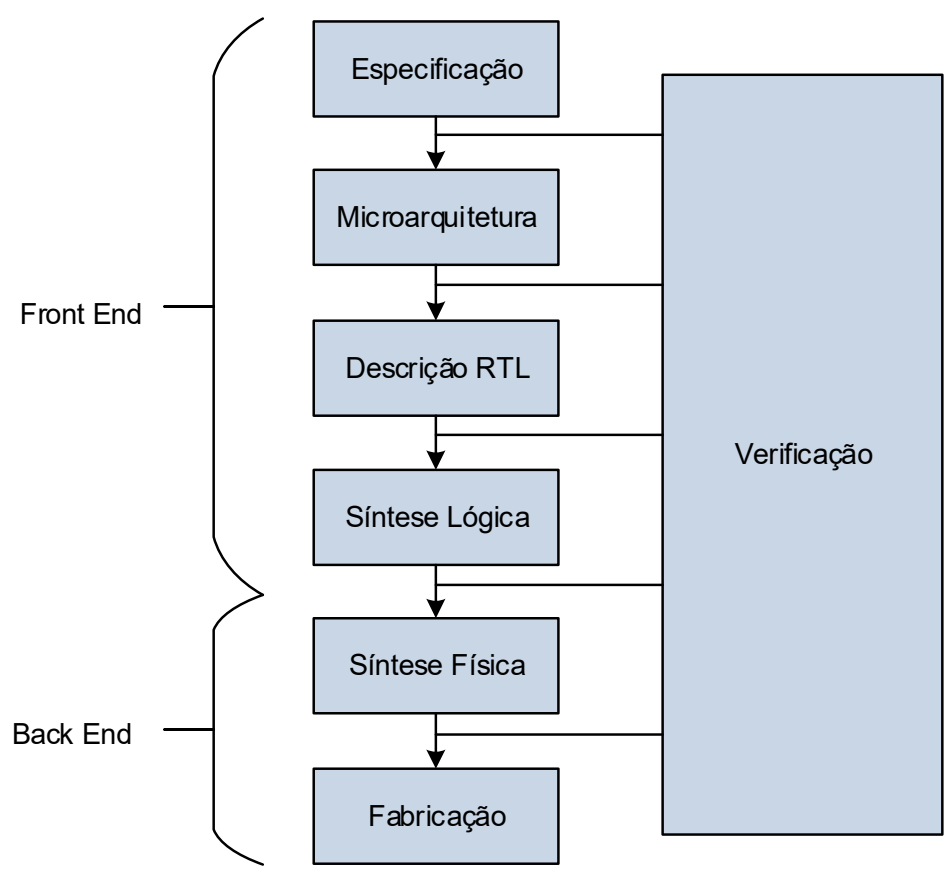

Fonte: (CARVALHO, 2016)

A última etapa da fase de Front End, a Sintese Lógica, é aquela onde os módulos definidos na arquitetura são detalhados, e funções no domínio comportamental são traduzidas para o nível lógico estrutural, usando-se portas lógicas, registradores, multiplexadores, pequenos macromódulos de biblioteca (parametrizáveis ou não), barramentos, entre outros.

Na fase de Back End, a primeira etapa é a de Síntese Física, quando um conjunto de passos são executados a partir da descrição estrutural do circuito, podendo-se, então, sintetizar a descrição geométrica final das máscaras (BHATNAGAR, 2002). Em seguida, observa-se que a segunda e última etapa da fase de Back End é a fabricação, onde o circuito, a partir da geometria das máscaras, passa por uma 
grande quantidade de processos físicos e químicos (DAVID HARRIS, 2005), até que a pastilha correspondente seja construída.

Ainda de acordo com a Figura 2.1, durante todas as etapas, deve-se ter um processo contínuo de verificação para garantir o correto funcionamento do circuito implementado. O processo de verificação varia em função da fase em que o desenvolvimento do circuito integrado se encontra e será melhor identificado na seção 2.1.3.

\subsubsection{Fluxo de Projeto de Circuitos Analógicos}

Um fluxo típico de projeto analógico é ilustrado na Figura 2.2, o qual abrange as etapas (de síntese) de Especificação, Modelo Comportamental, Esquemático, Layout, DRC/LVS (Design Rules Check/Layout Versus Schematic), Extração de Parasitas, e Fabricação. As várias etapas do fluxo de projeto analógico, assim como para o fluxo digital, devem garantir o correto funcionamento do circuito implementado. Analogamente ao fluxo digital, o fluxo analógico conta também com o auxílio de ferramentas de EDA, aumentando a produtividade dos projetistas.

Figura 2.2: Fluxo de Projeto de Circuitos Analógicos

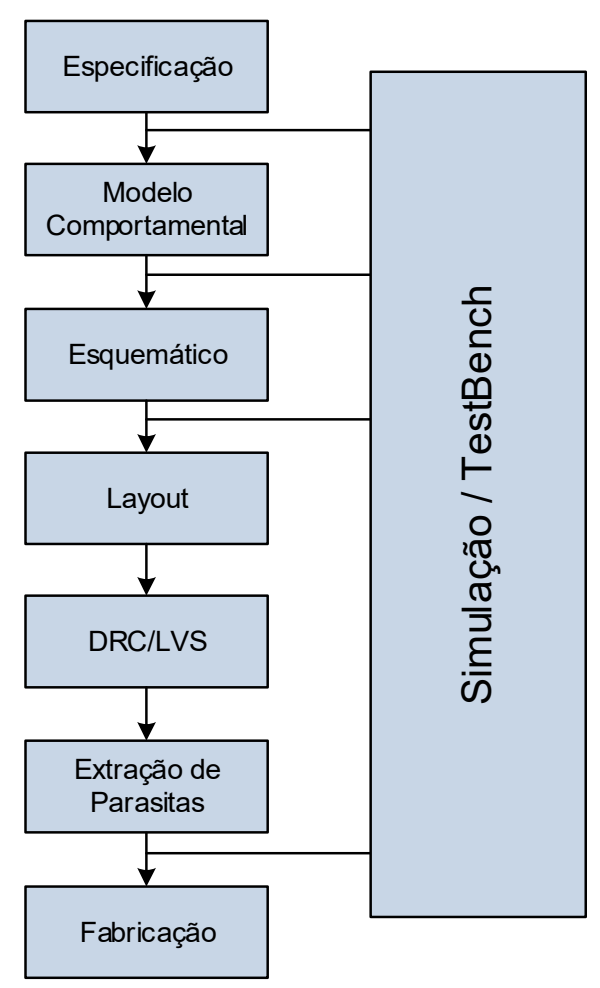

Fonte: (FERREIRA et al., 2011) 
Seguindo-se a Figura 2.2, a primeira etapa é a especificação das suas funções, das suas condições de operação e de seus modos de operação. Em seguida, baseandose nas especificações e no comportamento do sistema, o modelo comportamental é criado; uma linguagem de modelagem como, por exemplo, Verilog A (AISOLA et al., 1996), Verilog AMS (ACELLERA, 2014) e VHDL-A (IEEE, 2007), entre outras, é utilizada para descrever o comportamento do componente a ser desenvolvido. A próxima etapa, o Esquemático, é a obtenção de uma representação da funcionalidade do sistema ou bloco, utilizando-se dispositivos da biblioteca da tecnologia adotada, como por exemplo transistores, resistores e indutores. Em seguida, a etapa de Layout corresponde à disposição física dos componentes utilizados na etapa anterior.

Na próxima etapa, DRC/LVS, ocorre a verificação das regras de layout que irá garantir, por exemplo, que a distância mínima entre trilhas esteja sendo respeitada (DRC) ou que haja a compatibilidade entre o layout e o esquemático (LVS) (FERREIRA et al., 2011). Por fim, a etapa de fabricação finaliza o fluxo de desenvolvimento de um circuito analógico; nela, a partir da geometria das máscaras, lâminas de silício passam por uma grande quantidade de processos físicos e químicos (DAVID HARRIS, 2005), até que pastilhas correspondentes ao circuito sejam construídas.

\subsubsection{Verificação de Circuitos Integrados}

O processo de verificação objetiva garantir o correto funcionado do circuito projetado. Ele é normalmente aplicado em diferentes fases do fluxo de criação de circuitos integrados, da concepção da ideia do SoC, que realizará a(s) tarefa(s) pretendida(s), até a síntese física.

A verificação de circuitos integrados é uma atividade complexa que se inicia pelo plano verificação, passando pela definição da estratégia de verificação e finalizando na criação do testbench ou ambiente de simulação.

O plano de verificação, parte essencial para obter sucesso na verificação de $\mathrm{Cl}$, consiste de um documento que serve de referência ao engenheiro de verificação, fornecendo com riqueza de detalhes os objetivos, a arquitetura do testbench, os casos de testes aplicados ao Projeto sob Verificação (em inglês, Design Under Verification, DUV), a metodologia aplicada, os estímulos que serão gerados, o intervalo de valores 
das variáveis de entrada e saída do DUV e os níveis de cobertura esperados. O plano de verificação é um documento dinâmico e reflete o estado presente da verificação do DUV, sofrendo alterações sempre que alguma especificação ou parte da verificação sofrer alteração (SILVA, 2007).

A estratégia de verificação é a idealização de um conjunto de atividades a serem executadas durante o processo de verificação, com o objetivo de garantir que um determinado projeto desenvolvido pelo engenheiro de hardware está em conformidade com as exigências da especificação, satisfazendo as necessidades pretendidas para seu uso (IEEE, 2015).

Durante o desenvolvimento de um circuito integrado, o correto planejamento da estratégia de verificação mostrará em detalhes as características que devem ser testadas, o nível mínimo de cobertura funcional e de código alcançada, os pontos críticos, a estrutura do testbench e a estrutura do teste utilizada.

O testbench consiste de três unidades principais que são: unidades de monitoramento, unidades de geração de estímulo e unidades de checagem; outras unidades serão detalhadas na seção 2.1.3.2.2. Todo o conjunto de unidades é desenvolvido com objetivo de garantir o correto funcionamento do DUV.

\subsubsection{Verificação Funcional de Blocos Digitais}

A Verificação Funcional é definida como o processo que tem o objetivo de garantir que um projeto atenda às suas especificações numa perspectiva funcional, estabelecendo que a descrição do RTL seja implementada de acordo com funcionalidade pretendida. A verificação funcional pode ser formal ou por simulação, esta última é a mais comum nos projetos comerciais, sendo por esta razão, a abordada nesta dissertação.

O modelo de testbench funcional para blocos digitais é o esquema conceitual que permite garantir que o DUV esteja em conformidade com a especificação funcional. Com uma arquitetura bem definida, como mostrado na Figura 2.3, o testbench é responsável pela geração de estímulos a serem enviados para o DUV, pela observação dos seus dados de entrada e saída e também pela validação dos dados produzidos e dos protocolos presentes nas interfaces do DUV. 
Figura 2.3: Testbench Digital - eRM

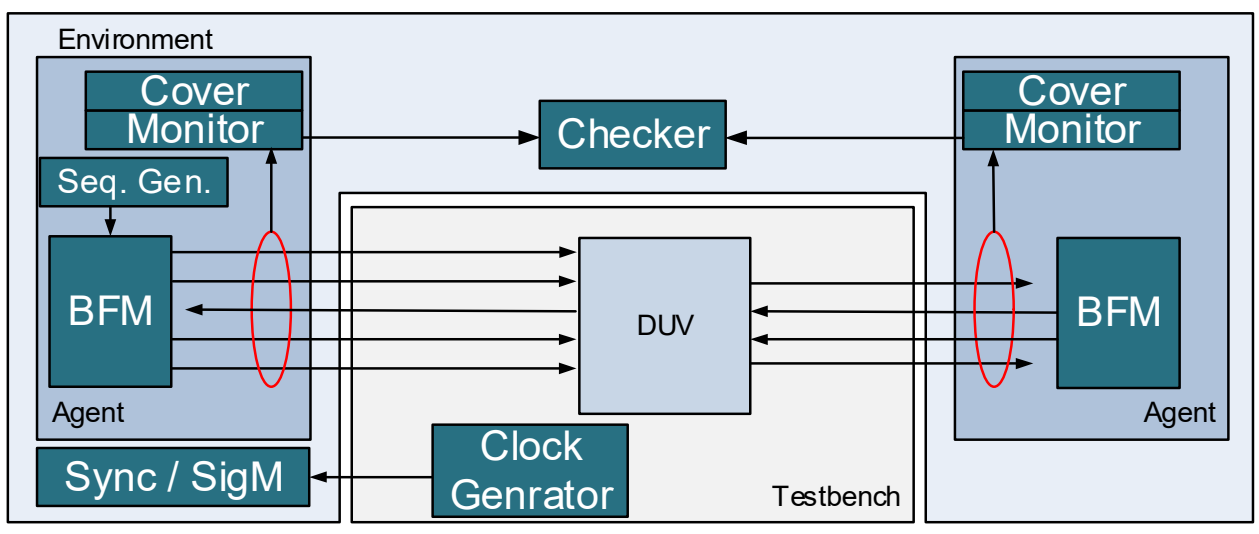

Fonte: Desenvolvido pelo autor

\subsubsection{Abordagens de Verificação Funcional}

A realização da verificação funcional pode ser executada utilizando três abordagens diferentes, mas que se complementam: White Box, Black Box e Grey Box. A definição do uso de uma ou outra depende diretamente do nível de abstração e da complexidade do testbench a ser construído.

A escolha da abordagem a ser utilizada durante a fase de verificação funcional é feita no plano de verificação de acordo com a etapa ou especificação do projeto. As características de cada uma das abordagens são apresentadas a seguir (BERGERON, 2006; VASUDEVAN, 2006; RODRIGUES, 2010).

\subsection{Black Box}

$\mathrm{Na}$ abordagem Black Box, a verificação funcional é realizada conhecendo-se apenas as interfaces do DUV, sem nenhum acesso às estruturas internas desenvolvidas. Quando esta abordagem é adotada, o engenheiro de verificação deve resolver o problema de falta de visibilidade e dificuldade de controle dos estados do circuito durante a simulação.

Em contrapartida, esta abordagem apresenta como vantagem a não dependência da forma como o projetista implementou a descrição de hardware (RTL), podendo esta passar por modificações sem que seja necessário atualizar o testbench - a não ser que ocorram modificações nas interfaces. Além disto, ao adotar esta abordagem, o engenheiro de verificação poderá reutilizar o testbench para validar outros dispositivos com funcionalidades semelhantes. 
Dada as restrições particulares da abordagem Black Box, um caso típico de uso é com um modelo de referência, em alto nível de abstração, que tem o foco na funcionalidade do componente e no protocolo de comunicação com os blocos vizinhos. Paralelamente, o engenheiro de hardware desenvolve o seu projeto de hardware em RTL, focando no protocolo de comunicação em termos de sinalização em baixo nível (bits e ciclo de relógio), estabelecido com os blocos vizinhos. Após este desenvolvimento inicia-se a simulação com o objetivo de garantir a funcionalidade do componente, confrontando a resposta a um estímulo do modelo com a resposta ao mesmo estímulo da descrição de hardware.

\subsection{White Box}

Esta abordagem, ao contrário da abordagem Black Box, dá ao engenheiro de verificação a visibilidade e o controle sobre todas as partes internas do DUV. Quando adotada esta abordagem, o engenheiro de verificação tem a vantagem de poder testar diretamente determinadas funções do dispositivo, podendo tornar mais simples a identificação e localização de erros.

Em contrapartida, esta abordagem apresenta como desvantagem a dependência da forma como o projetista implementou a descrição RTL, e em consequência disso, qualquer alteração realizada no DUV tem uma alta probabilidade de resultar em modificações no testbench. Além disso, é necessário que o engenheiro de verificação tenha conhecimentos de detalhes da implementação para saber quais casos de testes devem ser gerados e quais serão os resultados da aplicação destes testes. Isto leva a outro ponto negativo desta abordagem, que é a maior dificuldade, ou até mesmo a impossibilidade, do reuso do testbench em outros componentes, sem que grandes mudanças sejam feitas devido à alta dependência das características do DUV.

Dada as restrições particulares da abordagem White Box, é comum o uso de asserções, que são usadas para descrever uma propriedade ou características do DUV, com objetivo de prever o valor de registros e de barramentos.

\subsection{Grey Box}

A abordagem Grey Box apresenta características das duas outras abordagens: Black Box e White Box, procurando resolver o problema de dependência do testbench ao DUV, pela abordagem White Box, e de falta de controle da funcionalidade DUV em 
sua simulação, pela abordagem Black Box. Tipicamente a abordagem Grey Box é aplicada em verificação de grandes circuitos, onde se deseja ter acesso a sinais de comunicação entre blocos.

A abordagem Grey Box é aplicada de forma complementar às outras com o objetivo de melhorar ou até mesmo atingir ao máximo das métricas de cobertura, possibilitando ao engenheiro de verificação gerar estímulos para exercitar determinadas linhas de códigos ou para exercitar determinada funcionalidade. $\mathrm{Na}$ abordagem Grey Box, um caso típico de uso é em grandes projetos onde se tem uma hierarquia de blocos e é desejável validar o protocolo comunicação entre os blocos. Também é possível, utilizando-se esta abordagem, validar os dados de entrada e de saída de cada um dos componentes.

\subsubsection{Metodologias de verificação Funcional}

A metodologia de verificação é um conjunto de métricas e métodos com o propósito expresso de promover a verificação funcional de projetos complexos (VMMCENTRAL, 2013). A verificação funcional é uma atividade disseminada em todas as organizações que praticam o projeto de circuito integrado digital, porém a partir culturas diferentes, as instituições desenvolveram diferentes metodologias de verificação.

\subsection{Verificação Guiada por Métricas}

A Verificação Guiada por Métricas (do inglês, Metric-Driven Verification, MDV) é uma metodologia largamente aplicada para circuitos digitais durante o processo de verificação. A MDV é voltada para verificação funcional, cobertura funcional, geração de estímulos pseudoaleatórios e é independente da linguagem aplicada para a construção dos testbenches. Segundo (KHAN et al., 2011), projetos modernos de Cls apresentam grande quantidade de combinações na sua funcionalidade, sendo exercitadas apenas uma pequena parte de todas as combinações possíveis. A MDV é direcionada para se alcançar uma cobertura funcional elevada independente das circunstâncias.

De acordo com (KHAN et al., 2011), a MDV é baseada na especificação funcional, ao invés de ser focada na implementação do projeto. O plano de verificação é criado desta forma, destacando-se as características do DUV que devem ser testados e que 
compõem os itens da cobertura funcional. Esta torna-se uma métrica prática e eficiente do ponto de vista de verificação funcional, uma vez que a quantidade de estímulos testados é significativamente menor que o total de possibilidades apresentadas pelo projeto. Conforme (HEATON, 2014), algumas das metodologias mais populares (eRM, OVM e UVM), apresentadas a seguir, comumente aplicadas nas Casas de Projeto (em inglês, Design Houses, DHs), são baseadas no conceito MDV.

\subsection{Metodologia de Reuso com e language}

Dentre as diversas metodologias de verificação funcional de blocos digitais, destacam-se as seguintes:

- eRM (e Reuse Methodology) (SHVARTZ, 2014; IEEE, 2016)

- AVM (Advanced Verification Methodology) (AGGARWAL, 2012)

- VMM (Verification Methodology Manual) (SHETTY e MAHMOODI, 2012)

- OVM (Open Verification Methodology) (GLASSER, 2009; 2009)

- UVM (Universal Verification Methodology) (MEALE e ROSENBERG, 2013; INITIATIVE, 2014)

A metodologia eRM é uma metodologia de verificação desenvolvida pela Cadence ${ }^{T M}$ com objetivo principal automatizar a tarefa de verificação de um projeto de hardware e é voltada para o reuso de suas unidades. As principais características da metodologia eRM são: a) definição da nomenclatura de arquivos; b) Particionamento funcional do testbench; c) Biblioteca de mensagens e sequências (SHVARTZ, 2014).

A metodologia AVM é uma metodologia de verificação desenvolvida pela Mentor Graphics que permite a criação de testbenches modulares, reutilizáveis com conexões simples entre componentes e de código aberto usando o padrão de linguagem SystemVerilog (AGGARWAL, 2012).

A metodologia VMM é uma metodologia de verificação desenvolvida pela Synopsys que permite a criação de testbench robustos e escaláveis usando o padrão de linguagem SystemVerilog (SYNOPSYS, 2016). 
A metodologia OVM é a união da metodologia AVM e eRM com uma pequena evolução, gerando a uma metodologia reconhecida somente pelas ferramentas da Cadence $^{\mathrm{TM}}$ e da Mentor (DAS, 2016).

Por sua vez, a metodologia UVM é uma junção da metodologia OVM e VMM (DAS, 2016), com uma pequena evolução, gerando uma metodologia aberta e reconhecida por todas ferramentas. Para este trabalho de mestrado, a metodologia eRM foi adotada devida à familiaridade do autor com ela; apesar de uma perda em utilização de macros como os padrões presentes na metodologia UVM, as suas características são suficientes para realizar o trabalho proposto.

A Figura 2.3 ilustra um testbench digital baseado na metodologia eRM. A arquitetura proposta na Figura 2.3 é um exemplo de uma abordagem de verificação black box, pois o engenheiro de verificação não terá acesso a sinais internos do DUV. Na metodologia $e R M$, os testbenches para circuitos digitais são compostos pelas unidades:

- Modelo Funcional do Barramento (Bus Functional Model - BFM) - BFMs são responsáveis pelo envio dos dados para o DUV respeitando-se o protocolo, ou seja, as unidades de BFM emulam o comportamento da interface do DUV com outros blocos. As BFMs são unidades ativas dentro de qualquer testbench.

- Monitores (Monitors) - são responsáveis por amostrar os sinais do DUV diretamente nas suas portas, sem alterá-los e também garante o correto funcionando do protocolo da interface. Os monitores são unidades passivas dentro do testbench.

- Cobertura (Cover) - unidade responsável por coletar as informações referente a cobertura de código e a cobertura funcional. Normalmente, esta unidade é associada aos monitores e coleta as informações de cobertura diretamente das portas.

- Checador (Checker) - unidade que inclui um modelo de referência, criado, em alto nível, equivalente ao modelo do DUV com as características funcionais. $O$ checador é responsável por fazer a correlação entre de dados produzidos pelo modelo de referência e pelo DUV, gerando alertas de erros. 
- Gerador de Sequências (Sequence Generator) - unidade responsável pela geração dos dados em alto nível, que serão enviados para DUV. O constrait solver adota restrições estabelecidas pelo engenheiro de verificação para a produção de dados pseudoaleatórios de interesse.

- Sincronizador e Mapa de Sinais (Synchronizere Signal Map) - unidade que contém informações relativas às portas de entrada e de saída do DUV. Normalmente, o synchronizer contém informações dos sinais de clock, reset e sinais de habilitação; pode incluir outros sinais que são definidos dentro do mapa de sinais.

- Agente (Agent) - unidade utilizada para organizar o testbench. Normalmente, dentro da arquitetura do testbench utiliza-se dois ou mais agentes representando as interfaces. Dentro dos agentes encontram-se instâncias de monitores, BFMs e gerador de sequências.

- Testbench (Environment) - unidade topo utilizada para organizar a estrutura do testbench. Dentro desta unidade existirão instâncias de agentes, sincronizador e mapa de sinal, e checador.

$\mathrm{Na}$ metodologia $e R M$, todas as unidades do testbench de blocos digitais são costumeiramente implementadas nas mais diversas linguagens: SystemC, SystemVerilog, e language, C e C++. Nesta dissertação, a e language foi empregada, uma vez que o autor tem conhecimento de sua estrutura através de outros trabalhos anteriores. Conforme (NAHIR, 2007), as principais características dos testbenches utilizando e language, são:

- Linguagem orientada a objeto, focando a estratégia de dividir para conquistar.

- Geração de estímulos aleatórios e pseudoaleatórios.

- Pontos de cobertura funcional e métricas de cobertura funcional estabelecido pelo verificador.

- Verificação de protocolos utilizando checagem temporal.

- Verificação de dados.

- Ampla reutilização de código. 
Todos testbenches devem operar no modo passivo e no modo ativo. Operar no modo ativo, significa que o testbench está configurado para enviar estímulos para o DUV localmente, ou seja, neste modo de operação existirão instâncias das unidades Modelo Funcional do Barramento e do Gerador de Sequências. Já no modo passivo, as unidades que geram estímulos para o DUV são desabilitadas e contornadas, ou seja, este modo de operação não é contemplado com as unidades Modelo Funcional do Barramento e Gerador de Sequências.

\subsubsection{Métricas de Verificação}

O estudo da cobertura é uma técnica utilizada para aferir o progresso da verificação baseando-se em metas preestabelecidas e que devem ser alcançadas durante 0 processo de verificação. As métricas de verificação estão diretamente relacionadas com a qualidade de produto final, uma vez que é impossível ter uma simulação do projeto que exercite todas as condições de operação. Os projetos de produtos que atingem as métricas de cobertura estabelecidas, com graus de exigência mais altos, têm menor chance de apresentar erros quando fabricados.

Cobertura funcional e cobertura de código são métricas utilizadas pelos engenheiros de verificação para saber, respectivamente, quais funcionalidades e quais atributos de código da descrição de hardware foram exercitadas; passa-se, assim, ao verificador uma visão real de quais casos de testes devem ainda ser gerados para atingir-se um nível de cobertura satisfatório. Normalmente, o término do processo de verificação está vinculado à obtenção do nível de cobertura funcional e de código definido pela equipe de verificação e descrita no plano de verificação.

\subsection{Cobertura de Código}

A cobertura de código consiste em reportar partes da descrição de hardware que foram, ou não, exercitadas após um certo número de execuções de testbench. O não exercício de uma determinada parte de código pode esconder erros que eventualmente apareçam na operação do sistema. O uso deste tipo de cobertura requer uma instrumentação do DUV, que na maioria das vezes é feita pela ferramenta de simulação automaticamente. 
As métricas amplamente utilizadas para a cobertura de código são linhas de código, expressões, blocos procedurais, blocos combinacionais, chaveamento de sinais, estados da máquina de estados e arcos da máquina de estados. A Figura 2.4 referese ao relatório de uma cobertura de código extraído da verificação funcional de um bloco digital que integra o IP Transponder do SoC Potiguara, que será apresentado na seção 4.1.1. Neste relatório, a coluna 1 representa os parâmetros avaliados durante o processo de cobertura. As colunas 2 e 3 apresentam estatísticas de cobertura, descrevendo a quantidade de blocos, expressões, chaveamento de sinais e máquina de estados em termos percentuais atingidos durante o processo de verificação por simulação com instrumentação automática do DUV.

Figura 2.4: Cobertura de Código

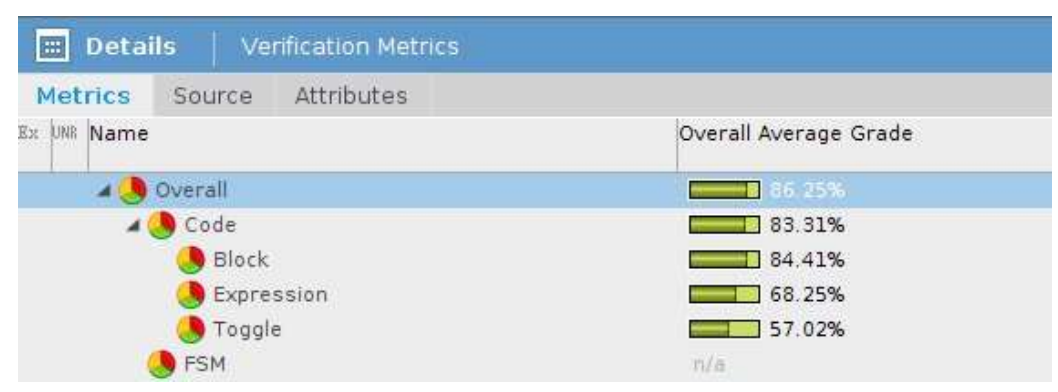

Fonte: Desenvolvido pelo autor

Na cobertura de código, é desejável se alcançar a cobertura total, exercitando-se nas simulações todas as condições a serem analisadas (blocos, expressões, chaveamento, entre outros). Entretanto, devido à criação de códigos defensivos, ou seja, descrições de hardware que nunca serão executadas mas existem para evitar o travamento do sistema ${ }^{2}$, muitas vezes, não há como se atingir o índice de $100 \%$ de cobertura de código.

Outro ponto que contribui para que a cobertura de código não atinja o valor máximo são os dead codes (GOERING, 2012), que não são percorridos em nenhum momento pela execução normal da descrição de hardware e também que não está associado a nenhum requisito da especificação.

\footnotetext{
2 É o caso, por exemplo, de uma opção default para uma descrição condicional "case".
} 


\subsection{Cobertura Funcional}

A cobertura funcional está diretamente ligada à especificação funcional e irá avaliar o quanto da especificação funcional foi exercitada e implementada nas execuções de testbench. Um exemplo de cobertura funcional é avaliar, como no caso do Packet Bank Ctrl (Banco de Registros), um bloco do IP Transponder do SoC Potiguara, se parâmetros de um sistema, tais como, tamanho e estrutura de pacotes, a existência de verificação de redundância cíclica, entre outros, ocorrem em uma quantidade adequada dentro de todas as suas possibilidades. Portanto, pode-se afirmar que a cobertura funcional está direcionada para a função implementada ao passo que a cobertura de código está direcionada para a execução do código.

O plano específico de verificação funcional depende diretamente da aplicação, fazendo com que a definição dos pontos de cobertura seja feita manualmente; os valores definidos para tais pontos são coletados durante a simulação e armazenados para posterior análise. A Figura 2.5 refere-se ao relatório de uma cobertura funcional extraído da verificação funcional do Packet Bank Ctrl, obtida através da ferramenta Incisive Metrics Coverage da Cadence ${ }^{\mathrm{TM}}$.

Figura 2.5: Cobertura Funcional

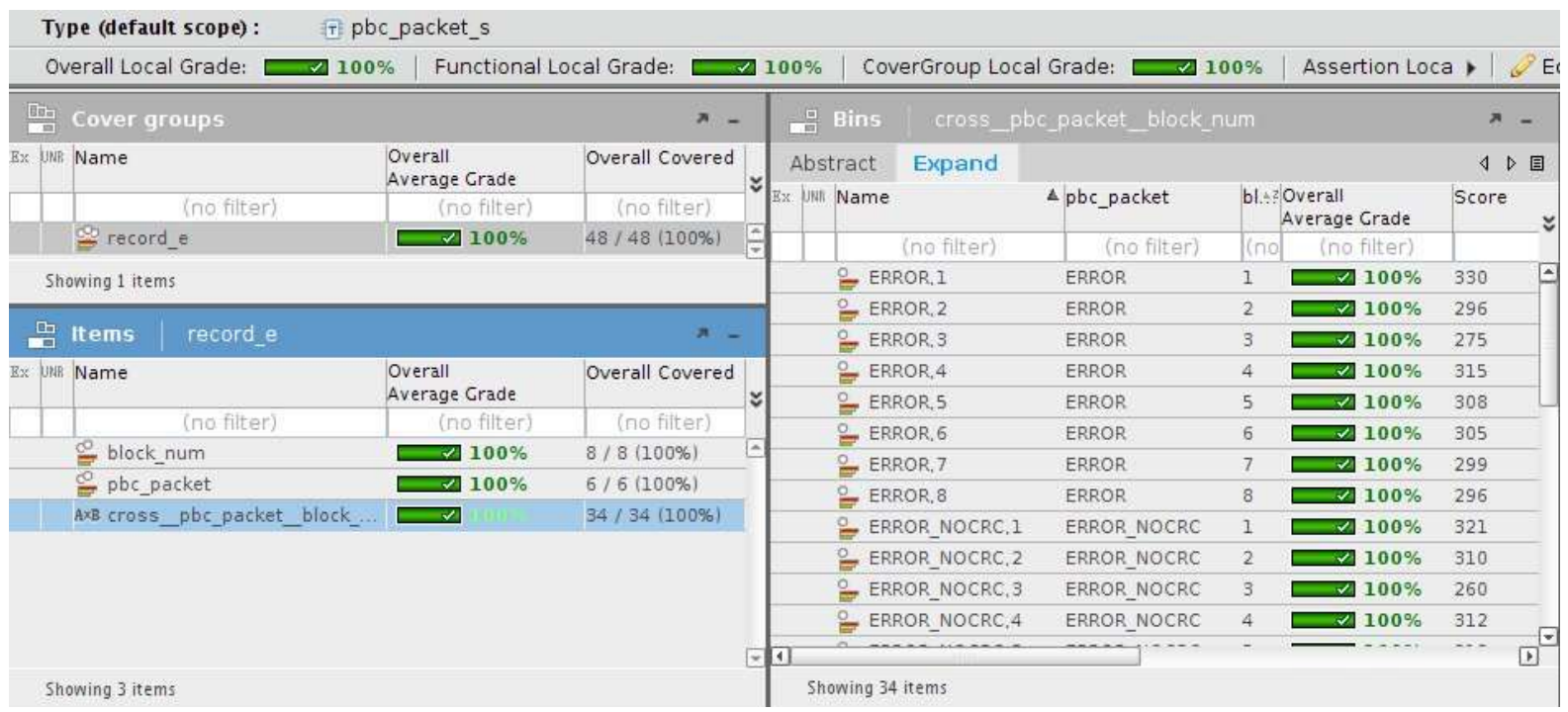

Fonte: Desenvolvido pelo autor

Pode-se observar que o DUV foi estimulado por pacotes com os mais diversos atributos, de acordo com as restrições estabelecidas na geração de estímulos e as características dos pacotes. Foram enviados, neste exemplo, pacotes com erros, 
pacotes sem erros e pacotes com os mais diversos tamanhos, tendo-se atingido um nível de cobertura satisfatório. Deste relatório de cobertura, pode-se extrair quais casos de testes foram executados e também a quantidade de repetições de cada teste.

É comum na cobertura funcional, devido à sua natureza, chegar a níveis elevados de cobertura na maioria das aplicações. Vale ressaltar que, obter $100 \%$ de cobertura funcional não garante que o DUV esteja completamente correto, ou seja, livre de erros, mas apenas que o DUV atende a todos os critérios de cobertura funcional definidos pela equipe de verificação; tais critérios correspondem normalmente, para circuitos complexos, apenas a uma pequena fração de toda a sua funcionalidade.

\subsubsection{Geração de Estímulos}

A geração de estímulos, que deve modelar o comportamento de usuários, dos blocos ou dos sistemas originadores de dados para a operação do DUV, é feita utilizando-se principalmente a geração aleatória. A geração de estímulos utiliza-se dos constraint solvers, que são programas solucionadores de restrições estabelecidas pelo verificador, a fim de se otimizar o processo de criação dos estímulos, evitando condições inexistentes.

Além da geração aleatória de estímulos, pode-se ter também a geração direta de casos de interesse. Qualquer uma das formas pode ser repetida quantas vezes forem necessárias; assim, o engenheiro de verificação poderá testar as condições mais conhecidas diretamente e terá mais chances de estimular os corners cases, que são cenários complexos e frequentemente mais difíceis de serem alcançados.

\subsubsection{Verificação de Blocos Analógicos}

A verificação de blocos analógicos, grande desafio para projetistas, consiste em um conjunto de métodos e procedimentos que são utilizados para garantir o seu correto funcionamento. A definição da técnica a ser utilizada depende diretamente das funcionalidades a serem checadas (transmitir, receber, amplificar, converter, misturar, entre outras) e das análises que serão realizadas (tempo, frequência, pontos de operação, entre outros). 
As técnicas utilizadas para verificação de circuitos digitais podem ser utilizadas na verificação de poucos circuitos analógicos devido à elevada quantidade de condições de operações que precisam ser avaliados nos circuitos analógicos (FONSECA, 2009). As técnicas de verificação de circuitos analógicos são baseadas em dois tipos de análise matemática: simbólica ou numérica. Em simuladores, como por exemplo o SPICE (Simulation Program with Integrated Circuit Emphasis) (FONSECA, 2009), análises numéricas são utilizadas para simular o real compartimento dos circuitos integrados. Utilizando-se ferramentas da Cadence ${ }^{\mathrm{TM}}$, como o Virtuoso e ADE (Analog Design Environment) (CADENCE, 2015), é possível realizar-se vários tipos de análises. Por outro lado, para executar uma análise formal matemática, com técnicas não baseadas em simulação (FONSECA, 2009), é necessária a obtenção das equações matemáticas através do uso de uma análise simbólica dos circuitos.

A técnica mais comum utilizada nas DHs para a verificação de circuitos analógicos é a análise numérica, pois o engenheiro projeta o hardware seguindo o fluxo de desenvolvimento analógico descrito na seção 2.1.1.2. Em seguida o engenheiro de desenvolvimento analógico elabora um testbench para estimular a implementação, definindo quais as análises serão realizadas. Em muitos blocos analógicos, a inspeção dos parâmetros é feita visualmente diretamente nas formas de onda produzidas durante as simulações numéricas.

A validação de blocos analógicos se dá utilizando-se formas de onda devido à grande quantidade de modos de operação e da dificuldade de se estabelecer nos testbenches uma forma automática e exata para o processo de geração de estímulos analógicos. A amostragem das entradas e saídas analógicas pode introduzir erros de quantização, dificultando a validação pelo modelo de referência dos dados amostrados. Em casos onde se realizam a validação de blocos analógicos por testbenches com geração pseudoaleatória, é preciso estabelecer uma margem de erro (para mais e para menos) para o resultado gerado pelo modelo de estímulos de entrada, ou seja, a probabilidade de um resultado exato é mínima.

\subsubsection{Verificação de Protocolo de Interface}

Protocolos são regras de comunicação estabelecidas entre blocos digitais, entre blocos digitais e analógicos ou até mesmo entre SoC's, que, devido ao 
desenvolvimento por diferentes engenheiros ou equipes de engenheiros, podem apresentar erros, levando eventualmente à falha completa do sistema. Geralmente os protocolos estão associados a interfaces, e devem seguir uma ordem de execução de um ou mais sinais.

Na Figura 2.6, um caso de dois blocos que trocam informações entre si é utilizado para ilustração. O bloco B somente poderá amostrar o dado na entrada de dados quando o sinal de valido for igual a 1; caso contrário, o bloco B poderá amostrar uma informação inválida ou incorreta. Uma segunda avaliação de protocolo é definido para a duração do tempo entre os sinais valido e recebido. Também pode-se avaliar o intervalo de tempo entre o recebimento do sinal valido pelo bloco $B$ (enviado pelo bloco A) e a geração, ainda no bloco $B$, do sinal recebido.

Figura 2.6: Verificação de Protocolo

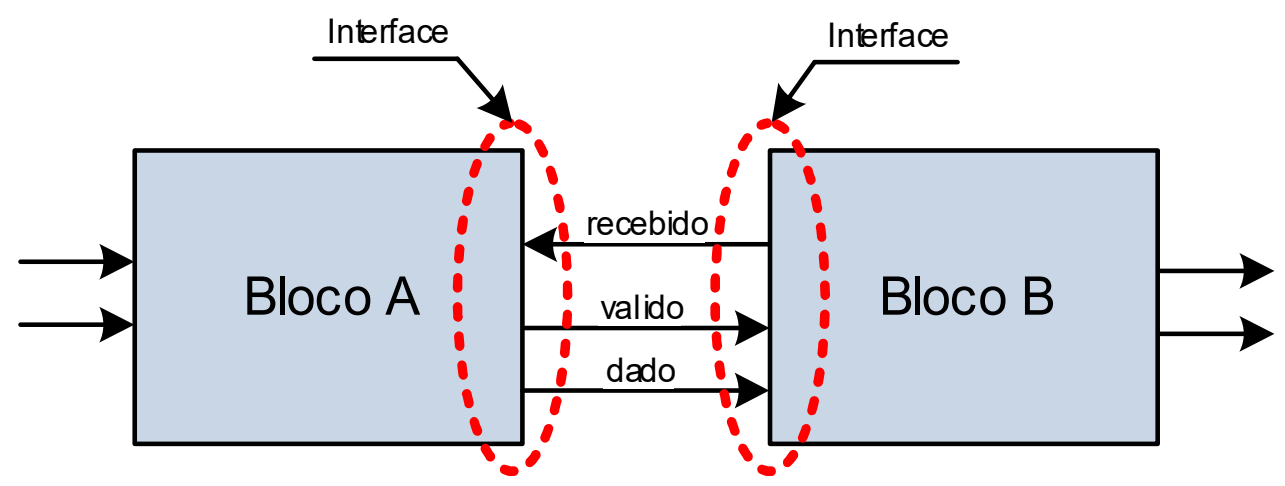

Fonte: Desenvolvido pelo autor

Para garantir a correta comunicação, existem várias estruturas de código criadas para testbenches, as quais são capazes de realizar a verificação de protocolos de comunicação. Um exemplo é o expect da e language, estrutura utilizada pela sua simplicidade e eficiência. Os expects interrompem uma simulação, caso uma regra de comunicação estabelecida seja violada. Para determiná-los, deve-se inicialmente definir eventos que são disparados quando um sinal mudar de estado. Em seguida, define-se a ordem em que os eventos devem acontecer. Como exemplo, considerese que, quando o sinal valido do bloco A da Figura 2.6 ocorrer, o sinal recebido emitido pelo bloco $B$ da Figura 2.6 deve ocorrer, entre dois a quatro ciclos de relógio; caso contrário, um erro deve ser apontado e a simulação é interrompida instantaneamente. A Figura 2.7 ilustra a avaliação do protocolo descrito. 
Figura 2.7: Código para Verificação de Protocolo

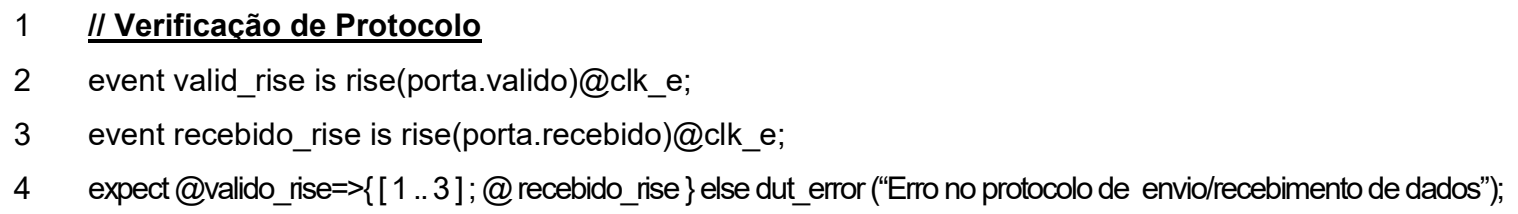

Fonte: Desenvolvido pelo autor

\subsubsection{Verificação Mixed-signal ou de interação analógico-digital}

Sistemas ou circuitos de sinais mistos podem ser entendidos como aqueles compostos por blocos digitais e analógicos; ademais, deve existir uma interação entre as duas partes, com uma ou mais interfaces onde os dados são transferidos de blocos digitais para analógicos e vice-versa.

$\mathrm{Na}$ realidade, como o projeto de blocos digitais e analógicos está bem estabelecido, como visto em seções anteriores, um projeto de circuitos de sinais mistos preocupase primordialmente com a interface analógico-digital. Devido ao desenvolvimento por equipes distintas e que muitas vezes não se comunicam, os circuitos das interfaces, tanto digitais quanto analógicas, podem apresentar erros causando o mau funcionamento ou falha total.

Assim, em se tratando da verificação da interação analógico-digital, o engenheiro analógico cria uma gama de testes direcionados para alguns casos específicos, exercitando as características descritas na especificação. Com esta configuração é possível garantir que a interface analógico-digital, assim como o circuito todo, apresente o correto funcionamento de acordo com a especificação. Os testes gerados são aplicados ao projeto através de testbench.

A verificação de blocos analógicos além de apresentar um vasto número de modos de operação, apresenta também uma dificuldade na geração automática de estímulos devido à sua complexidade. Também vale destacar que o processo de monitoramento das entradas e saídas introduz erros de quantização, que refletem-se diretamente no desenvolvimento do modelo de referência, trazendo grandes dificuldade na criação da unidade de checagem de dados. 


\subsubsection{Sistemas de Comunicação}

Um sistema de comunicação é definido como um conjunto de componentes que viabilizam o transporte de uma informação (áudio, vídeo, imagem, texto, dados coletados por sensores, entre outros) da origem até o um destino qualquer, e são compostos basicamente por transmissores (TX), canais de transmissão e receptores (RX), como ilustrado na Figura 2.8. Para realizar o transporte da informação, os sistemas de comunicação utilizam canais de transmissão, conhecidos também como mídias de transporte, que podem ser cabos metálicos, fibras ópticas, ar, guias de onda, vácuo, entre outros.

Figura 2.8: Sistema de Comunicação

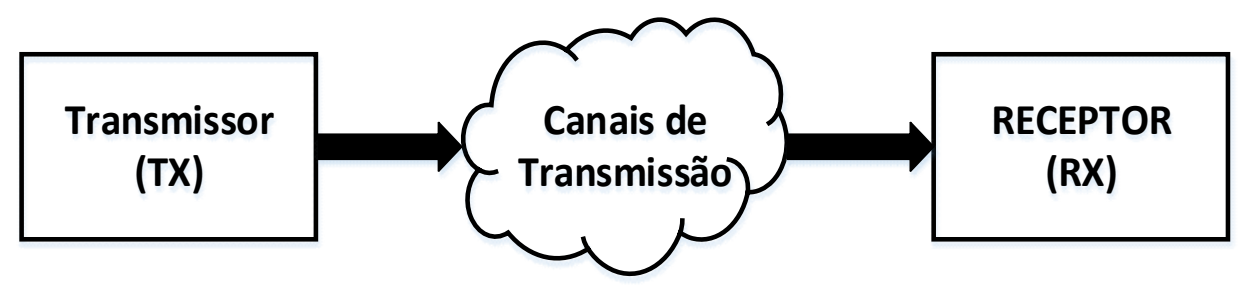

Fonte: Desenvolvido pelo autor

De acordo com a direção do fluxo de informação em um canal de comunicação, os sistemas de comunicação são classificados como simplex e duplex, sendo este último dividido em dois, o half-duplex e o full-duplex. O modo simplex, tem como característica a transmissão em um único sentido, como por exemplo na televisão, no rádio e no sistema brasileiro de coleta de dados, caso de estudo desta dissertação. Os modos half-duplex e o full-duplex possibilitam a comunicação nos dois sentidos, sendo que no half-duplex, o canal de comunicação é ocupado por um sentido de transmissão de cada vez como, por exemplo, com o walkie-talkie; já em full-duplex, o canal de comunicação pode ser utilizado simultaneamente nos dois sentidos de transmissão.

\subsubsection{Modulação}

Usualmente, a informação a ser transmitida está codificada ou representada em alguma forma inadequada para o canal de transmissão. A modulação é processo de adequação do sinal, onde um outro sinal, uma onda portadora ou simplesmente portadora, terá uma ou várias de suas características modificadas pelo sinal a ser transmitido, ou seja, pelo sinal modulante. Na maioria dos casos, a modulação se torna 
essencial para a utilização de alguns canais de transmissão, reduzindo o ruído e interferências introduzidos pelo meio, tornando a transmissão mais eficiente e precisa.

A onda portadora é tipicamente uma onda senoidal de alta frequência. O processo de modulação pode modificar as suas características de amplitude, frequência ou fase, originando três tipos de modulação, que são:

- Modulação em Amplitude (AM - Amplitude Modulation) - é o processo de modulação onde a amplitude da portadora varia de acordo com a amplitude do sinal de interesse, mantendo a fase e a frequência constantes.

- Modulação em Frequência (FM - Frequency Modulation) - é o processo de modulação onde a frequência da portadora varia de acordo com a amplitude do sinal de interesse, mantendo a fase e a amplitude constantes.

- Modulação em Fase (PM - Phase Modulation) - é o processo de modulação onde a fase da portadora varia de acordo com a amplitude do sinal de interesse, mantendo a amplitude e a frequência constantes.

\subsubsection{Sistema de Comunicação Digital}

Um sistema de comunicação digital, segue a definição geral dada na seção 2.1.7, tendo como missão transmitir os dados na forma digital de uma fonte de informação para um destino, garantindo que a informação recebida seja a mesma informação enviada. O transmissor (TX) e o receptor (RX) são compostos pelos blocos ilustrados na Figura 2.9.

Figura 2.9: Sistema de Comunicação Digital

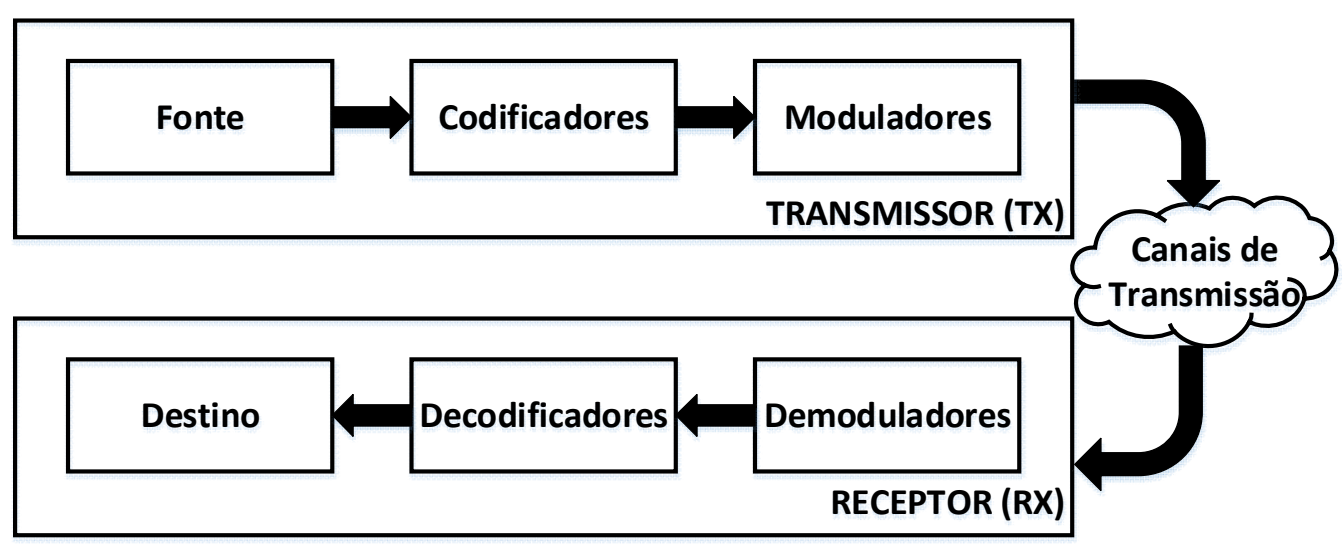

Fonte: Desenvolvido pelo autor 
No transmissor do sistema de comunicação digital a fonte é responsável por gerar os símbolos, normalmente binários, que serão transmitidos. O codificador é responsável por alterar os dados originais preparando-os para serem transmitidos, visando a melhor eficiência do sistema. O modulador tem a função de converter as informações digitais recebidas para ondas analógicas utilizadas para a transmissão. Já no receptor do sistema de comunicação digital realiza o processo inversor do transmissor. Os demoduladores são responsáveis por receber as formas de ondas analógicas e transformá-las em símbolos que serão decodificados e entregues ao destino.

\subsubsection{Transponder}

Transponder, da abreviação transmitter-responder, é um conjunto de dispositivos eletrônicos interligados que recebem e transmitem sinais automaticamente. Normalmente, os transponders são utilizados em satélites, aviões e sistemas baseados em RFIDs (Radio-Frequency IDentification), com o objetivo de receber um sinal em uma determinada frequência, amplificá-lo e retransmiti-lo em uma frequência diferente evitando interferência de um canal em outro (TANENBAUM, 2002).

De acordo com (RODDY, 2001), os componentes típicos de um transponder são:

- Dispositivo na entrada para limitar a banda passante (filtro).

- Dispositivo de amplificação de baixo ruído (do inglês, Low Noise Amplifier - LNA)

- Dispositivo para converter a frequência.

- Dispositivo para limitar o sinal de saída (filtro).

- Dispositivo para amplificar o sinal (amplificador de potência).

\subsubsection{Padrão Manchester}

O padrão Manchester é uma técnica utilizada em telecomunicações, na transmissão dados, para facilitar a sincronização de recepção entre o transmissor e o receptor. De acordo com (TANENBAUM, 2010; BERNAL, 2013), na codificação Manchester, o tempo utilizado para representar um bit na entrada é estendido na saída a dois intervalos de tempo iguais. A Tabela 2.1 ilustra a codificação Manchester seguindo dois padrões existentes, E.G. Thomas e o IEEE 802.3, sendo que na primeira coluna é definido o padrão utilizado, a segunda coluna representa qual bit será transmitido ou recebido e na terceira coluna representa qual será o sinal enviado. 
Tabela 2.1: Padrão de codição Manchester

\begin{tabular}{|c|c|c|}
\hline Padrão & Bit a ser transmitido & Sinal Enviado \\
\hline \multirow{2}{*}{ E.G. Thomas } & 0 & 01 \\
\cline { 2 - 3 } & 1 & 10 \\
\hline \multirow{2}{*}{ IEEE 802.3 } & 0 & 10 \\
\cline { 2 - 3 } & 1 & 01 \\
\hline
\end{tabular}

Fonte: Desenvolvido pelo autor

Como vantagem, a codificação Manchester facilita a sincronização entre o transmissor e o receptor, uma vez que os dois intervalos de tempo iguais com bits opostos na saída obrigam a uma transição na parte intermediária. Por outro lado, apresenta como desvantagem, exigir duas vezes mais largura de banda em relação à codificação binária direta, para realizar o envio da mesma informação.

\subsection{Trabalhos Correlatos}

O assunto de verificação de circuitos integrados de sinais mistos, compostos por blocos analógicos e digitais, é relativamente novo até mesmo para grandes empresas do segmento de microeletrônica. Até o presente momento sugiram poucos estudos e metodologias que tratam de verificação de circuitos integrados de sinais mistos para sistemas de comunicação. Neste capítulo, uma breve descrição de alguns trabalhos relacionados à verificação de circuitos integrados que são compostos por blocos digitas e analógicos de sinais mistos será feita, sendo o trabalho dos autores Bonfini, Chiavacci, Mariani e Pescari (BONFINI et al., 2006) descrito na seção 2.2.1, o trabalho dos autores lliuţă e Ţepuş (ILIUŢĂ e ŢEPUŞ, 2014), na seção 2.2.2 e o trabalho dos autores Muhammad, Murphy e Staszewski (MUHAMMAD et al., 2007), na seção 2.2.3.

\subsubsection{Kit de Verificação de Circuitos Integrados de Sinais Mistos}

Bonfini et al., autores de (BONFINI et al., 2006), apresentam o kit de verificação de circuitos integrados de sinais mistos como uma forma estabelecer a geração de sinais analógicos a partir de testbenches com um estrutura semelhante àquela utilizada para verificar circuitos digitais. 
A essência do kit de verificação de circuitos integrados de sinais mistos é uma biblioteca de terminais controláveis e configuráveis utilizada para monitorar e estimular sinais analógicos conhecida como vProbes e vSource e está focado na utilização da ferramenta Specman Elite [49]. Ainda de acordo com (CADENCE, 2016), as vSources representam "fontes de verificação" que são os modelos de fontes de sinal com objetivo de estabelecer uma ponte entre o domínio de verificação, onde os estímulos são produzidos como palavra digital, ou seja, zeros e uns, e domínio analógico que é capaz de processar somente estímulos de tempo contínuos. Os VProbes são "sondas de verificação", ou seja, são pontas de provas utilizadas para amostrar sinais no domínio contínuo e enviá-las para o testbench digital que são capazes de processar somente sinais digitalizados.

A validação do kit para verificação de circuitos de sinais mistos é feita pelos autores do artigo, aplicando-se a técnica a um Bandgap, que é um circuito responsável por fornecer uma tensão estável independente da temperatura. As especificações para tensão de alimentação, temperatura de operação, tensão de saída e settling time estão descritas na Tabela 2.2 e a Figura 2.10 ilustra a estrutura de verificação utilizada para validar o Bandgap.

Tabela 2.2: Principais Especificações do DUV Bandgap

\begin{tabular}{|l|c|c|c|c|}
\hline \multicolumn{1}{|c|}{ Parâmetros } & Mínimo & Típico & Máximo & Unidade \\
\hline Tensão de Alimentação & 3 & 3.3 & 3.6 & $\mathrm{~V}$ \\
\hline Temperatura de Operação & -40 & 27 & 150 & ${ }^{\circ} \mathrm{C}$ \\
\hline Tensão de Saída & $1,22-1 \%$ & 1,22 & $1,22+1 \%$ & $\mathrm{~V}$ \\
\hline Settling Time $^{3}$ & 50 & & 230 & $\mu \mathrm{s}$ \\
\hline
\end{tabular}

Fonte: (BONFINI et al., 2006)

O kit de verificação de circuitos de sinais mistos aplicado ao Bandgap é relativamente eficiente, apresentando uma boa cobertura funcional, mas devido ao fato de as entradas e saídas serem grandezas contínuas, sinais precisam ser amostrados e este processo pode introduzir erros de quantização; tal situação deve ser considerada no momento de se realizar a checagem automática, onde o sinal de saída deve ser

\footnotetext{
${ }^{3}$ Trata-se do tempo de subida da tensão de saída do circuito de zero até ao valor estável desejado.
} 
apresentado dentro de um intervalo de valores e não um valor exato, o que poderia mascarar algum erro de quantização.

Figura 2.10: Kit de Verificação de Circuitos Sinais Mistos Aplicado ao Bandgap

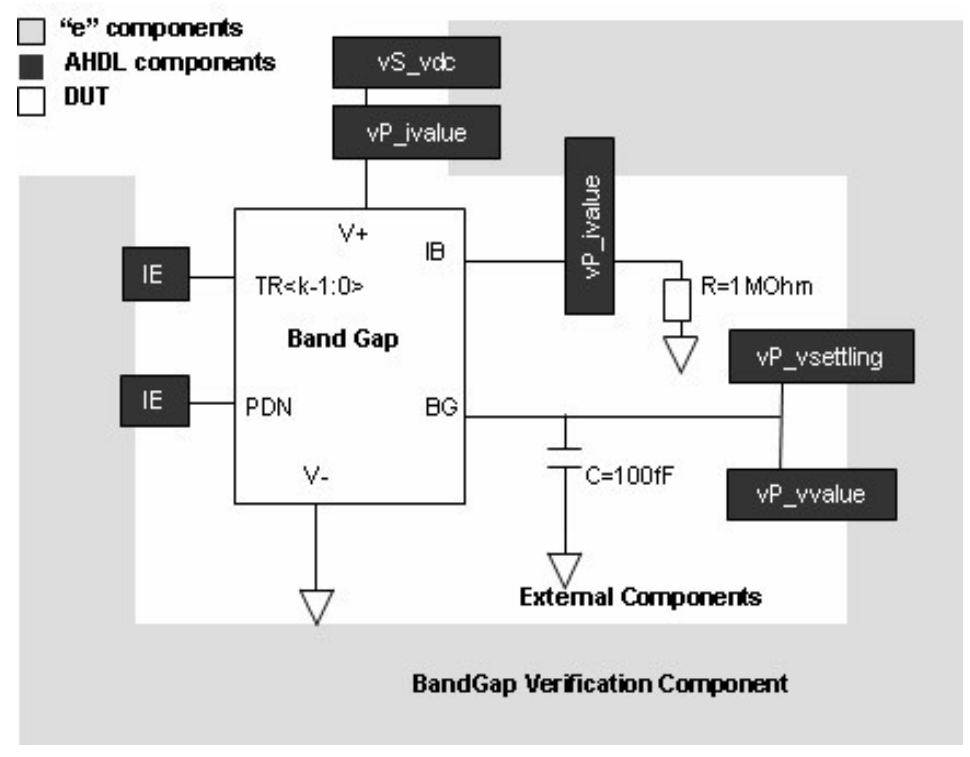

Fonte: (BONFINI et al., 2006)

A base do sistema de verificação é um testbench que monitora e envia sinais no domínio contínuo. Apesar dos avanços obtidos por Bonfini et al., os autores aplicaram a técnica apenas a circuitos com poucos transistores, não ficando claro se ela serviria para circuitos de maior complexidade. Adicionalmente, não há no texto, preocupação com aspectos de conversão analógico digital, necessária para a amostragem dos sinais de entrada e saída, tampouco com o protocolo de comunicação de cada interface que garantiria a correta troca de informações entre os componentes.

\subsubsection{Estímulo Pseudoaleatório e a Cobertura Funcional na Verificação de Sinais Mistos}

Iliuţă e Ţepuş apresentaram em (ILIUŢĂ e ŢEPUŞ, 2014) uma forma de mensurar a qualidade dos estímulos pseudoaleatórios gerados pelo testbench para circuitos de sinais mistos. Além disso, propuseram uma checagem formal para incrementar a confiança no projeto antes da fabricação (ou tape out), utilizando-se ferramentas do fluxo digital: Specman Elite e Incisive Enterprise Simulator da Cadence ${ }^{T M}$ (CADENCE, 2016), juntamente com o simulador analógico XA da Synopsis (SYNOPSYS, 2016).

A base do sistema de verificação é um testbench que estimula os circuitos analógicos e monitora as respostas do bloco digital, como pode ser visto na Figura 2.11. Para 
validar tal técnica, utiliza-se o SBC (System Basis Chip) (ILIUŢĂ e ŢEPUŞ, 2014), que possui uma parte digital complexa, juntamente com alguns blocos analógicos.

Figura 2.11: Diagrama de Blocos do Testbench

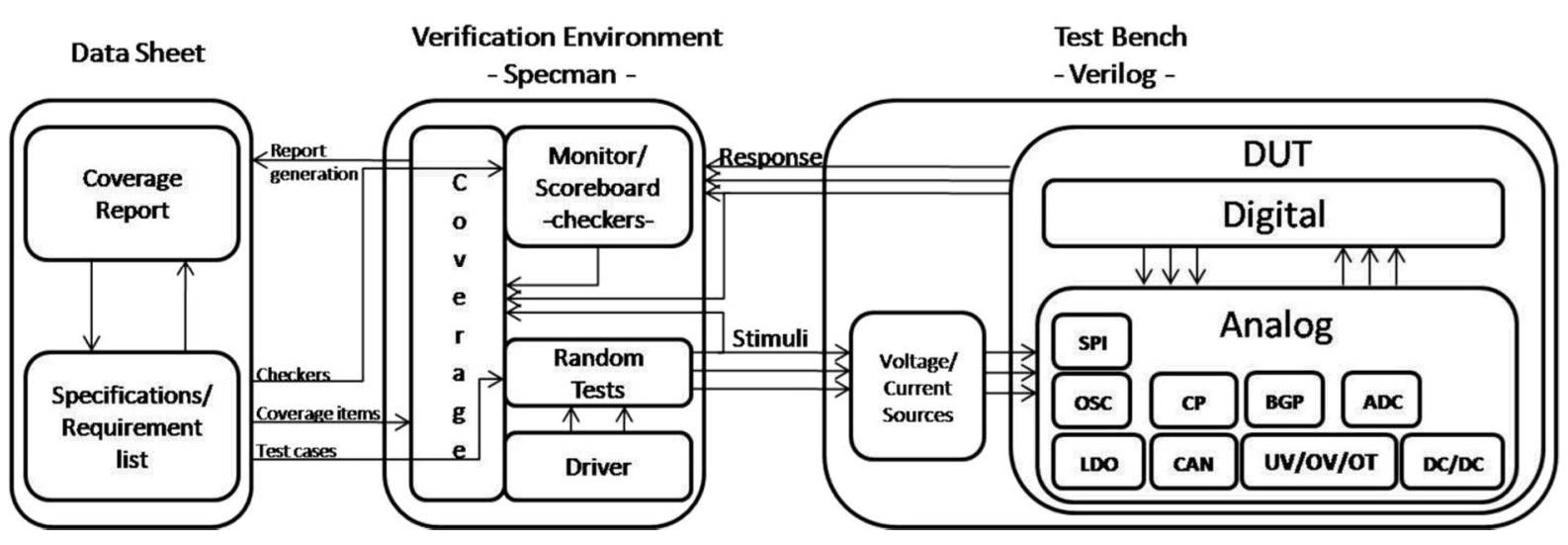

Fonte: (ILIUŢĂ e ŢEPUŞ, 2014)

O testbench de circuitos compostos por blocos digitais e analógicos são similares à arquitetura do testbench utilizado para verificar circuitos integrados puramente digitais, exceto que os estímulos enviados para os blocos analógicos não são baseados em zeros e uns lógicos, mas sim em números reais com objetivo de simular correntes, tensões, cargas, temperaturas nas faixas especificadas (ILIUŢĂ e ŢEPUŞ, 2014).

Para a validação da técnica de verificação, os autores escolheram o bloco conhecido como Comparador de Baixa Tensão (do inglês, under voltage comparator). O comparador possui quatro limiares de tensões diferentes que podem ser selecionados por dois bits em um registro de controle; de outro lado, a tensão de alimentação, que é monitorada, pode assumir dois valores, $3,3 \vee$ e $5 \mathrm{~V}$, estando está disponível em 2 modos $\mathrm{SBC}^{4}$ diferentes portanto, existem 16 combinações possíveis que devem ser testadas neste comparador (ILIUŢĂ e ŢEPUŞ, 2014). Adicionalmente, os valores de limiar de descida e subida são diferentes devido à histerese.

A solução apresentada por lliuţă e Tepuş é eficiente para SoCs com poucos blocos analógicos; não há preocupação com a verificação de circuitos integrados de maior complexidade. Um aspecto positivo desta estratégia é a possibilidade de reuso do testbench, porém a alteração de parâmetros depende diretamente das características

\footnotetext{
${ }^{4}$ Trata-se de um chip utilizado como exemplo para verificação de sinais mistos e que possui uma parte digital complexa ao lado de um número maior de blocos analógicos.
} 
descritas na especificação do bloco e muitas vezes não é viável a reaplicação da mesma estrutura. Quanto à conversão analógico-digital, os autores não trataram a criação de estímulos analógicos por testbenches, o que pode gerar erros de quantização mascarando erros no DUV.

\subsubsection{Implementação da Verificação de Processadores RF Digitais}

O trabalho desenvolvido por Muhammad et al. (MUHAMMAD et al., 2007) é focado no desenvolvimento de um modelo de testbench para telefones celulares com tecnologia GSM que possui em sua arquitetura, filtros, switches, amplificadores de potência, transceptores de RF para vários padrões, gerenciadores de energia, codificadores e decodificadores de áudio e vídeo, processadores de banda base, processador, memória, entre outros periféricos. Objetiva estabelecer um fluxo de verificação eficiente para sistemas compostos por blocos analógicos e digitais, como o exemplo apresentado no artigo e replicado na Figura 2.12.

A base do sistema de verificação é centrada em uma estrutura unificada onde os detalhes críticos do projeto são visíveis e os modelos comportamentais analógicos utilizados para validar o desempenho de todo o sistema apresentam, inicialmente, uma descrição simples de complexidade reduzida, mas são progressivamente melhorados com o avanço do projeto. Assim, a medida que mais detalhes são inseridos, aprimora-se a qualidade e a precisão dos resultados, quando comparados com os modelos iniciais (MUHAMMAD et al., 2007).

Figura 2.12: Diagrama de Blocos Simplificado de um SoC para um Telefone GSM

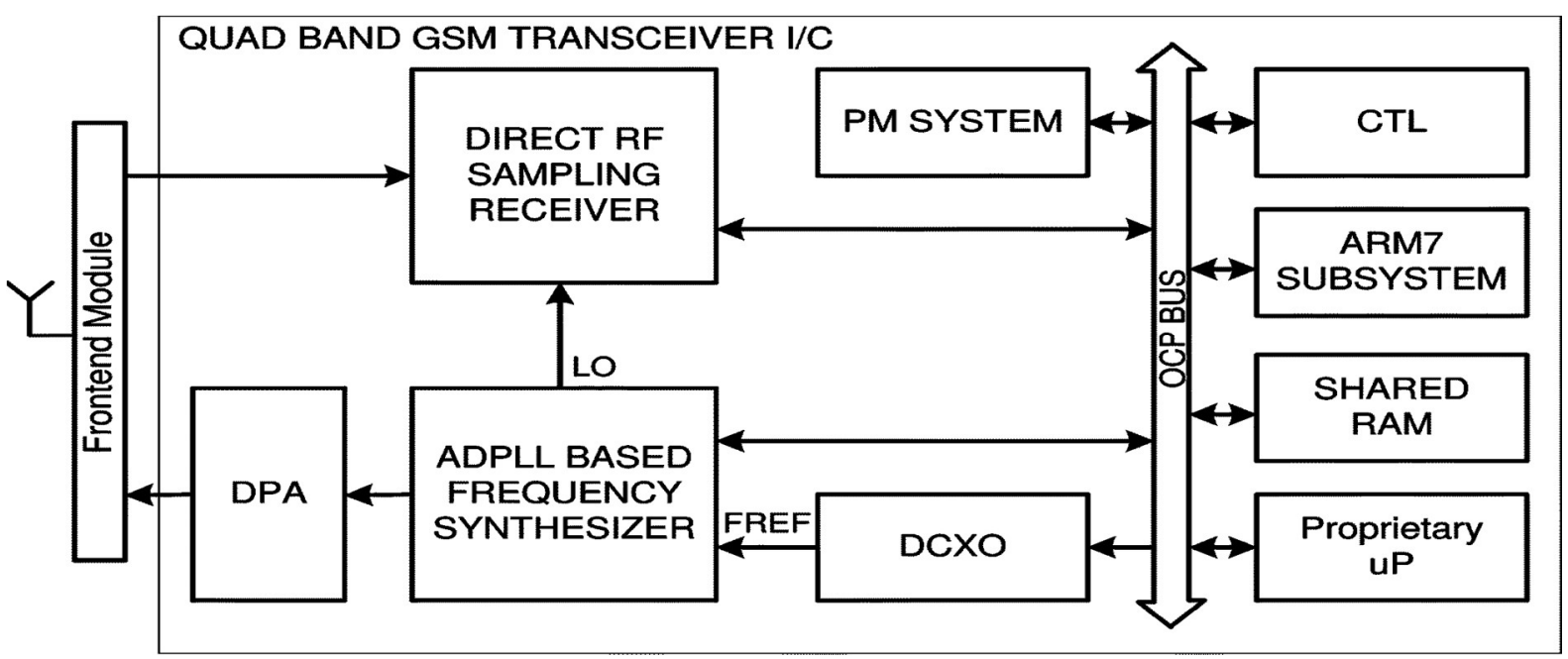

Fonte: (MUHAMMAD et al., 2007) 
De acordo com (MUHAMMAD et al., 2007), a metodologia de verificação baseia-se na filosofia de que todas as verificações devem ser automatizadas o mais cedo possível, com reaproveitamento máximo de estruturas de verificação já desenvolvidas previamente. Em um SoC complexo como este, os testes mais valiosos são aqueles que estimulam todo o sistema, exercitando as principais características descritas na especificação.

Para garantir o correto funcionamento do SoC, os autores realizaram a verificação em dois passos: a verificação do transmissor e a verificação do receptor separadamente. No transmissor, os estímulos foram produzidos a partir de sequência de dados e armazenados em um arquivo chamado Stim, enquanto as instruções para as diversas configurações foram produzidas e armazenadas em um arquivo de configuração. A partir destes arquivos, as ferramentas de CAD eram capazes de estimular o DUV e os resultados produzidos foram gravados em um outro arquivo para posterior análise por rotinas criadas em Matlab; após processamento dos resultados, estariam disponíveis informações se cada estímulo enviado causaria uma falha ou não no transmissor (MUHAMMAD et al., 2007), conforme ilustrado na Figura 2.13.

Figura 2.13: Fluxo de Verificação do Transmissor

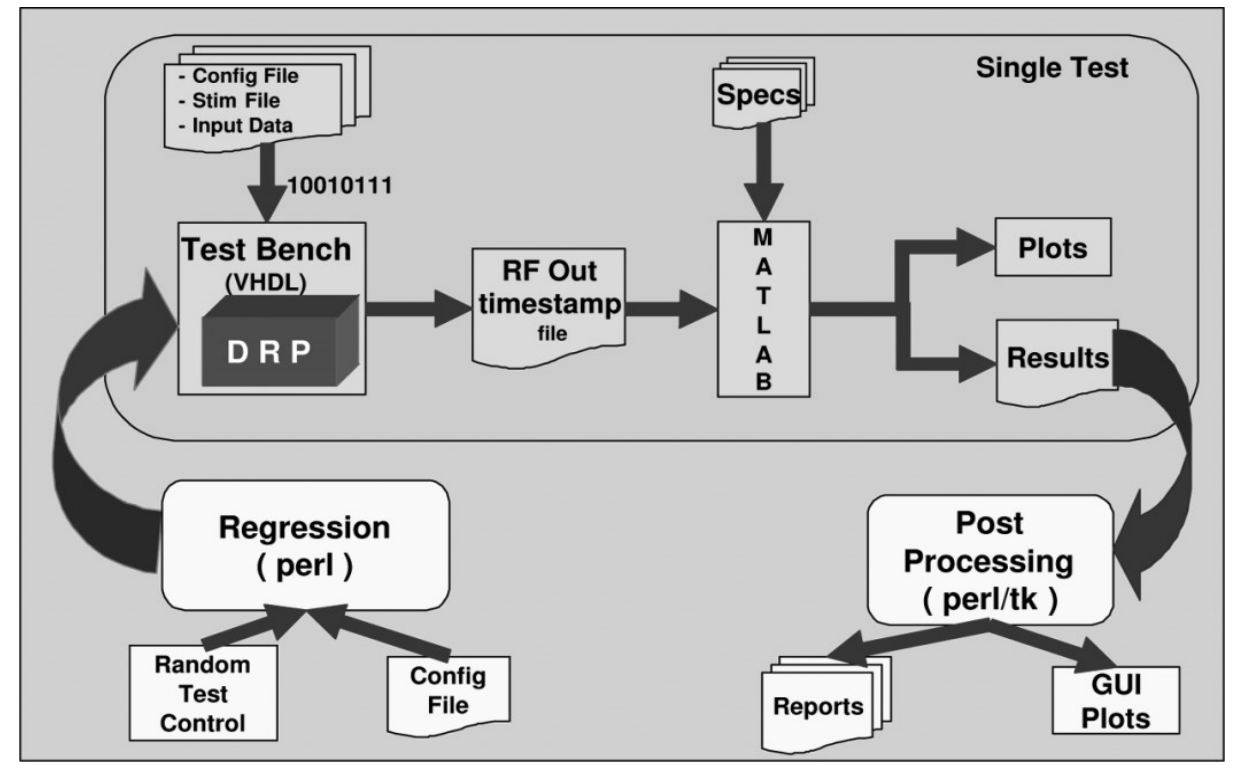

Fonte: (MUHAMMAD et al., 2007)

Analogamente ao transmissor, para o receptor, os dados foram produzidos em Matlab ou em $\mathrm{C}$ e enviados para o testbench, o qual adicionou ao canal ruídos e deficiências de propagação. Também foi utilizado um arquivo que continha informações de 
configurações para o DUV. Os resultados produzidos foram armazenados e em seguida processados por scripts em $\mathrm{C}$ e Matlab, que após serem executados e os resultados interpretados, definem se cada estímulo enviado provocou uma falha ou não no receptor (MUHAMMAD et al., 2007), conforme pode ser observado na Figura 2.14 .

Figura 2.14: fluxo de Verificação do Receptor

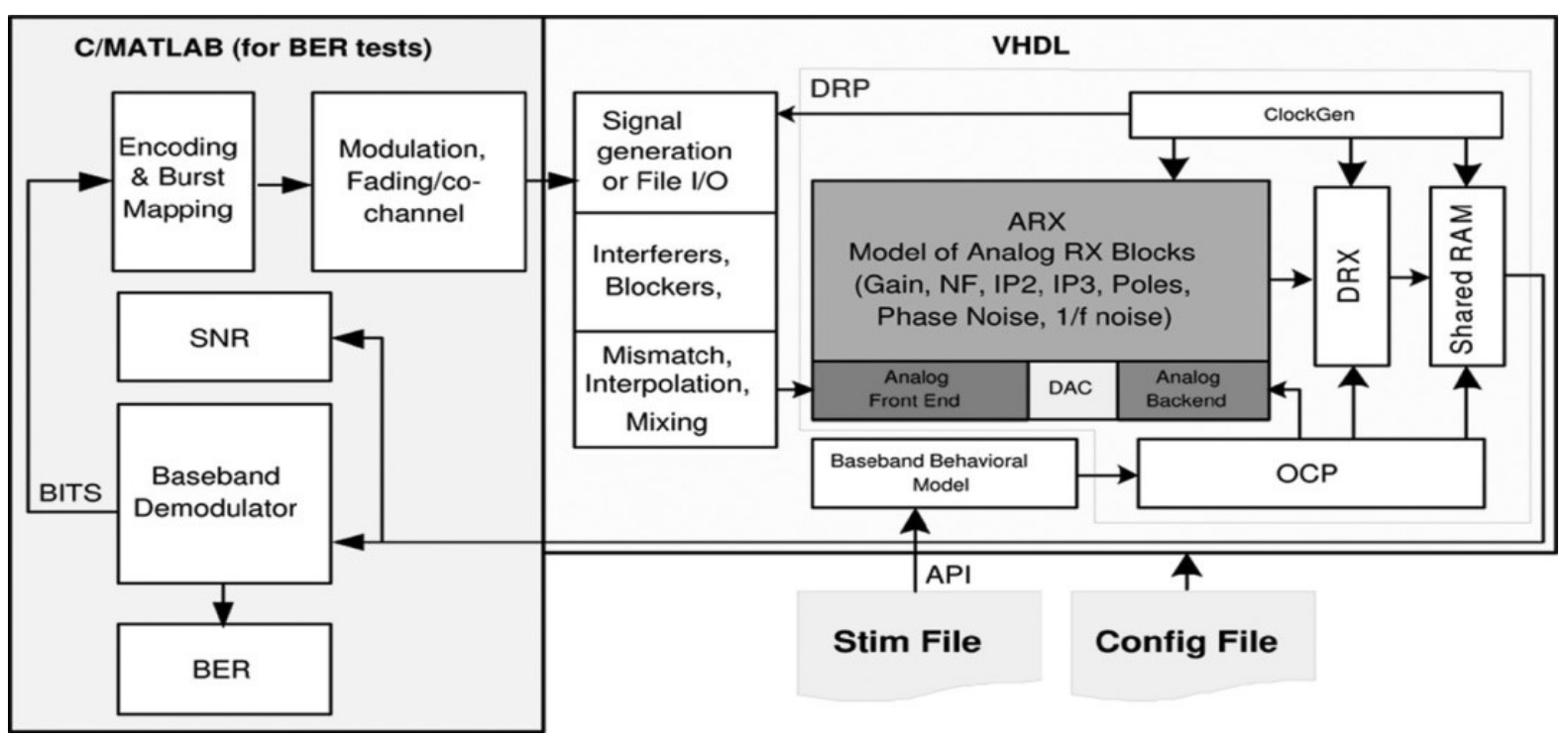

Fonte: (MUHAMMAD et al., 2007)

$\mathrm{Na}$ proposta descrita acima, os autores não se preocuparam com a verificação do sistema como um todo, ou seja, com o transmissor e o receptor operando em uma única simulação; os autores limitaram-se a realizar uma verificação que denominamos nesta dissertação como tradicional (ver seção 3.2.1), do receptor e transmissor separadamente, não validando todo o conjunto arquitetural do SoC. Desta forma, fica uma lacuna na verificação da interação entre transmissor e receptor, ou seja, na comunicação e interação entre todos os blocos desenvolvidos, especialmente entre os blocos digitais e analógicos. 


\section{Verificação Integrada de Circuitos de Comunicação}

Apesar de não existirem metodologias de verificação consolidadas de projetos de circuitos de sinais mistos, existem uma série de práticas correntes utilizadas no fluxo de projeto desta categoria de sistemas. Elas são, de forma genérica, adequadas à verificação de uma ampla variedade de sistemas, como por exemplo, para sistemas automotivos (SIMON et al., 2016), displays LCD (Liquid Crystal Display) (CHAO, 2013), entre outros.

Dentre o enorme conjunto de aplicações de circuitos de sinais mistos, a área de grande destaque é a de comunicações pelas suas tradição e relevância. Diferente de outros sistemas de sinais mistos, os de comunicação, particularmente na forma apresentada na Seção 2.1.7, caracterizam-se por possuírem fluxos similares, mas opostos, de transmissão e recepção, tornando-os aptos a adotarem técnicas e metodologias particulares de verificação, como será visto em seções seguintes.

Nesta seção, apresentaremos os vários aspectos que integram o que denominamos de verificação integrada de circuitos de comunicação. Uma primeira parte desta estratégia consiste nas metodologias e práticas mais genéricas, tradicionalmente adotadas no projeto de circuitos de sinais mistos, as quais serão descritas na seção 3.1. Em uma segunda parte, na seção 3.2, trataremos da metodologia desenvolvida no âmbito deste trabalho de mestrado, aplicado para sistemas de comunicação.

\subsection{Verificação de Circuitos de Sinais Mistos}

A verificação de circuitos de sinais mistos compreende em validar funcionalmente circuitos integrados compostos por blocos digitais e blocos analógicos, considerando toda e qualquer interação existente entre eles. A validação funcional é medida através da cobertura funcional. Não menos importante, a cobertura de código exibirá informações das partes de código que foram exercitadas e as partes de código que precisam ser exercitadas.

\subsubsection{A Integração e a Simulação da Interface Analógica-Digital}

Tradicionalmente, a verificação de circuitos compostos por testbenches digitais e testbenches analógicas são realizadas separadamente, sem nenhuma dependência 
entre eles. Os projetistas de circuitos analógicos, baseando nas características descritas nos documentos de referência (especificações funcionais), criam testbenches analógicos para realizar simulações dos blocos individualmente, respeitando e seguindo as características específicas de cada bloco. Analogamente, os engenheiros de verificação de circuitos digitais, baseando nas características descritas nos documentos de referência (especificações funcionais), desenvolvem testbenches para garantir o correto funcionamento dos blocos digitais de forma individual.

Após garantir o correto funcionamento dos blocos individualmente, a fase integração é iniciada. O engenheiro de System-on-Chip, em uma abordagem tradicional de verificação circuitos integrados de sinais mistos, normalmente ignora a funcionalidade dos blocos analógicos, considerando-os como caixas pretas, e realiza apenas testes básicos, com uma taxa de troca de dados muito limitada ou baixíssima entre os blocos digitais e analógicos. No entanto, a utilização de blocos analógicos está aumentando cada vez mais e tornando-se mais complexa, pois exige uma interação maior com os blocos digitais de controle. Desta forma, a integração analógico digital tem se tornado uma grande fonte de erros no funcionamento de circuito integrado ou re-spins, pois nenhuma verificação é realizada para validar a integração entre os domínios analógico e digital (BALASUBRAMANIAN et al., 2013).

No contexto acima, os circuitos integrados de sinais mistos teriam as interfaces analógico-digital e digital-analógico e a integração testada somente após a fabricação, podendo gerar elevados custos que poderiam ser evitados com a verificação destas interfaces e da integração entre os circuitos digitais e analógicos durante a fase de projeto.

\subsubsection{Modelagem de Circuitos de Sinais Mistos para Simulação}

A simulação de circuitos de sinais mistos, incluídos os de comunicação que são o foco desta dissertação, associa em um único fluxo de simulação componentes analógicos e digitais. A tarefa de verificação de circuitos de sinais mistos envolve, como na verificação digital, a criação de um plano de verificação, o desenvolvimento de uma estrutura de verificação (testbench), a simulação e o processamento dos 
resultados que incluem medições (cobertura de código e cobertura funcional) e comparações com a especificação.

Com objetivo de mitigar os problemas de integração digital-analógico, utiliza-se a estratégia de verificação baseado na metodologia MDV largamente utilizada nas DHs, discutida na seção 2.1.3.2.1, tendo-se como principal objetivo garantir uma simulação eficiente e relativamente rápida focada em cobertura de código e cobertura funcional. Segundo (NIZIC, 2014), a metodologia MDV é utilizada em larga escala para verificação de blocos digitais, mas tem se expandido também para aplicações de circuitos analógicos e circuitos de sinais misto, foco principal deste trabalho.

\subsubsection{Modelo Comportamental de Blocos Analógicos}

Os modelos comportamentais analógicos além de reproduzir com fidelidade o comportamento dos blocos, permitem que sejam feitas simulações com velocidades que vão de moderadas a rápidas dependo da aplicação e dos níveis de detalhes empregados no desenvolvimento dos modelos. Os modelos analógicos, normalmente, são descritos utilizando-se: Verilog A (AISOLA et al., 1996), Verilog AMS (ACELLERA, 2014) e VHDL-A (IEEE, 2007) e SystemVerilog (IEEE, 2012a).

As linguagens de descrição analógicas acima permitem descrever o comportamento de vários tipos de sistemas, tais como, elétricos, mecânicos, termodinâmicos, entre outros. Para descrever um sistema deve-se inicialmente estabelecer a estrutura interna do sistema e, em seguida, os comportamentos individuais de cada componente, que são descritos através de relações matemáticas entres as entradas e as saídas. Em se tratando de um transponder, por exemplo, é comum utilizar senos e cossenos para representar o comportamento de alguns blocos. Também, as funções de transferência de filtros são largamente utilizadas para modelar o comportamento matemático destes tipos de circuito.

\subsubsection{Verificação de Circuitos de Sinais Mistos Utilizando Modelos}

Com a criação de systems-on-chips cada vez mais complexos, integrando uma grande quantidade de blocos analógicos em uma mesma pastilha, os engenheiros de verificação devem realizar simulações que envolvam todos os blocos digitais e analógicos, com objetivo de garantir as interações entre ambos. Neste contexto não é possível utilizar somente uma abordagem black box, que assume que todos os 
blocos analógicos e todas as interfaces já passaram pelo processo de verificação, pois alguns erros de integração podem ocorrer, tornando mais difícil a sua detecção. Assim, para a verificação de circuitos de sinais mistos deve-se incluir as abordagens white box ou grey box que se adequem melhor a este tipo de circuitos, uma vez que se faz necessário a verificação do protocolo de comunicação estabelecido entre os blocos.

A verificação de circuitos integrados de sinais mistos utilizando-se modelos apresenta as seguintes características:

- Capacidade de depurar a integração analógico-digital.

- Validação da funcionalidade dos blocos analógicos e digitais.

- Simulação em um mesmo ambiente de blocos analógicos e digitais.

- Utilização de métricas para cobertura de código e funcional em circuitos de sinais mistos.

- Tempo de simulação de moderado.

A arquitetura de um testbench para validar circuitos de sinais mistos é similar à arquitetura de verificação de blocos digitais, divergindo-se apenas pela utilização dos ambientes para blocos digitais em modo passivo. Assim, como é mostrado na Figura 3.1 , os ambientes no modo passivo não geram dados, sendo utilizados apenas para garantir o protocolo de comunicação e dados das interfaces.

Figura 3.1: Arquitetura do Testbench de Circuitos de Sinais Mistos

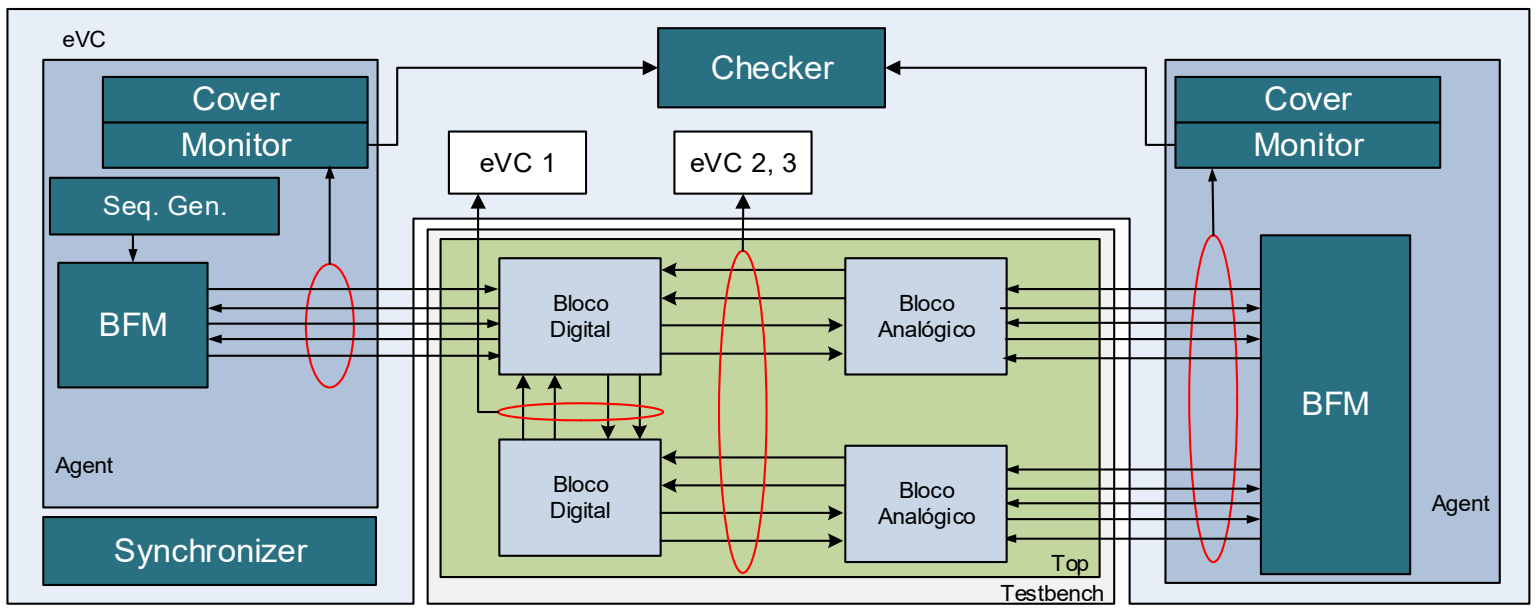


Fonte: Desenvolvido pelo autor

Neste modelo de testbench, além de gerar estímulos para os blocos digitais, deve-se gerar também estímulos que serão consumidos pelos blocos analógicos, com pode ser visto na Figura 3.1. As interfaces entre blocos analógicos e digitais são locais de monitoramento, podendo ser uma entrada ou saída do bloco analógico. Já os sinais que estão "conectados" ao testbench são monitorados caso sejam saídas e podem ser monitorados ou estimulados caso sejam entradas.

\subsubsection{Desafios da Verificação de Circuitos de Sinais Mistos}

Com o crescente aumento do tamanho, da complexidade, da interação analógicodigital e do número de modos de operação, a verificação de circuitos integrados de sinais mistos avançados tem encontrado grandes desafios na criação de vetores de teste devido à complexidade das características do estímulo e na verificação automática dos resultados para testes tradicionais devido à complexidade de implementar um modelo de referência eficaz, tendo que buscar alternativas para validar a integração analógico-digital.

A verificação de circuitos integrados de sinal misto é um grande desafio no seu fluxo de projeto por várias razões. Primeiramente, o projeto abrange componentes digitais e analógicos, que apresentam, entre si descrições em diferentes formas e níveis de abstração. Devido à grande gama de representatividade destes circuitos (diagramas esquemáticos, netlists, modelos comportamentais analógicos e modelos digitais), é importante utilizar uma abordagem hierárquica que suporte diferentes níveis de abstração, diferentes mecanismos de simulação e diferentes linguagens de modelagem.

Outro problema é a dificuldade de se modelar com fidelidade o comportamento dos blocos analógicos, utilizando-se para isto linguagens de descrição de hardware não sintetizáveis. A criação de um modelo pode durar semanas dependo dos níveis de detalhes e da finalidade de seu uso. Adicione-se a isto, a falta de uma metodologia consolidada para a verificação de blocos analógicos como a existente para o domínio digital (esta vista na seção 2.1.3).

A dificuldade para a verificação analógica é aumentada na estratégia de verificação conjunta de blocos analógicos e digitais, com o testbench apresentado na Figura 3.1, pois deve-se ser capaz de se modelar as relações de entrada-saída (analógica-digital 
ou digital-analógica) do DUV. Como pode ser visto na Figura 3.1, a presença de dados analógicos na saída cria-se a necessidade de trabalhar com monitores de sinais analógicos, aumentando a complexidade de verificação dos dados nas unidades checadoras. Da mesma forma, pode-se criar a necessidade de trabalhar com geradores de sinais analógicos de complexidade elevada devido à necessidade de gerar sinais com as características adequadas às definidas na especificação.

\subsection{Estratégia de Verificação de Circuitos Integrados de Sinais Mistos para Comunicação}

\subsubsection{Estratégia Tradicional}

As estratégias de verificação de circuitos integrados de sinais mistos variam conforme as características da aplicação, principalmente, na dependência aos blocos analógicos. Para circuitos integrados de comunicação, blocos transmissores e receptores são tipicamente verificados em separado, como visto na seção 3.1 ; isto ocorreria mesmo em circuitos como o transponder, contendo ambos os blocos, não se avaliando a integração existente entre eles. Um exemplo típico desta estratégia é o trabalho de Muhammad et al. (MUHAMMAD et al., 2007), apresentado na subseção 2.2.3 da seção 2.2. Desta forma, um testbench seria desenvolvido para validar todo o transmissor, como ilustrado na Figura 3.2 (a), levando-se em consideração que o estímulo seria feito a partir do transmissor digital e um outro ambiente seria desenvolvido para validar todo o receptor, como na Figura 3.2 (b), levando em consideração que o estímulo seria feito a partir do receptor analógico.

Figura 3.2: Verificação do Transmissor e Receptor Separadamente

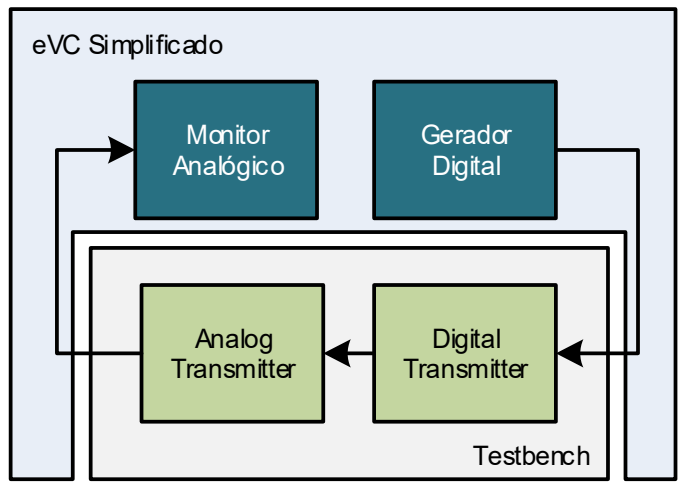

(a)

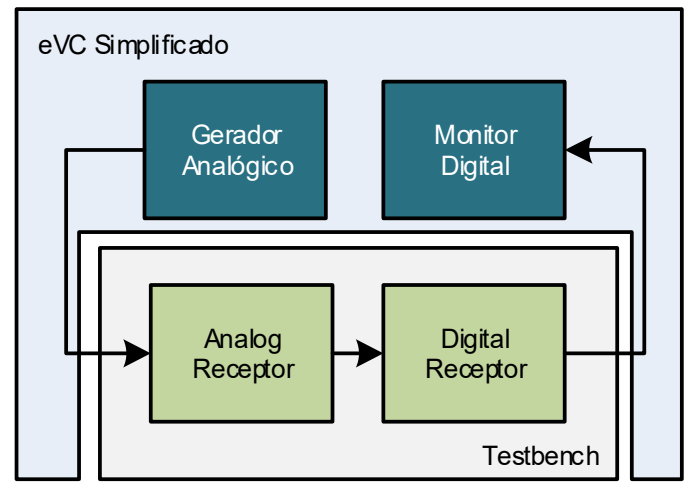

(b) 
Fonte: Desenvolvido pelo autor

Como discutido da Seção 3.1.5, em ambos os testbenches que são desenvolvidos, deve-se existir uma preocupação em monitorar resultados analógicos para o transmissor da Figura 3.2 (a) ou gerar estímulos analógicos para o receptor Figura 3.2 (b). Tratam-se de sinais analógicos de complexidade elevada, além de que não é possível garantir a integração de todo o sistema devido à não realização de uma simulação e verificação de todo o circuito integrado de sinais mistos.

\subsubsection{Estratégia de Verificação Integrada para Circuitos de Comunicação}

No âmbito desta dissertação, elaboramos uma verificação integrada para circuitos de comunicação com um fluxo fechado de sinal entre o transmissor e receptor, como mostrado na Figura 3.3. Para estabelecer-se o fluxo fechado, adiciona-se um modelo que represente as características do meio de transmissão utilizado pelo sistema (fibra, ar, par trançado, guias de onda, entre outros). Dentre os vários tipos de comunicações existentes, citadas na seção 2.1.7, exemplos de sistemas que aceitariam tal forma seriam a comunicação entre computadores, transmissão de televisão ou via satélite, etc. Nesta dissertação, por simplicidade, esta abordagem será aplicada a circuitos que apresentem sinais de entrada e saída com características semelhantes e operem em modo simplex, mas que para trabalhos futuros poderão ser testados casos fullduplex e half-duplex.

Para estabelecer um fluxo fechado entre o transmissor e o receptor, deve-se levar em consideração as características destes componentes, como por exemplo a frequência e potência utilizada, tomando-se os devidos cuidados para garantir que o sinal enviado ao receptor tenha as características que atendam as especificações de recepção, evitando que o sinal seja descartado pelo filtro de entrada e que não leve os componentes analógicos de entrada à saturação.

Um modelo do ambiente, com as características do meio de transmissão, deve ser criado, utilizando-se qualquer linguagem de descrição de hardware, devendo ser capaz de: 
- Realizar atenuação do sinal com objetivo de avaliar qual é o mínimo nível de sinal que poderá ser recebido pelo IP Transponder sem causar dano a informação.

- Adequar o nível de sinal enviado ao receptor sem que o mesmo entre em saturação.

- Transladar a frequência, ou seja, converter a frequência do sinal emitido pelo transmissor na frequência que pode ser recebida pelo receptor.

- Inserir ruído para avaliar o quanto o sistema é capaz de separar ruídos de sinais realmente úteis.

A Figura 3.3 ilustra o fluxo que o sinal inserido através do transmissor digital deve percorrer, validando toda a integração e toda a comunicação existe entre os blocos do circuito de comunicação. Ao exercitar todo o transmissor digital, automaticamente, respeitando a ordem a ser seguida, serão exercitados todos os blocos do transmissor analógico, o modelo do ambiente, todos os blocos do receptor analógico e todos os blocos do receptor digital.

Figura 3.3: Estratégia de Verificação de Circuitos de Sinais Mistos com Modelo

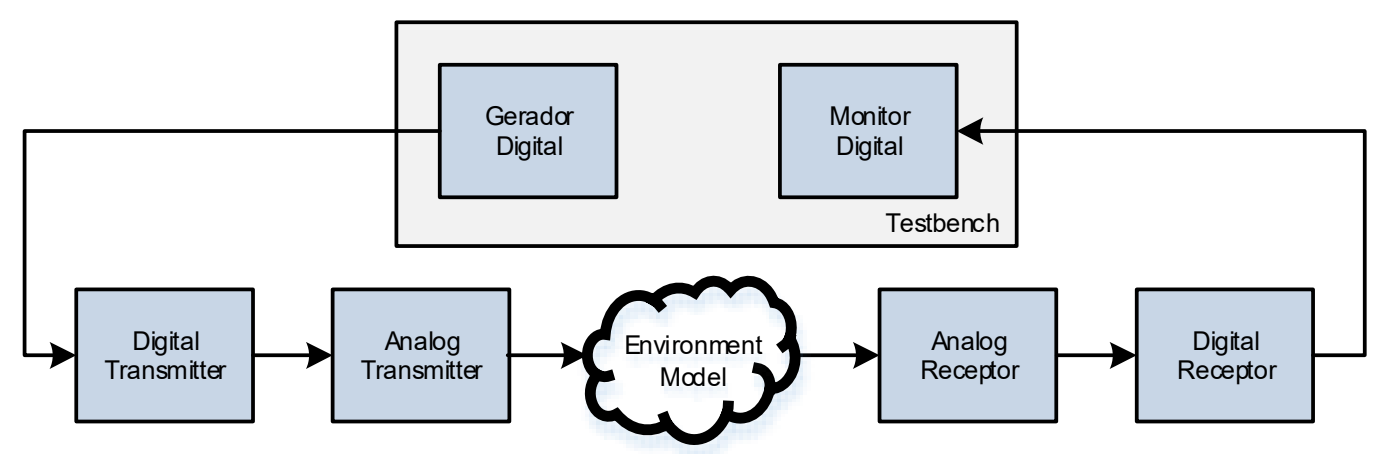

Fonte: Desenvolvido pelo autor

Com a criação deste fluxo, pode-se também validar, além das interfaces analógico digital, a funcionalidade de todos os blocos analógicos, assim como todas as interfaces de comunicação definidas para os blocos digitais. Para que esta estratégia seja válida, as funcionalidades de cada um dos blocos digitais devem ser garantidas previamente e para que as interfaces sejam verificadas é necessário o uso das estruturas de verificação em modo passivo mantendo somente os checadores e monitores operando durante a simulação. 


\section{Aplicação da Metodologia de Verificação de Circuitos de Sinais Mistos a um Transponder}

Neste capitulo será apresentado o sistema de coleta de dados brasileiro juntamente com o desenvolvimento de um SoC (Potiguara) dedicado para satélite, que é o caso de estudo apresentado nesta dissertação. Além disso, explicita-se a metodologia de verificação funcional integrada aplicada a circuitos integrados de sinais mistos, apresentada na seção 4.5, ao bloco Transponder, o componente principal do SoC Potiguara.

\subsection{Sistema Brasileiro de Coleta de Dados}

O Sistema Brasileiro de Coleta de Dados (SBCD), criado pelo Instituto Nacional de Pesquisas Espaciais (INPE), consiste em uma constelação de satélites de baixa órbita, estações de tratamento de dados e Plataformas de Coleta de Dados (PCDs) (COSTA, 2009). Os satélites recebem sinais das Plataformas de Coleta de Dados (PCDs) e os retransmitem para uma estação central onde os dados coletados serão tratados e analisados. Como ilustrado na Figura 4.1, a comunicação entre as PCDs e o satélite (uplink) é feita em frequência ultra alta (do inglês, Ultra High Frequency UHF) utilizando o modo simplex. Já a comunicação entre o satélite e as estações de tratamento de dados (downlink) é feita em Banda-S (COSTA, 2009) utilizando também o modo simplex. No SBCD, as informações vão apenas em um único sentido, não existindo comunicação do satélite para a PCD. As frequências utilizadas na recepção e transmissão são de 401,635 MHz e 2,2 GHz, respectivamente.

Os satélites são construídos em sua grande maioria, se não na sua totalidade, de componentes discretos. Com objetivo de reduzir espaço ocupado e o consumo de energia, um SoC, denominado Potiguara, foi especificado, combinando blocos digitais, de sinais mistos e de radiofrequência. O SoC Potiguara foi projetado no programa Cl-Brasil, pelos Centros de Treinamento I e III ${ }^{5}$ durante a fase de projeto no ano de 2016 (NEGREIROS et al., 2015). As PCDs, espalhadas por todo território brasileiro, utilizam sensores que estão a elas acoplados, para captar dados

\footnotetext{
${ }^{5}$ Local destinado a realizar o treinamento de recursos humanos na área de microeletrônica, cujo foco principal é formar mão de obra capacitada a trabalhar no desenvolvimento de circuitos integrados. Atualmente, os centros de treinamento estão localizados em Porto Alegre - RS e em São Paulo - SP.
} 
ambientais, tais como umidade, temperatura, nível de reservatórios de água, entre outros.

Figura 4.1: Sistema Brasileiro de Coleta de Dados

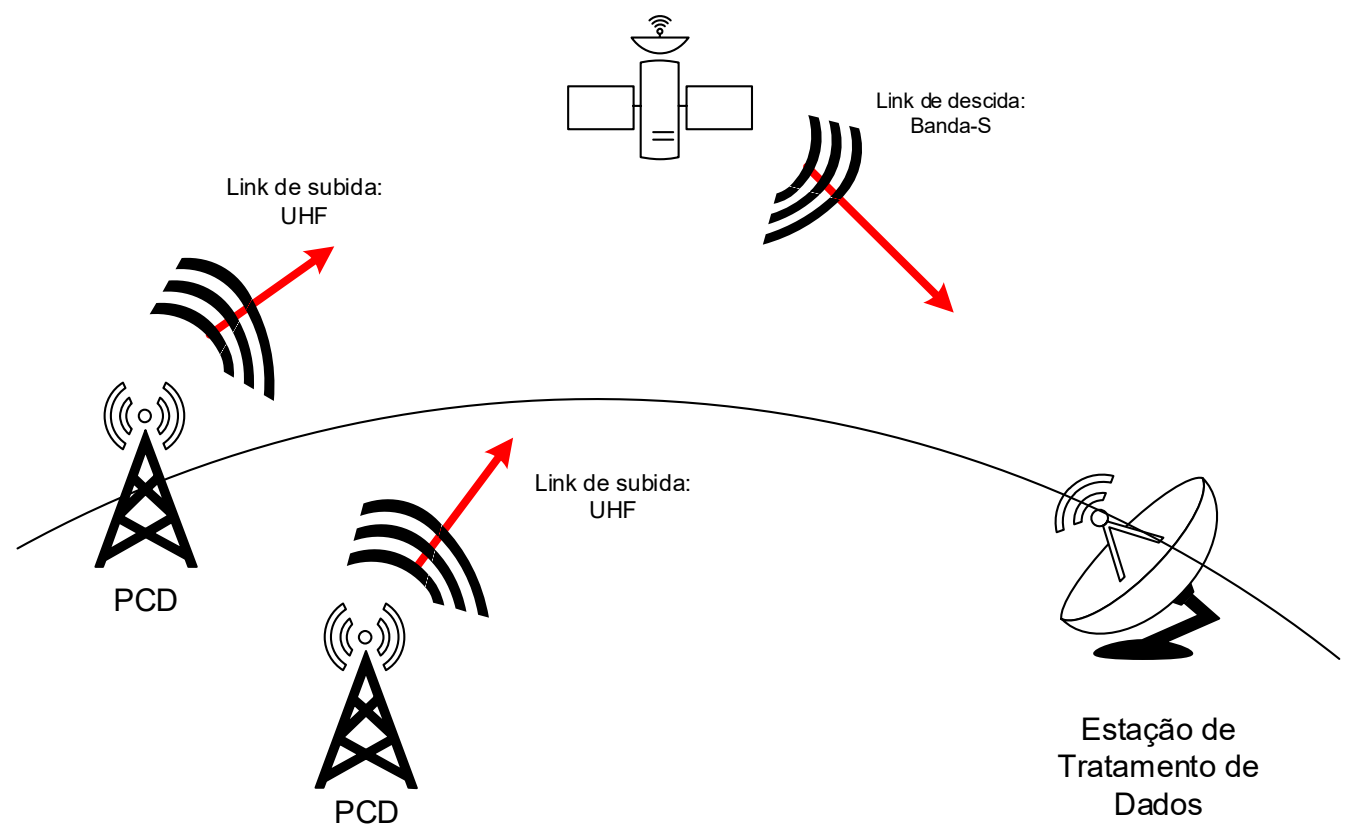

Fonte: (NEGREIROS et al., 2015)

\subsubsection{Arquitetura do Sistema Potiguara e do IP Transponder}

O SoC Potiguara apresenta uma estrutura básica, como pode ser visto no diagrama de blocos na Figura 4.2, sendo constituído pelos blocos Inter-Integrated Circuit (I2C) (NXP, 2014), timers, Serial Peripheral Interface (SPI) (MOTOROLA, 2000), ARM core, barramentos de comunicação - Advanced Peripheral Bus (APB) (ARM, 2003) e Advanced High Performance Bus (AHB) (ARM, 1999), Boot Loader, memória interna e o IP Transponder, este último delimitado pela linha tracejada.

Nas próximas seções, o IP Transponder será visto com mais detalhes, por ser o circuito utilizado como caso de estudo para a metodologia apresentada na Seção 3. A principal funcionalidade do bloco transponder é receber um sinal a partir do frontend analógico composto por vários blocos de radiofrequência e de sinais mistos, realizar a modulação de fase no sinal recebido utilizando a modulação BPSK e enviar o sinal resultante do processamento para o transmissor analógico. A recuperação do sinal é planejada de modo que o sistema desenvolvido seja capaz de remover localmente do sinal a ser enviado para estação de tratamento de dados os ruídos 
obtidos indesejadamente introduzidos durante o processo de transmissão dos dados das PCDs para o satélite (NEGREIROS et al., 2015).

Figura 4.2: Diagrama de Blocos da Arquitetura do Potiguara SoC

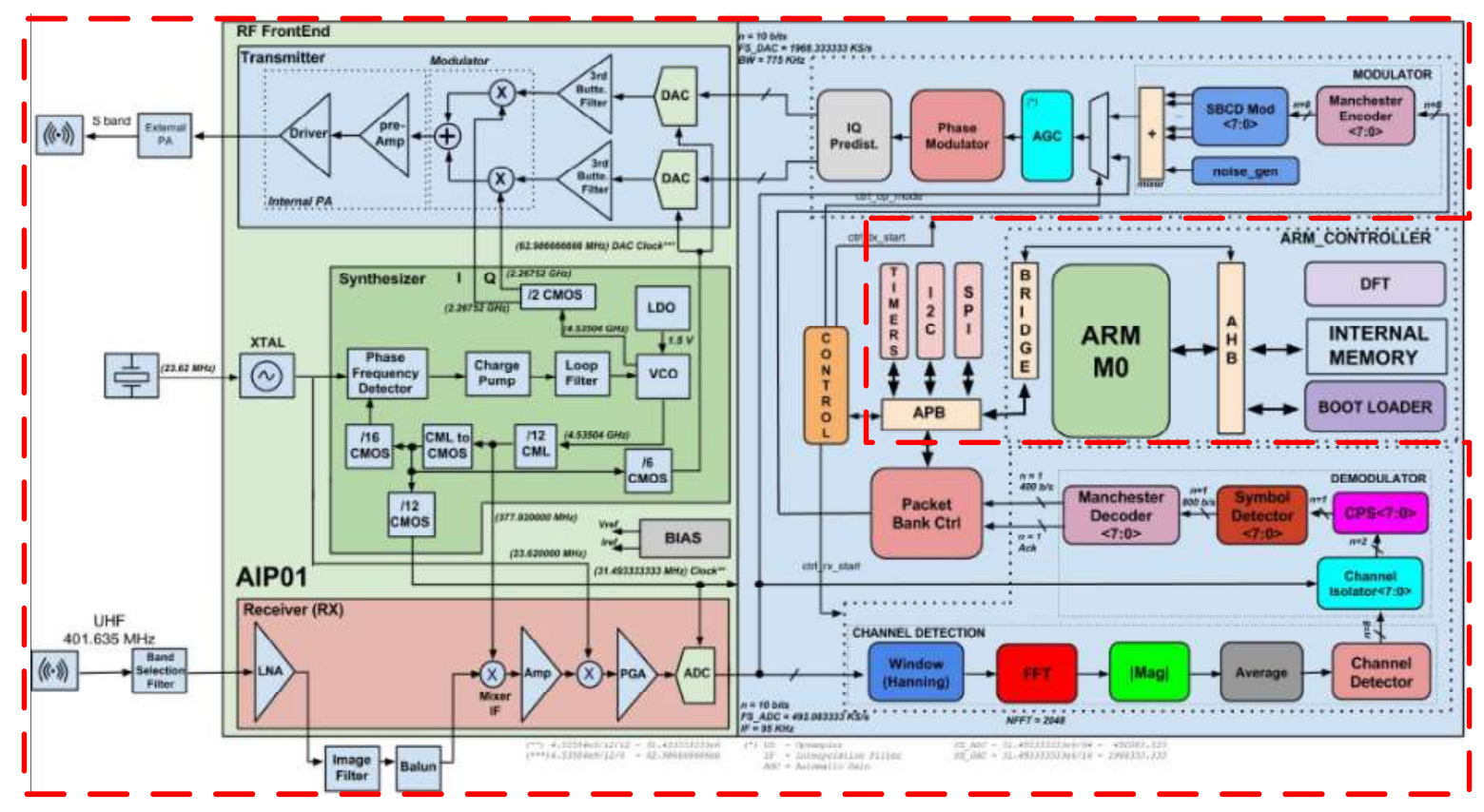

Fonte: (NEGREIROS et al., 2015)

O IP Transponder possui três modos de operações, que são: fast, direto e indireto. No modo de operação fast, o IP Transponder opera como um espelho, retransmitindo os dados recebidos sem nenhum tipo de tratamento ou processamento. No modo de operação direto, o IP Transponder recebe o sinal, demodula, decodifica, recodifica, remodula todo o sinal, reduzindo o nível ruídos presente no sinal e validando os pacotes de acordo com os campos de controle presentes no pacote recebido. No modo de operação indireto, o IP Transponder funciona como no modo direto, diferindo-se apenas pela existência da funcionalidade de corrigir, se necessário, o dado recebido da PCD, através do campo CRC (Cyclic Redundancy Check) do pacote recebido(NEGREIROS et al., 2015).

\subsubsection{Arquitetura Digital do Transponder}

O IP Transponder é o principal bloco dentro do projeto Potiguara e é composto por quatro grandes blocos digitais, operando como um processador digital de sinais (PDS). Como pode ser visto na Figura 4.3 os principais sub-blocos são: Channel Detector, Demodulator, Packet Bank e Control e por último o Modulator. 
O Channel Detection, que como o próprio nome diz, é responsável por identificar a frequência utilizada pela plataforma de coleta de dados no envio da informação para o satélite. Para encontrar a frequência enviada, são necessários cinco blocos: Window, Fast Fourier Transform (FFT), Magnitude, Average e Channel Detector. O Demodulator, que como o próprio nome diz, é responsável por extrair do sinal recebido a informação que foi enviada pela plataforma de coleta de dados. Para realizar a extração dos dados, são utilizados quatro blocos: Channel Isolator, Carrier Phase Synchronizer (CPS), Symbol Detector e Manchester Decoder. O Packet Bank e Control são responsáveis por receber, montar e validar a estrutura do pacote recebida pelo Demodulator e gerar os sinais de controle para todo o IP Transponder. Finalmente, o Modulator, como o próprio nome diz, é responsável por preparar o dado a ser enviado para a terra, iniciando o processo de modulação. Para o envio dos dados são necessários cinco blocos: Manchester Encoder, SBCD Mod, Automatic Gain Control (AGC), Phase Modulator e IQ Predistorsion.

Figura 4.3: Diagrama de Blocos da Arquitetura Digital

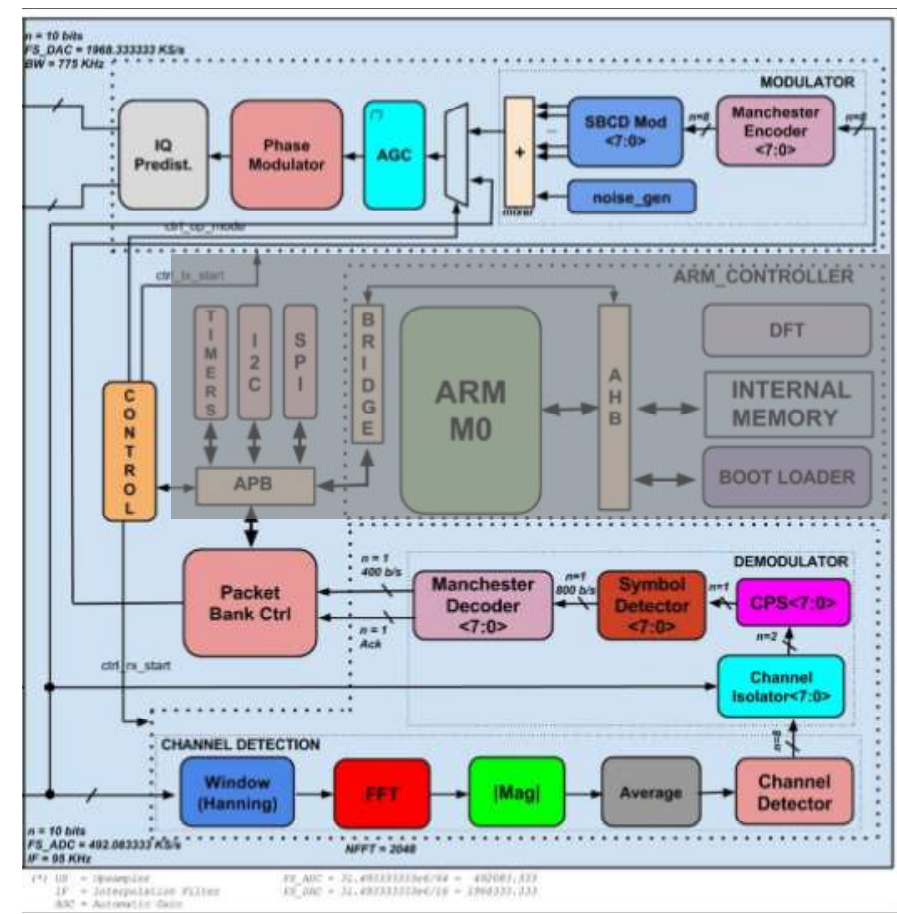

Fonte: (NEGREIROS et al., 2015)

O processador digital de sinais foi projetado para ter a capacidade de processar até oito canais ao mesmo tempo devido à largura de banda de frequências reservado para o SBCD, que é de $120 \mathrm{kHz}$ (RAE, 2005). Após o recebimento das informações das PCDs, pode-se estabelecer uma separação mínima entre as frequências dos 
canais utilizados para reenviar a informação para a terra, facilitando o processo de demodulação nas estações de tratamento de dados.

\subsubsection{Fluxo do Sinal Digital}

Após o sinal ser recebido e convertido para banda base pelos blocos analógicos, deixando-o mais adequado para tratamento digital (descrição na seção 4.1.3), o sinal é enviado para os blocos digitais. O macrobloco Channel Detection é responsável por detectar picos de potência no intervalo do espectro de $35 \mathrm{KHz}$ a $155 \mathrm{KHz}$ e informar ao Demodulator a presença de uma portadora de sinal em uma determinada frequência. O tempo detecção de picos de potência não pode ser superior a 160 ms, tempo pelo qual a portadora não está carregando nenhuma informação codificada de acordo com a estrutura do pacote mostrado na Tabela 4.1, explicada com mais detalhes na Seção 4.1.2.2.

O macrobloco Demodulator, capaz de tratar até oito canais simultaneamente, após conhecer a frequência na qual está localizada a portadora de informação, inicia o processo de isolação do canal, realizando uma série de multiplicações e utilizando uma série filtros digitais. Uma vez isolado o canal, o sinal passa pelo bloco CPS (Carrier Phase Synchronizer) que é responsável por realizar a correção de fase, devido aos erros provocados por efeitos naturais de deslocamento de fase. A correção de fase feita pelo CPS se faz necessária, uma vez que a PCD envia a informação codificada em Manchester modulada em fase, sendo que um deslocamento de fase de $+60^{\circ}$ representa o "1" e que um deslocamento de fase de $-60^{\circ}$ representa o “0”(RAE, 2005). Após a correção de fase, é necessário identificar qual é o símbolo (0 ou 1) está sendo recebido, atividade realizada pelo o Symbol Detector. Em seguida, o símbolo identificado é enviado ao Manchester Decoder para que se possa realizar a decodificação, a qual pode ser feita no padrão IEEE ou Thomas, variando-se o padrão de acordo com um registro definido pelo bloco Control. Após a decodificação, o dado recebido é enviado para o Packet Bank CtrI(NEGREIROS et al., 2015). Neste ponto, os dados recebidos são os mesmos dados coletados pelos sensores das PCD's.

O Packet Bank Ctrl recebe bit a bit até formar a estrutura do pacote com todos os campos, como definido na Tabela 4.1. Após completar a recepção de todos os bits, o Packet Bank Ctrl baseado nos campos de controle irá validar o pacote. Depois da 
validação do pacote, caso o modo de operação do transponder estiver definido como modo direto, a transmissão é iniciada. Se o modo de operação do transponder estiver definido como modo indireto, o bloco irá sinalizar através de interrupção para o core do processador ARM que existe um pacote e este deve ser verificado utilizando-se o campo CRC do pacote recebido antes de ser iniciado o processo de transmissão. Desta forma, o bloco fica aguardando que o core ARM acesse o pacote via barramento o APB, verifique a estrutura do o pacote e autorize o Packet Bank Ctrl para enviar os dados caso o pacote esteja correto ou descartar o pacote caso tenha recebido um pacote com dado incorreto.

Uma vez validado todo o pacote, o Packet Bank Ctrl aciona o macrobloco Modulator para iniciar o processo de reconstrução do sinal que será enviado para a estação de tratamento de dados. O pacote enviado deve obedecer a mesma estrutura que foi recebida da PCD. O processo de envio é iniciado pelo Manchester Encoder que irá codificar o dado de acordo com os padrões IEEE ou Thomas. O sinal codificado é enviado para $S B C D \_$Modulator que irá modular cada canal em fase, conforme descrito em (RAE, 2005; NEGREIROS et al., 2015).

O sinal modulado de cada canal é somado e normalizado para produzir um único sinal com excursão máxima que vai de -1 até +1 e será entregue ao bloco AGC, que é composto por três sub-blocos: o Upsampling, o Interpolation Filter e o AG. O Upsampling tem a função de aumentar em quatro vezes a quantidade de amostras recebidas, ou seja, o bloco insere a cada amostra, outras três com valor zero. Em seguida, o Interpolation Filter define o novo valor de cada uma das amostras inseridas e o sub-bloco AG irá amplificar o sinal baseado nas amostras recebidas anteriormente. Finalizado as tarefas do AGC, o sinal produzido é enviado para o Phase Modulator que é responsável por iniciar o processo de modulação em fase do sinal, produzindo um sinal complexo em sua saída.

Finalizado o processamento digital, o último bloco digital é o IQ Pre-distortion que tem a função de atenuar a amplitude do sinal produzido pelo processamento digital, realizando a multiplicação do sinal recebido por uma constante recebida do bloco Control e tem um valor default igual a 1 , ou seja, com as constantes recebidas no valor default, o sinal de entrada não sofre nenhuma alteração, sendo replicado para a saída do bloco. A atenuação somente será aplicada no IQ Pre-distortion caso seja 
necessário fazer algum ajuste no sinal que será enviado aos blocos analógicos após a fabricação do SoC. A aplicação do ajuste realizado pelo $I Q$ Pre-Distortion somente ocorrerá se o modulador estiver saturando os blocos analógicos, ou seja, o sinal a ser enviado para o transmissor analógico será atenuado.

Paralelamente ao fluxo de sinal digital, o bloco Control, que é acessado através do barramento APB, tem a função de:

- Produzir sinais de habilitação e desabilitação para determinados blocos;

- Definir o modo de operação do IP Transponder;

- Definir o valor das variáveis de entrada de alguns blocos.

\subsubsection{Estrutura da Informação Enviada pela PCD}

O formato da mensagem enviada pela PCD é mostrado na Tabela 4.1. A primeira parte do sinal enviado corresponde a 160 milissegundos de portadora não modulada, ou seja, durante este período a frequência utilizada pela PCD não está sofrendo nenhum tipo de modulação. Para o IP Transponder, o tempo de 160 milissegundos é utilizado pelo macrobloco Channel Detection (Figura 4.2) para identificar a frequência que a PCD está enviando o sinal. A transmissão da portadora não modulada pela PCD corresponde ao tempo de 64 bits com a possibilidade de variação para mais ou para menos de um bit. Em seguida, a PCD inicia o processo de modulação da mensagem a ser transmitida baseado nos campos de $A$ até $G$.

Tabela 4.1: Formato da Mensagem

\begin{tabular}{|c|c|c|c|c|c|c|c|}
\hline Portadora Pura & \multicolumn{6}{|c|}{ Portadora Modulada } \\
\hline $160[\mathrm{~ms}]$ & A & B & C & D & E & F & G \\
\hline
\end{tabular}

Fonte: (RAE, 2005)

De acordo com a estrutura dos campos da portadora modulada apresentada na Tabela 4.2, o número máximo de bits transmitidos será de 312 bits que é obtido quando o pacote possuir o número máximo de blocos de dados de 32 bits, ou seja, oito blocos, somados ao campo $\mathrm{CRC}$, que deve estar presente. O número mínimo será de 80 bits que é obtido quando o número de blocos de dados de 32 bits a ser transmitido for igual a um e não possuir o campo CRC que é opcional. 
Tabela 4.2: Conteúdo dos Campos da Mensagem Transmitida

\begin{tabular}{|l|c|c|}
\hline Campo & Número de bits & Informação Transmitida \\
\hline A - Sincronização de Bit & 15 & 111111111111111 \\
\hline B - Sincronização de Palavra & 8 & 00010111 \\
\hline C - Inicialização da mensagem & 1 & 1 \\
\hline D - Número de Blocos de 32 bits (Nb) & 4 & $1 \sim 8$ \\
\hline E - Identificação da PCD & 20 & - \\
\hline F - Dados dos Sensores & $32^{\star} \mathrm{Nb}$ & - \\
\hline G - CRC (opcional) & 8 & - \\
\hline
\end{tabular}

Fonte: (RAE, 2005)

Os campos definidos com "-" na Tabela 4.2 tem seu conteúdo preenchido de acordo com as informações que serão transmitidas pela plataforma de coleta de dados.

\subsubsection{Arquitetura Analógica}

O receptor analógico foi projetado utilizando-se uma arquitetura super-heteródino capaz de converter o sinal recebido pela antena na faixa de UHF em sinal centrado em $95 \mathrm{kHz}$ para ser tratado pelo IP Transponder.

O diagrama de blocos da arquitetura analógica, que é composta por blocos de radiofrequência e de sinais mistos como pode ser visto na Figura 4.4. O front-End analógico é composto basicamente por três blocos, que são o Receiver, o Frequency Synthesizer e o Transmitter que utilizam a modulação em fase.

O Receiver, como o próprio nome diz, é responsável pela recepção, amplificação e conversão do sinal do domínio analógico para o domínio digital. O Synthesizer é o bloco responsável por entregar aos outros blocos sinais de frequência de referência, utilizando um cristal externo com um baixo nível de ruído, conectado a um - PhaseLocked-Loop (PLL) e vários divisores de frequência. Por fim, o Transmitter, como o próprio nome diz, é responsável pela transmissão, conversão do sinal do domínio digital para o domínio analógico, modulação e amplificação. 
Figura 4.4: Diagrama de Blocos da Arquitetura Analógica

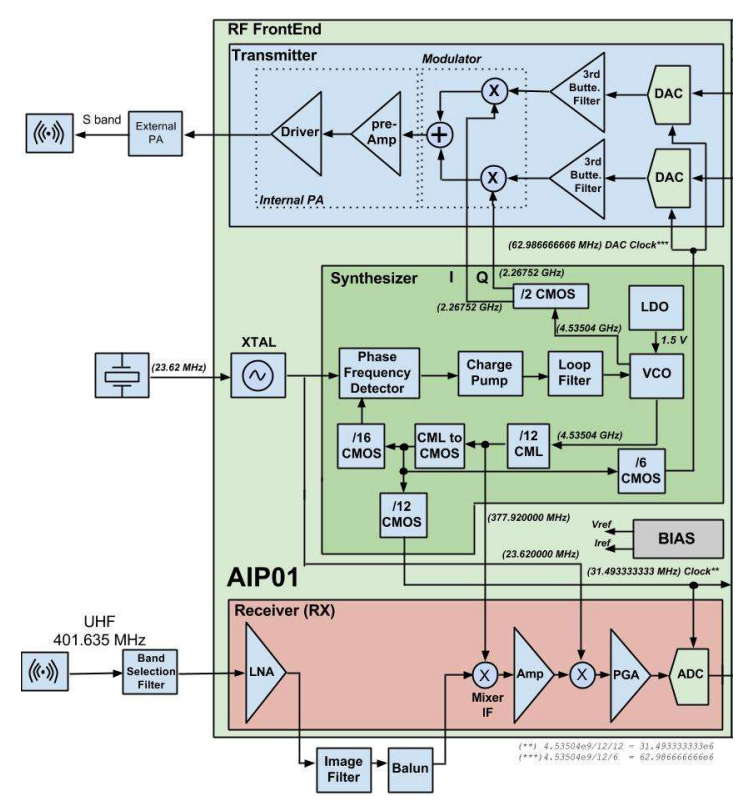

Fonte: (NEGREIROS et al., 2015)

\subsubsection{Fluxo de Sinal Analógico}

O sinal recebido pela antena irá passar por um seletor de banda externo ao SoC que atuará como um filtro, deixando passar somente a faixa de interesse. O sinal resultante será enviado ao estágio de recepção do IP Transponder, o Receiver.

No Receiver, o sinal irá passar por um amplificador de baixo ruído (LNA) que é responsável por uma amplificação inicial com uma baixa inserção de ruído. Para que o LNA tenha esta característica é preciso que seu circuito esteja bem casado com o circuito do filtro externo, que é responsável por rejeitar a frequência imagem do sinal. Em seguida, o sinal de saída do filtro externo irá passar por uma cascata de dois misturadores (mixers), onde o primeiro apresenta uma frequência de saída centrada em $23 \mathrm{MHz}$ e o segundo possui uma frequência de saída centrada em $95 \mathrm{kHz}$.

O sinal modulado será filtrado e em seguida amplificado pelo Calibrated Gain Amplifier (CGA) com finalidade de atingir a excursão máxima do sinal, garantido assim uma alta performance no estágio do Analog to Digital Converter (ADC).

O bloco ADC é responsável pela interface entre o ambiente de sinais contínuos e o de sinais discretos, gerando palavras de 10 bits que serão interpretadas pelo sistema digital. O ganho do receptor está projetado para que o ADC alcance o intervalo máximo quando o sinal recebido pela antena apresentar a potência máxima especificada. 
Para a transmissão, o sistema digital após processamento, entrega para os Digital to Analog Converters (DAC) um sinal complexo que será convertido do domínio de sinais discretos para o domínio de sinais contínuos. Em seguida, o sinal será amplificado e modulado gerando um sinal diferencial que irá conter a informação a ser transmitida. Posteriormente o sinal passa através de um amplificador de potência integrado antes de ser enviado para um estágio de amplificação de potência externo. Após ser amplificado, o sinal é encaminhado para a antena para ser transmitido para uma estação de tratamento de dados.

\subsubsection{Operação do IP Transponder}

Após detectar e receber um sinal de uma PCD, em uma determinada frequência delimitada entre $35 \mathrm{kHz}$ e $155 \mathrm{kHz}$, um canal do demodulador e um canal do modulador serão reservados para realizar o processamento do sinal recebido. $O$ demodulador irá decodificar o sinal em forma de bits e entregar a mensagem a uma FIFO (First In, First Out) intermediária (Packet Bank). Após receber o pacote com a mensagem, o Packet Bank valida a mensagem baseado nos campos de controle e inicia o processo de retransmissão(NEGREIROS et al., 2015).

O funcionamento do IP Transponder varia de acordo com o modo de operação selecionado, ativando ou desativando partes do SoC. Para definir o modo de operação deve-se inserir um valor no registro apropriado disponível no bloco Control do IP Transponder (ver Figura 4.2), configuração que é realizada através do barramento APB. O registro do Control pode estar definido com o valor binário b'001, b'010 ou b'100, significando que o IP Transponder irá operar no modo fast, direto ou indireto, respectivamente.

Independentemente do modo de operação, o bloco Control irá enviar dados com informações de constantes e parâmetros para todos os blocos, definindo características de operação de cada bloco. Todos os registros do bloco Control podem ser acessados para leitura e escrita através do barramento APB.

\subsubsection{Modo Fast}

Uma vez definido o modo de operação como fast, atribuindo b'001 ao registro ctrl_config_mode_reg presente no bloco Control, o IP Transponder começa a funcionar como um espelho, e toda informação recebida será novamente enviada sem nenhum 
tratamento do sinal, incluindo o ruído recebido junto com a informação. Neste modo de operação, estarão habilitados a recepção analógica, os blocos digitais AGC, Upsampling, Interpolation Filter, Phase Modulator e IQ Predistorsion e o transmissor analógico.

No modo fast, além de desabilitar grande parte do processamento digital, o IP Transponder possui um multiplexador no transmissor digital que irá selecionar entre o sinal que será espelhado e o sinal que foi "processado" pelo PDS, sendo que neste caso o seletor irá deixar passar o sinal a ser espelhado. A delimitação por linha tracejada da Figura 4.5 ilustra o fluxo de sinal no modo de operação fast e os blocos que serão utilizados do IP Transponder neste modo de operação.

Figura 4.5: Diagrama de Blocos da Arquitetura do Potiguara SoC - Modo Fast

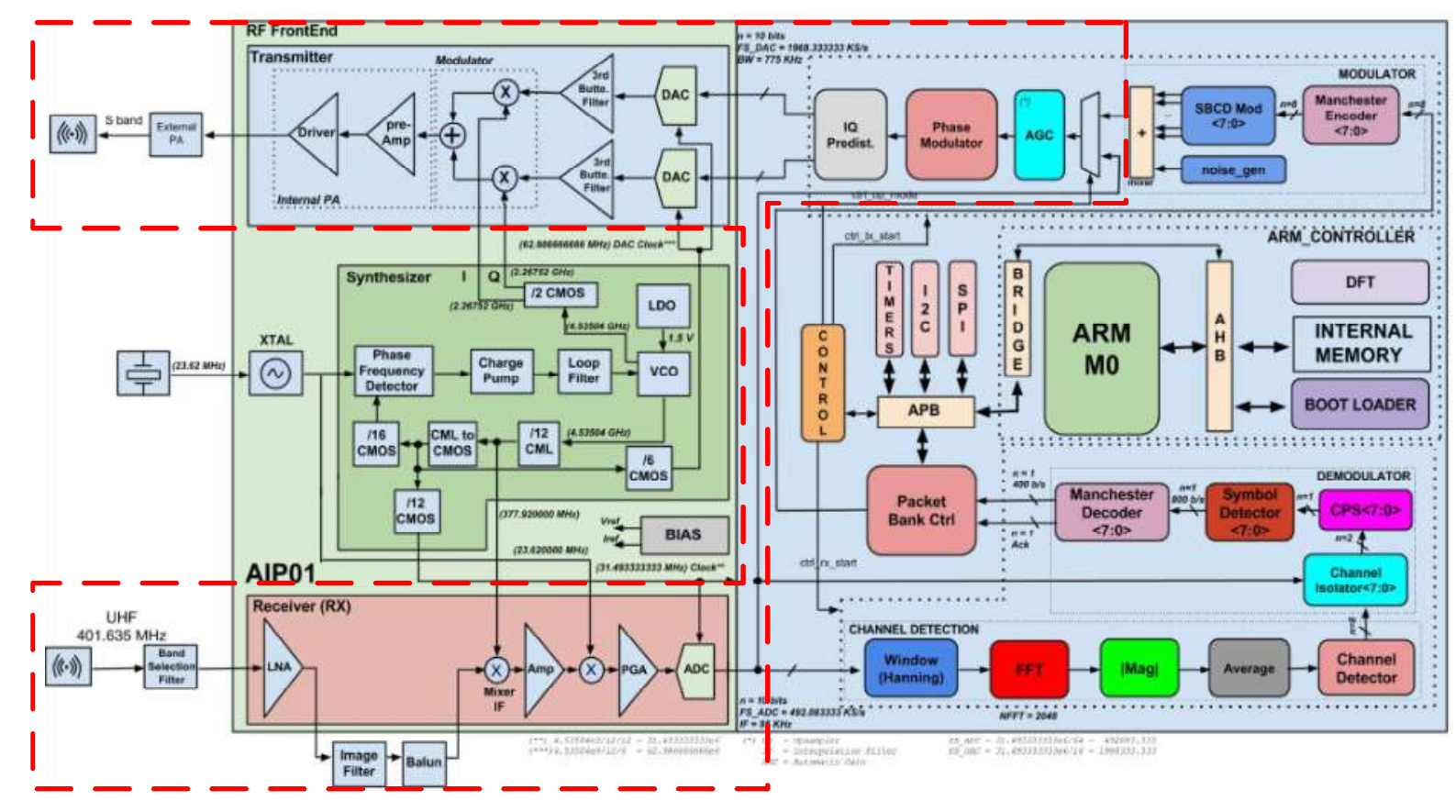

Fonte: (NEGREIROS et al., 2015)

\subsubsection{Modo Direto}

Uma vez definido o modo de operação como direto, atribuindo b'010 ao registro ctrl_config_mode_reg presente no bloco Control, o IP Transponder começa a funcionar como um PDS, recebendo todos os dados, processando e reenviado para a estação de tratamento de dados. Neste modo de operação estão habilitados toda recepção analógica, toda recepção digital, o Packet Bank, toda transmissão digital e toda transmissão analógica, como pode ser observado pela delimitação por linha tracejada na Figura 4.6. 
Figura 4.6: Diagrama de Blocos da Arquitetura do Potiguara SoC - Modo Direto

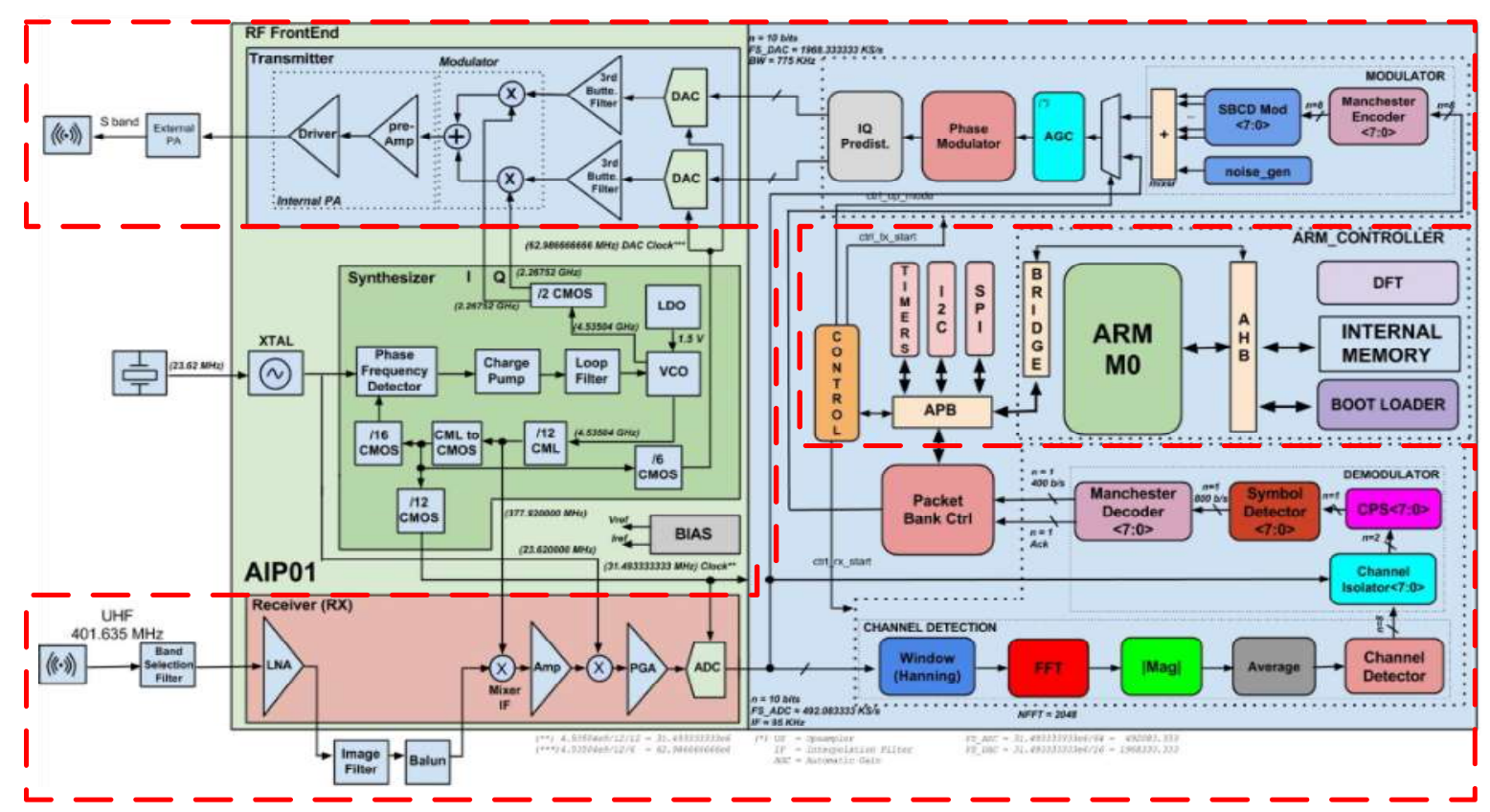

Fonte: (NEGREIROS et al., 2015)

No modo de operação direto, o processamento é focado em receber o sinal, extrair a informação captada pelos sensores das PCD, validar o pacote baseado somente nos campos de controle "A" e "B", conforme Tabela 4.1, e reenviar o sinal para estação de tratamento de dados. A existência do campo "G" neste modo de operação não é utilizada para validar a informação recebida, uma vez que o processador não estará habilitado para validar o pacote recebido (característica essencial do modo de operação direto).

\subsubsection{Modo Indireto}

Uma vez definido o modo de operação como indireto, atribuindo b'100 ao registro ctrl_config_mode_reg presente no bloco Control, o IP Transponder começa a funcionar como um PDS, recebendo todos os dados, processando (validando e corrigindo quando possível) e reenviado para a estação de tratamento de dados. Neste modo de operação estão ativos as estruturas de comunicação entre o IP Transponder e o processador ARM que são os barramentos de transferência de dados APB e AHB, além de todas as estruturas utilizadas no modo direto, como é mostrado pela delimitação por linha tracejada na Figura 4.7. 
Figura 4.7: Diagrama de Blocos da Arquitetura do Potiguara SoC - Modo Indireto

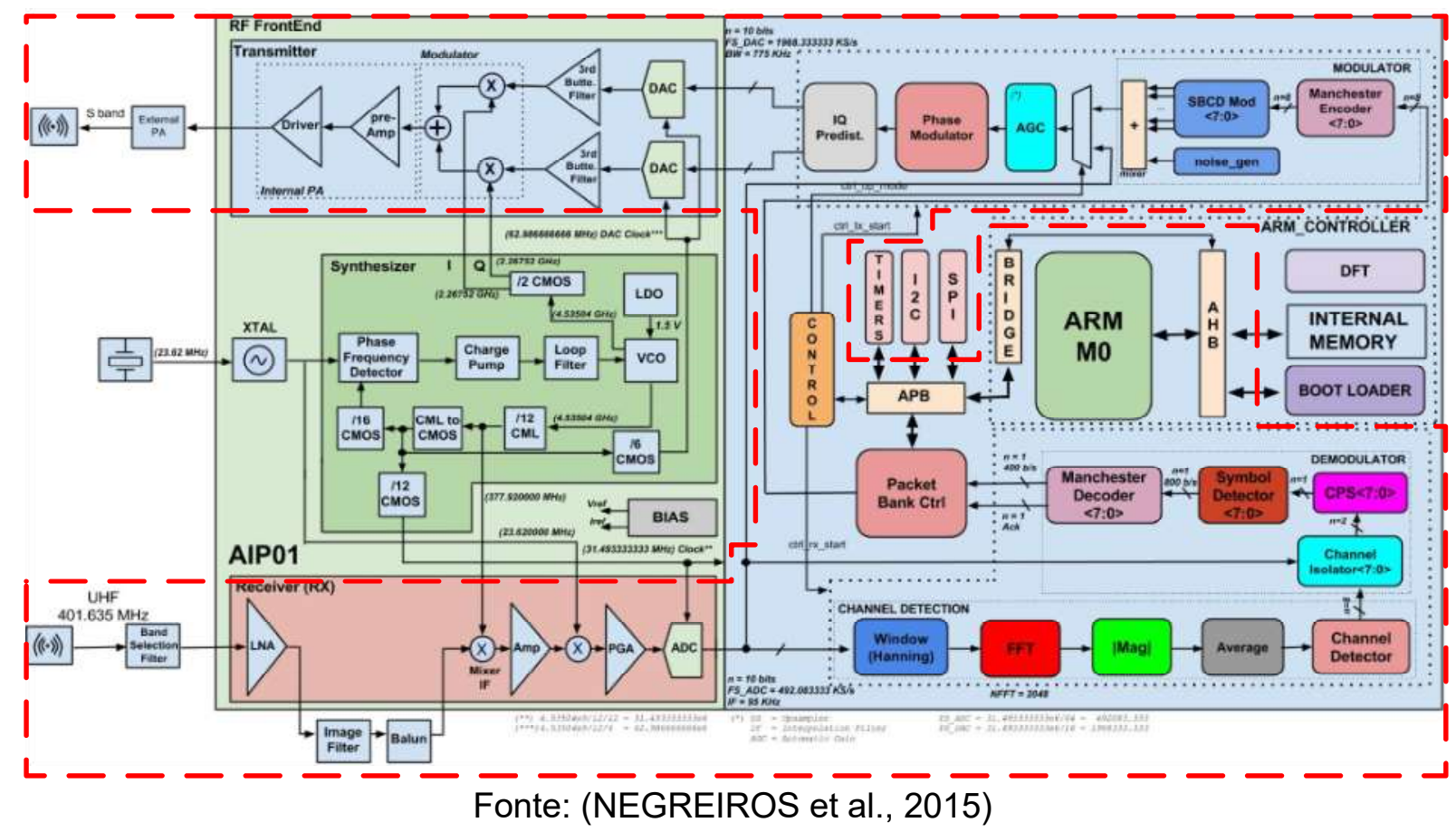

No modo de operação indireto, como no direto, o processamento é focado em receber o sinal, extrair a informação captada pelos sensores das PCD, validar o pacote, e reenviar o sinal para estação de tratamento de dados. Neste modo de operação, o IP Transponder tem a possibilidade de realizar a validação ou a correção do pacote recebido através de um software armazenado na memória interna. O processador ARM é responsável por realizar a correção do pacote baseado no campo "G" (CRC) caso seja necessário (característica única e exclusiva do modo de operação indireto). $O$ acesso ao pacote pelo processador é feito através do barramento AHB e APB que está conectado ao Packet Bank Ctrl.

\subsection{Verificação do IP Transponder - Componentes Digitais}

O IP Transponder foi escolhido para validar a técnica de verificação de circuitos integrados compostos por sinais mistos, descrita na seção 3 , pois possui uma interação analógico-digital e digital-analógico.

Devido a elevada complexidade do IP Transponder, foi necessário definir uma estratégia de verificação que permitisse validar funcionalmente não somente os blocos digitais, mas que também garantisse a funcionalidade dos blocos analógicos e o protocolo de comunicação estabelecido entre eles. 


\subsubsection{Estratégia de verificação}

Para garantir o correto funcionado do Transponder IP adotou-se uma estratégia buttom-up descrita na seção 2.1.2, com abordagem inicial black box, descrita na seção 2.1.3.1, para os blocos digitais. Esta será estendida em abordagem grey box, também descrita na seção 2.1.3.1, na verificação da recepção digital e da transmissão digital, na integração dos componentes digitais e no topo de sinais mistos. Também, será adotada a estratégia de verificação integrada, descrita em 3.2.2, que visa conectar os blocos de TX e RX, consumindo-se menor tempo e recursos e, ainda, atendendo a janela de mercado.

\subsubsection{Verificação dos Blocos Digitais}

Inicialmente, desenvolveram-se testbenches para cada um dos blocos digitais (DUV), com a finalidade de garantir que a descrição de hardware criada pelo projetista atenda as funcionalidades descritas em cada uma das especificações funcionais específicas.

Os testbenches desenvolvidos devem seguir a estrutura descrita na seção 2.1.3. Cada testbench desenvolvido deve ser preparado para operar nos modos passivo e ativo. Os ambientes desenvolvidos são compostos por monitores, cobertura, BFMs, drivers, agentes, checador, gerador de sequências, testbench, sincronizador e mapas de sinais.

\subsubsection{Verificação do Receptor e Transmissor Digital}

Depois de todos os blocos digitais serem cuidadosamente testados e apresentarem funcionalidade garantida, a fase de verificação da integração do receptor e do transmissor é iniciada com objetivo de garantir que todos os blocos estejam respeitando o protocolo de comunicação previamente estabelecido entre eles. Neste momento, todos os testbenches estão operando no modo passivo, exceto os ambientes que estão localizados nas extremidades, pois estes têm a função de gerar estímulos para o circuito global. Ao estimular o primeiro bloco, este produzirá em sua saída sinais que irão estimular o próximo bloco, gerando uma reação em cadeia.

Com esta arquitetura do testbench, pode-se validar os blocos individualmente quanto ao protocolo de comunicação e também com relação à sua funcionalidade; os ambientes, configurados para operar no modo passivo, realizam a captura dos dados 
nos barramentos de comunicação entre os blocos, através dos monitores e enviam as informações para os checadores.

A arquitetura dos testbenches propostos para garantir o correto funcionamento do receptor e do transmissor são mostrados na Figura 4.8 e Figura 4.9 respectivamente. No receptor da Figura 4.8, todos testbenches devem ser instanciados no modo passivo, conforme descrito na seção 3.1.4, exceto pelo ambiente do bloco Window, que nesta fase da verificação deve ser configurado para operar no modo ativo. Analogamente, no transmissor da Figura 4.9 todos os testbenches estão configurados para operar em modo passivo, exceto pelo ambiente do Manchester Encoder, que nesta fase da verificação está configurado para operar no modo ativo.

Figura 4.8: Arquitetura do Testbench para o Receptor

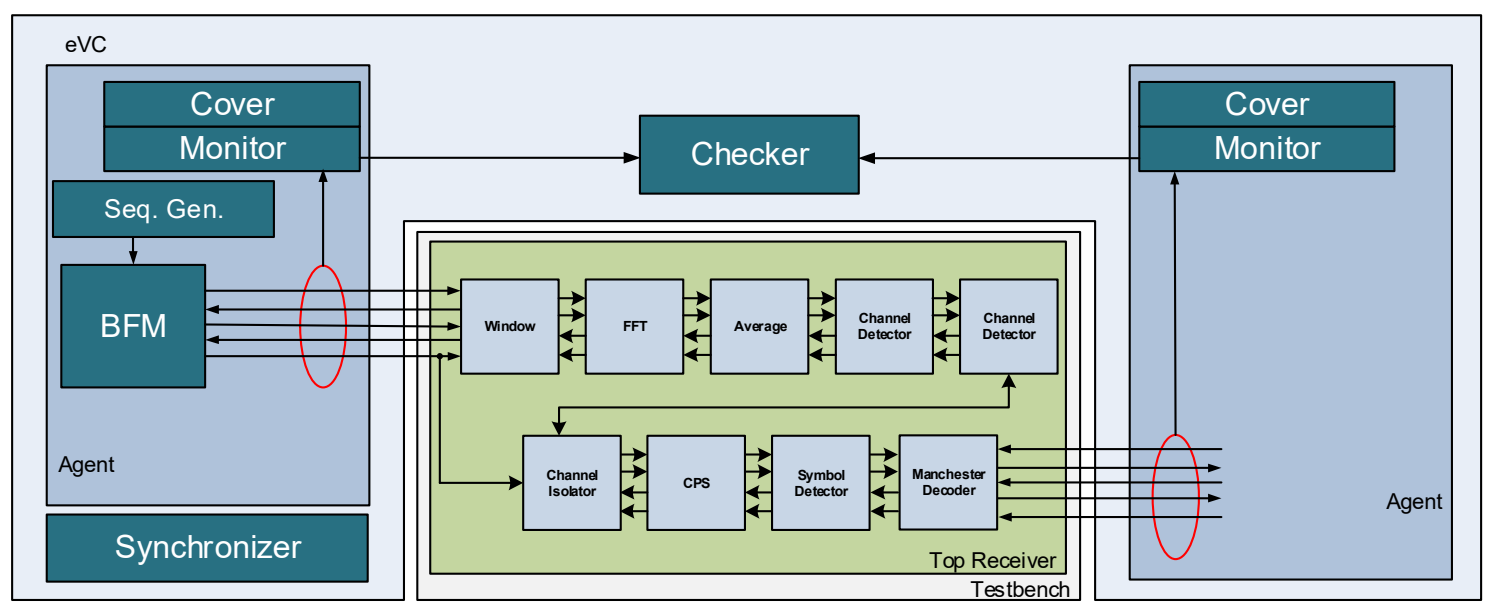

Fonte: Desenvolvido pelo autor

Figura 4.9: Arquitetura do Testbench para o Transmissor

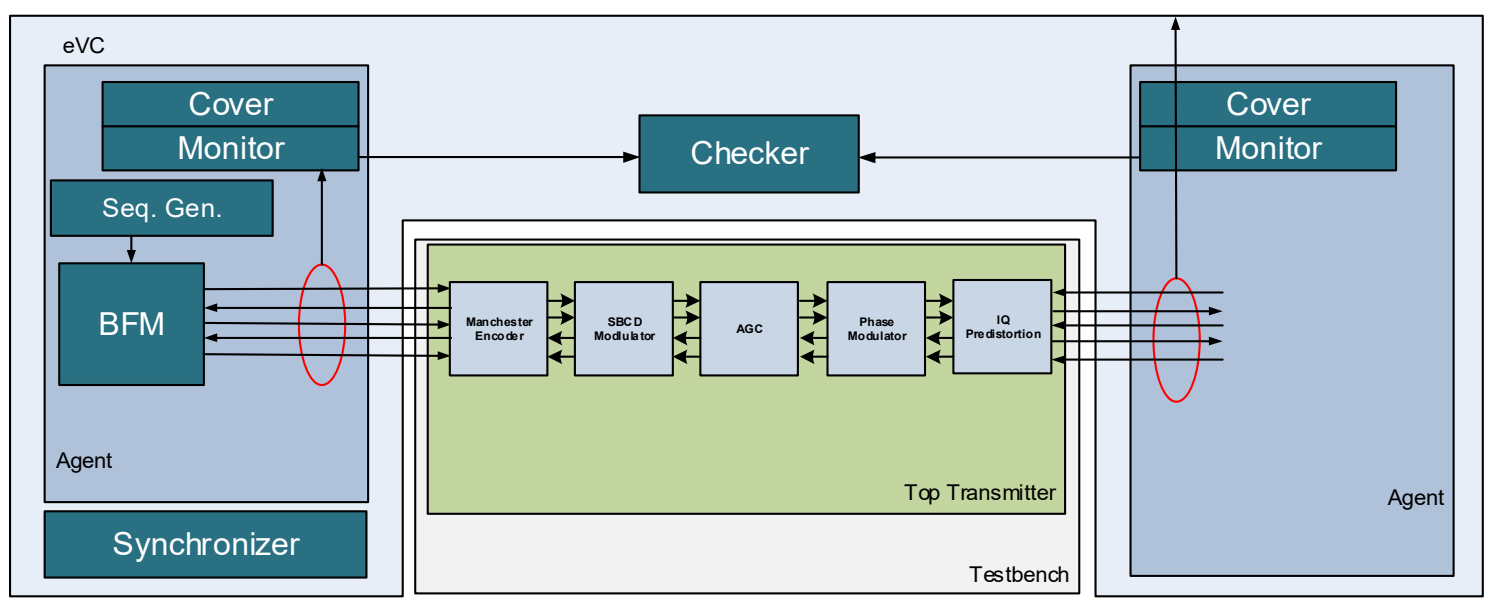

Fonte: Desenvolvido pelo autor 


\subsection{Verificação da Integração dos Componentes Digitais do IP Transponder}

A verificação da integração dos componentes digitais do IP Transponder prossegue com o receptor e o transmissor então operando de acordo com as especificações e com blocos que compõem a arquitetura do topo de digital do IP Transponder, previamente verificados seguindo a metodologia descrita em 2.1.3. Assim, nesta abordagem, pode-se avaliar a comunicação do receptor com o Packet Bank Ctrl, assim com a comunicação do Packet Bank Ctrl com o transmissor digital.

A Figura 4.10 ilustra a arquitetura proposta para verificação dos componentes digitais do IP Transponder, tendo sido configurada para operar no modo direto, onde não existe nenhuma interferência do processador sobre o pacote a ser recebido pelo Packet Bank Ctrl.

Figura 4.10: Arquitetura do Testbench para a Validação da Integração dos Componentes Digitais

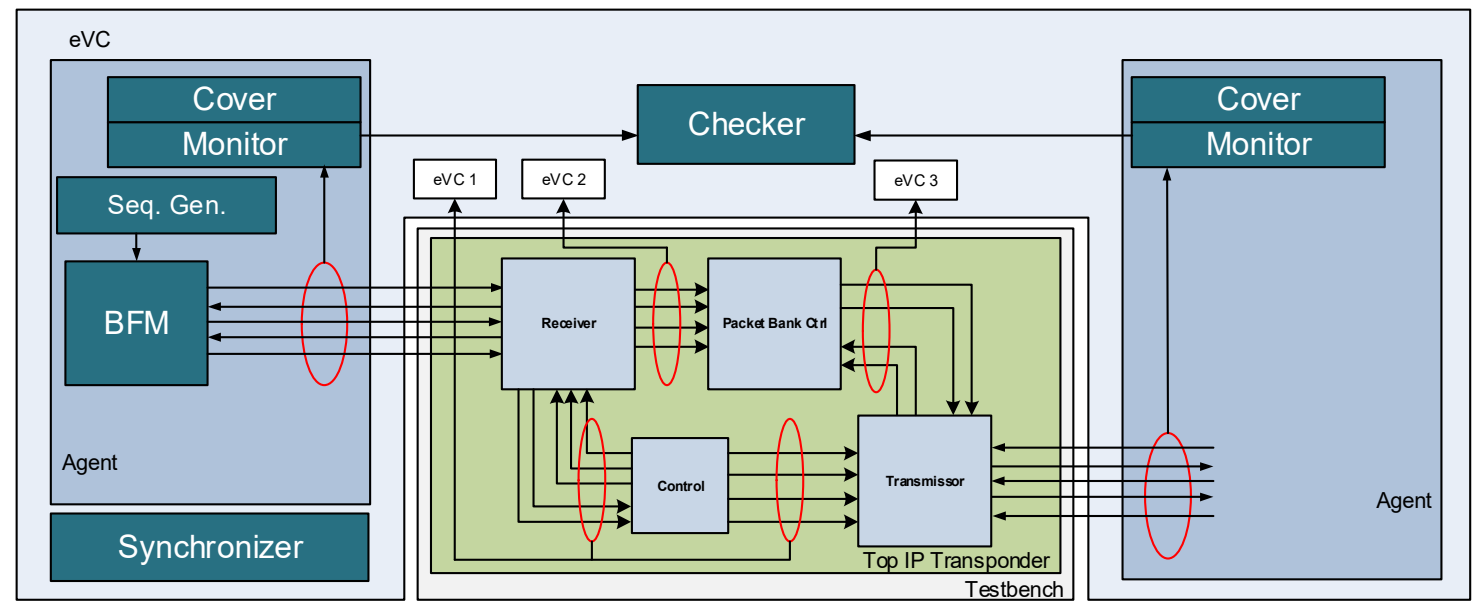

Fonte: Desenvolvido pelo autor

Os estímulos gerados para verificar o topo digital do IP Transponder podem ser reaproveitados da mesma estrutura de geração de dados aplicado ao receptor descrito na seção 4.2.3.

\subsection{Verificação do IP Transponder - Componentes Analógicos e Interface Analógico-Digital}

Conforme citado na seção 2.1.4, a verificação de circuitos analógicos e de interfaces analógicos-digitais é delicada devido aos vários modos de operação que um circuito 
analógico pode assumir, tendo relação direta com a funcionalidade a ser checada. Assim, uma metodologia de verificação digital não pode ser aplicada na verificação daqueles tipos de blocos.

A fim de se garantir o correto funcionamento de cada um dos componentes do transmissor e do receptor do IP transponder, deve-se criar um testbench simples para geração e aplicação de estímulos. Realiza-se a verificação de cada um dos blocos através de formas de onda, ou seja, o projetista cria uma estrutura de teste que pode ser composta por fontes de sinais, resistores, capacitores para estimular o bloco analógico ou de interface, e coleta em suas saídas as formas de onda. Baseando-se nos níveis de tensão e no formato em que as formas de ondas são obtidas nas saídas dos blocos, o projetista analógico atesta-os como verificado ou não.

A Figura 4.11 ilustra um testbench para validar o receptor analógico, sendo que parte da estrutura foi reutilizada dos testes básicos realizados por projetistas analógicos, como por exemplo tensões de alimentação; o testbench executa tarefas como: conectar blocos, gerar estímulos para o receptor com a frequência e amplitude obtidas na especificação do IP Transponder e gerar o sinal de relógio (clock). A linha tracejada na Figura 4.11 destaca alguns componentes utilizados para gerar sinais capazes de estimular os circuitos analógicos e interfaces Analógico-Digital.

Figura 4.11: Estrutura para Verificação de Blocos Analógicos

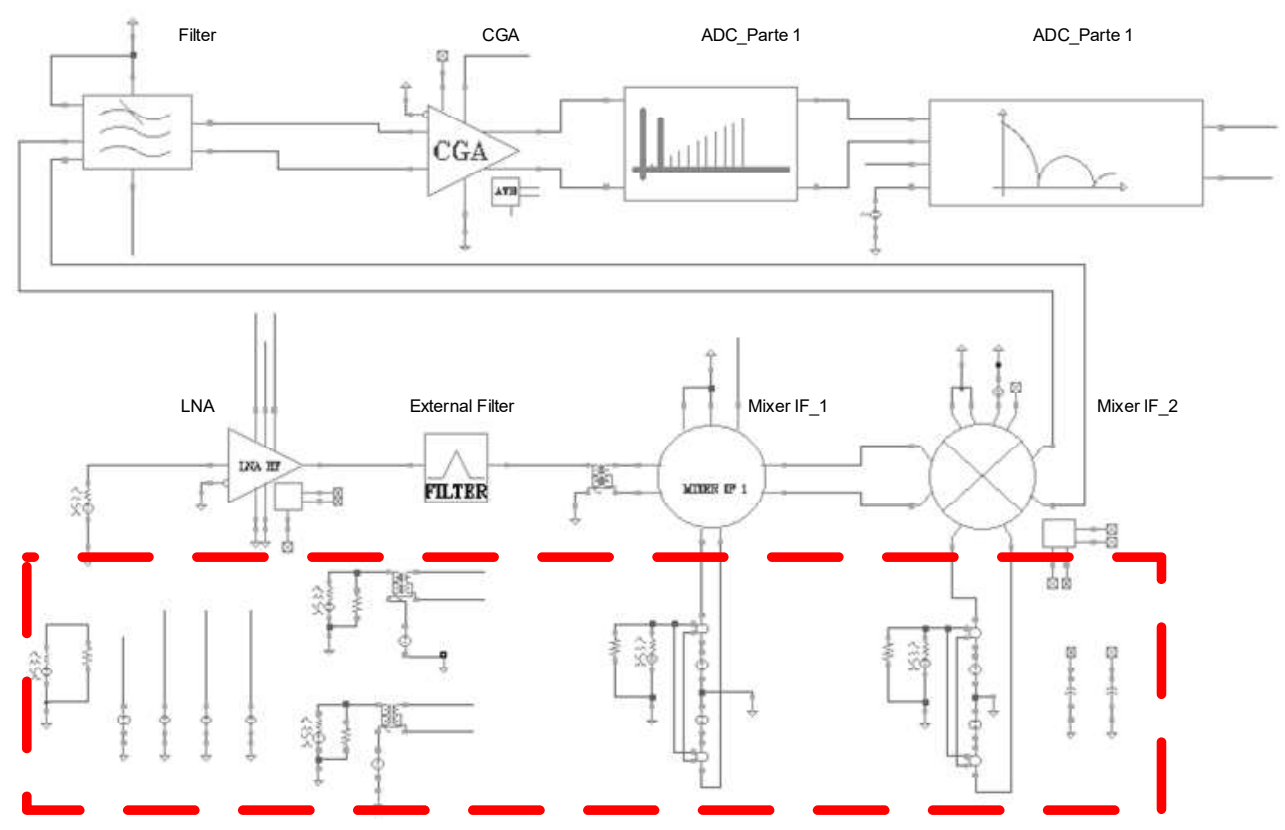

Fonte: Desenvolvido pelo autor 


\subsection{Verificação Integrada do IP Transponder}

Após todas as etapas de verificação digital e verificação analógica concluídas com sucesso, é iniciado o processo de verificação de todo o IP Transponder utilizando a abordagem integrada descrita na seção 3.2.2 (pagina 60).

\subsubsection{Estratégia de Verificação do IP Transponder}

Como estratégia de verificação do IP Transponder, optou-se por dividi-lo entre o Packet Bank Ctrl e o Manchester Decoder. A razão é que, exatamente entre estes dois componentes digitais, as características dos dados enviados e monitorados, respectivamente, em ambas as interfaces são bem conhecidas e são representadas pela estrutura de pacote descrita na seção 4.1.2.2. Os dados usados para estimular o Packet Bank Ctrl devem ser os mesmo dados amostrados na saída do Manchester Decoder.

A verificação integrada do IP Transponder segue o modelo da Figura 3.3 (pagina 61), sendo desenvolvido um modelo do ambiente. Este bloco representa os efeitos ambientais sobre o sinal, além de converter a frequência de saída do IP Transponder para uma outra, de entrada, interconectando os transmissor e receptor analógicos. Desta maneira, possibilita-se criar um fluxo completo para o sinal, dos blocos de TX para os de RX. O diagrama de blocos simplificado para realizar a verificação integrada do IP Transponder passa a ser o descrito conforme Figura 4.12.

Assim, a integração do IP Transponder segundo o fluxo de sinal proposto inicia-se com o Packet Bank Ctrl estimulando o Digital Modulator. Em seguida, o Digital Modulator estimula toda a parte analógica, iniciando pelo Analog Blocks Transmitter, passando pelo Environmental Model e finalizando no Analog Block Receiver. Finalmente, o Analog Block Receiver estimula o Channel Detection e o Digital Demodulator. Ou seja, o mesmo estímulo enviado ao Packet Bank Ctrl deve ser obtido na saída do Digital Demodulator, sem que ocorra nenhuma modificação nas informações enviadas. 
Figura 4.12: Arquitetura do IP Transponder utilizada durante o Processo de Verificação Integrada

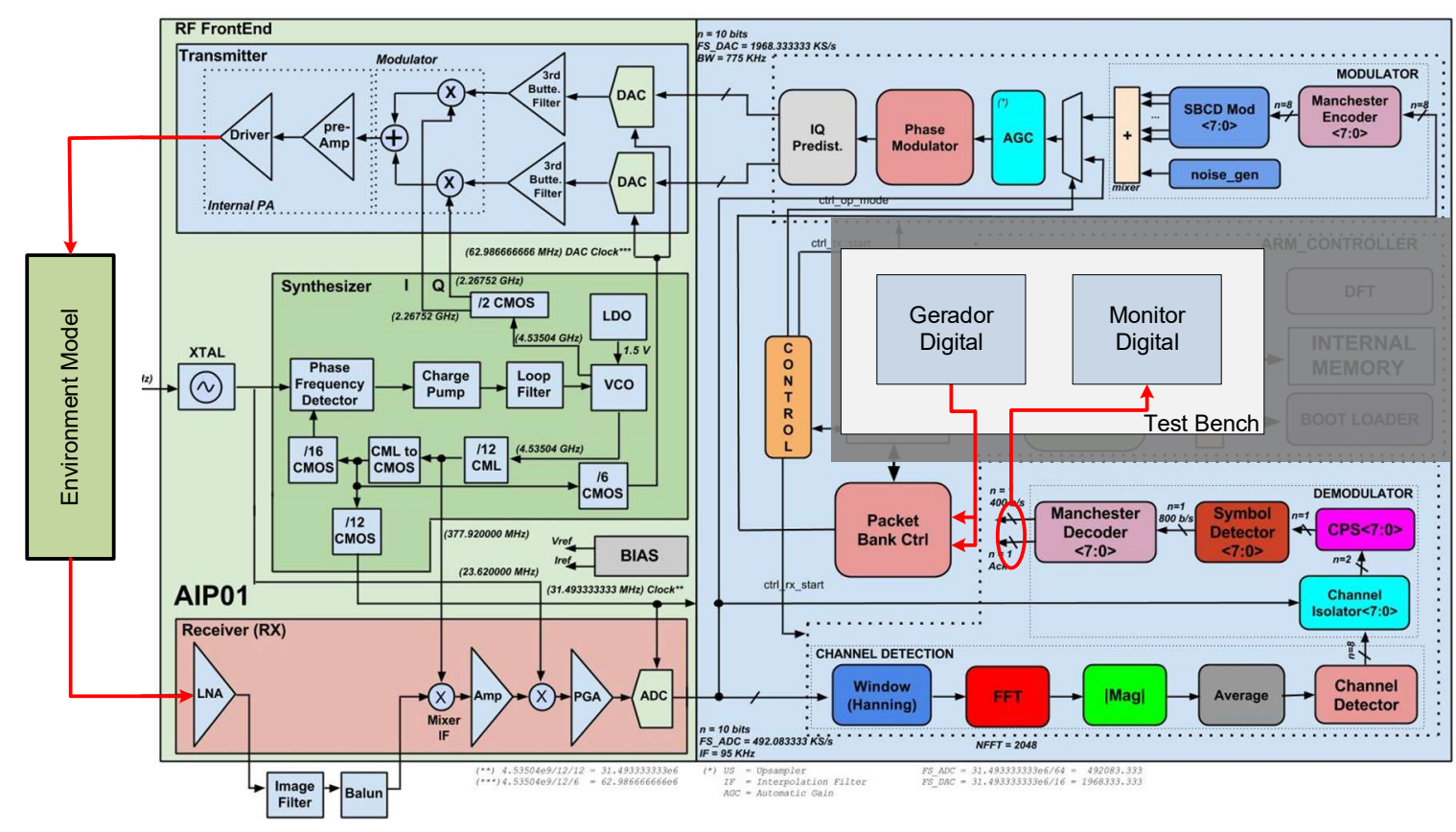

Fonte: Desenvolvido pelo autor

\subsubsection{Modelo do Ambiente}

O modelo do ambiente tem como objetivo conectar o transmissor analógico ao receptor analógico, criando um fluxo completo para os estímulos aplicados, de acordo com o descrito na seção 3.1.5. O modelo, pode ser desenvolvido utilizando-se uma linguagem de modelagem comportamental analógico como a Verilog-AMS, com a função de manipular as características dos sinais da saída do transmissor e adequando-o para a entrada do receptor.

O modelo deve apresentar algumas características como:

- Realizar a conversão da frequência de transmissão na Banda-S $(2,2 \mathrm{GHz})$ em frequência de recepção em UHF (401,635 MHz), utilizada na transmissão de informações pela PCD.

- Filtrar o sinal após ser transladado de frequência para eliminar ou atenuar os componentes de alta frequência gerados durante o processo de conversão de alta frequência para baixa frequência. 
- Atenuar o sinal de forma parametrizada para permitir a modificação durante a simulação; pode-se, assim, monitorar o nível de atenuação limite para a operação do IP Transponder na recepção do sinal enviado por uma PCD.

\subsubsection{Arquitetura do Testbench Integrada}

Para garantir a correta integração dos blocos digitais e analógicos, o protocolo de comunicação estabelecido entre eles e também o correto funcionamento do IP Transponder, uma arquitetura de testbench como a da seção 3.1.4 deve ser utilizada. A Figura 4.13 ilustra o testbench, fundamentado na metodologia $e R M$, composto por seus componentes, com a particularidade de não se ter uma BFM conectada ao bloco de recepção, pois não se faz necessário inserir estímulos na entrada do receptor deixando esta atividade sob responsabilidade do Environmental Model.

Com a arquitetura do testbench proposta acima é possível realizar a verificação funcional do IP Transponder, exercitando a comunicação entre os blocos, exercitando linhas de descrição de hardware e a possibilidade de obter-se cobertura funcional e cobertura de código. Esta arquitetura apresenta como vantagem principal a geração de estímulos digitais baseados na estrutura de pacotes descritos na seção 4.1.2.2, mas com a possibilidade de simular em uma única simulação toda a arquitetura do IP Transponder.

Figura 4.13: Testbench para Validação do IP Transponder

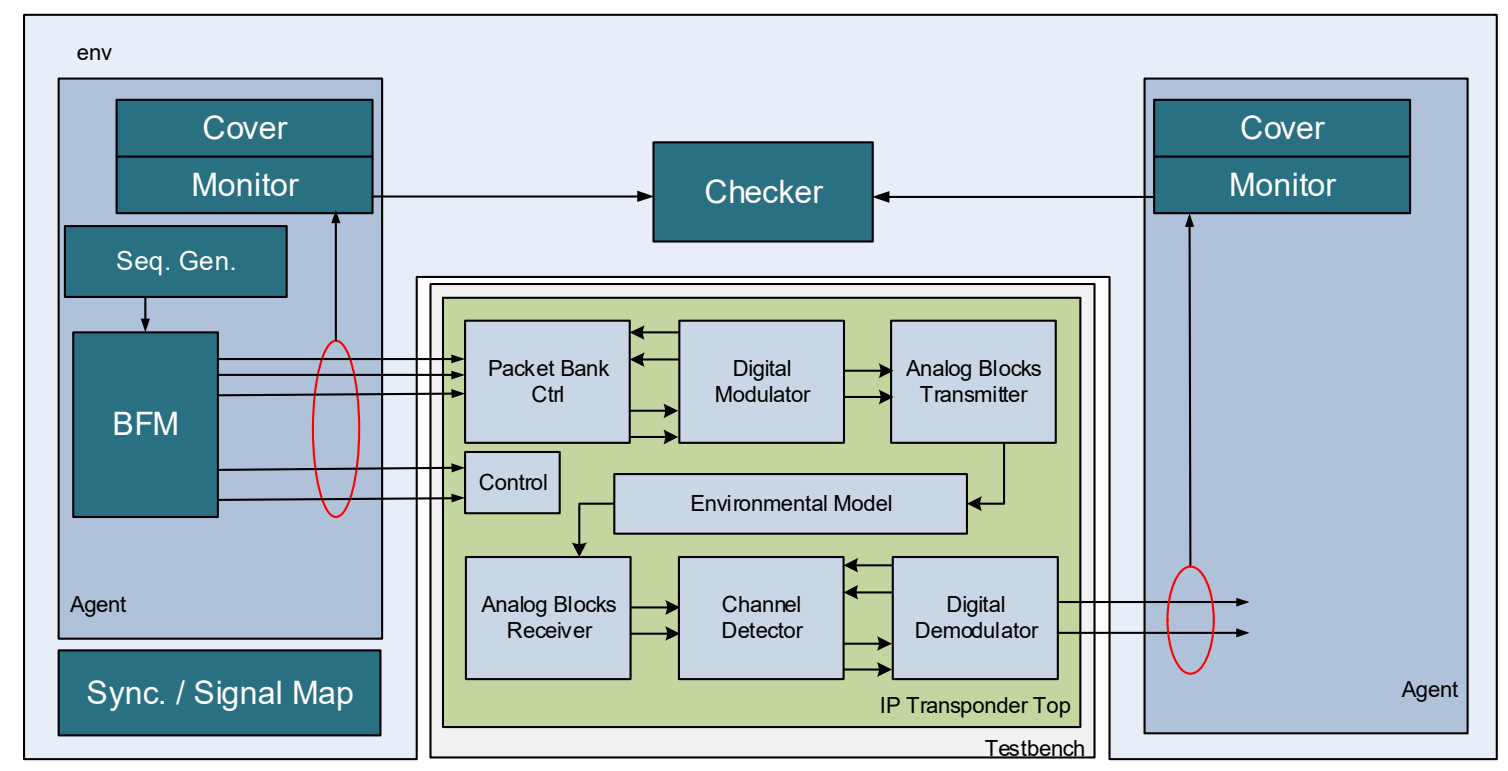

Fonte: Desenvolvido pelo autor 


\section{Resultados}

Neste capitulo serão apresentados alguns resultados obtidos durante a verificação do IP Transponder. Inicialmente a verificação das estruturas digitais (abrangendo a verificação de blocos digitais), a verificação do transmissor e receptor integrados e a verificação de todas as estruturas digitais integradas. Em seguida serão abordados, na seção 5.6, a estrutura do modelo do ambiente e a sua validação.

Ainda neste capítulo serão apresentados os resultados obtidos (extraídos das simulações) durante a verificação da integração do receptor analógico e também de todo o sistema de comunicação para satélite, o IP Transponder.

\subsection{Estratégia de Simulação}

A estratégia de verificação adotada para o IP Transponder foi bottom-up, iniciandose pela verificação de cada um dos blocos no nível de hierarquia mais baixo, seja ele digital ou analógico, de forma individual e, gradativamente, passando para um "nível acima" até verificar todo o IP Transponder integrado. Em seguida, realizou-se a verificação da união dos blocos do transmissor e do receptor, tanto do digital quanto do analógico. Posteriormente, foi realizado a verificação da integração de todos os blocos digitais que compõem o IP Transponder. A próxima etapa consistiu em realizar a validação do modelo do ambiente. E finalmente, realizou-se a verificação da integração de todo o IP Transponder (MARTINS et al., 2017).

Para realizar a verificação, utilizou-se a ferramenta Virtuoso da Cadence $^{\mathrm{TM}}$, onde foi possível criar um ambiente para simulação do IP Transponder que contou com uma instância do bloco digital, o PDS, do transmissor e receptor analógicos, e do modelo do ambiente.

Após a realização de testes nos componentes digitais, o PDS digital foi instanciado dentro do ambiente de simulação, criando-se um fluxo completo para o sinal, conforme ilustrado na Figura 5.1, que representa o diagrama de blocos do IP Transponder extraído da ferramenta Virtuoso da Cadence ${ }^{\mathrm{TM}}$. A partir deste momento o fluxo de simulação passa a ser integrado entre digital e analógico. 
Figura 5.1: Diagrama de Blocos do IP Transponder para Simulação

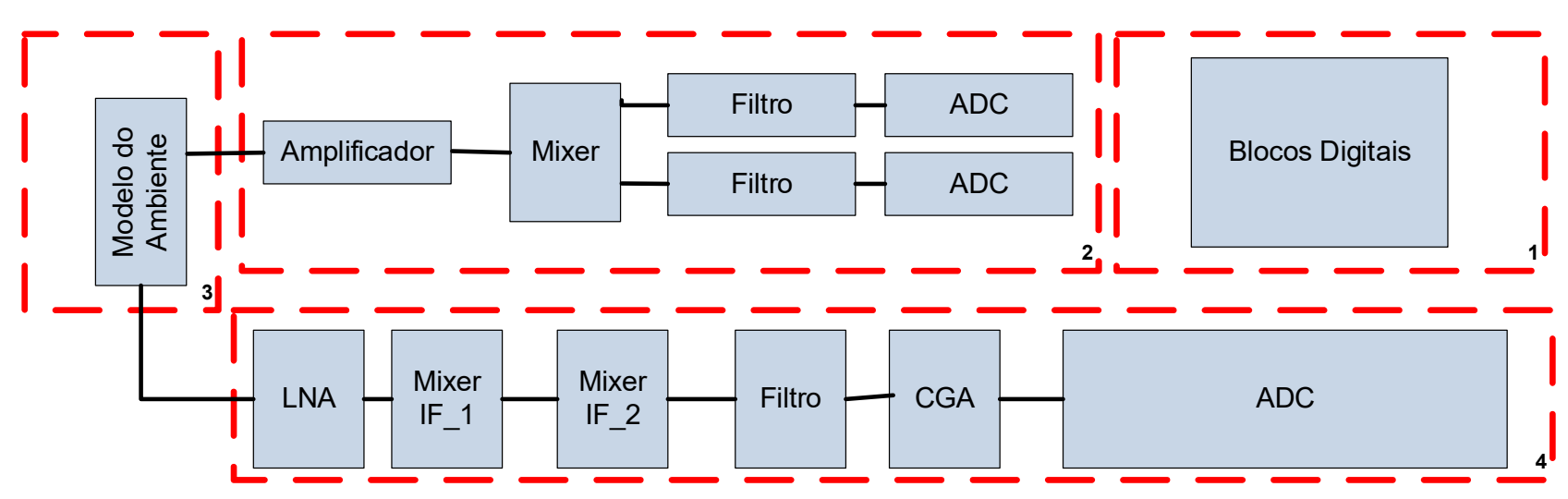

Fonte: Desenvolvido pelo autor

Na Figura 5.1, a linha tracejada de número 1 representa a parte digital do IP Transponder, de número 2 representa o transmissor analógico, de número 3 representa o modelo do ambiente e de número 4 representa o receptor analógico.

\subsection{Verificação Digital}

\subsubsection{Verificação de Blocos Digitais}

Os testbenches desenvolvidos para verificar os blocos digitais seguem a estrutura descrita na seção 4.2.2, podendo sofrer pequenas variações de acordo com a funcionalidade de cada um dos blocos e também da necessidade de comunicação entre as unidades presentes nos testbenches projetados.

Todos os blocos digitais do IP Transponder foram desenvolvidos por terceiros, durante várias etapas de cursos de treinamento do Programa Cl-Brasil. Todos os respectivos testbenches foram desenvolvidos dentro deste presente trabalho, exceto para alguns blocos, já previamente verificados, também no âmbito do Programa $\mathrm{Cl}$ Brasil: o Channel Detector, o Channel Isolator, o AGC, SBCD Modulator e o CPS. Para os testbenches desenvolvidos pelo presente autor, a Tabela 5.1 exibe, a quantidade de cada um dos seus componentes destacando-se que todos os testbenches contêm uma unidade do sequencer generator, signal map, eVC e synchronizer. O nome do bloco é apresentado na coluna 1, enquanto as colunas 2 a 5 são apresentados a quantidade monitores, BFMs, agentes e checkers presentes em cada um dos testbenches. A última coluna indica se o testbench operará no modo passivo ou ativo na verificação do transmissor, do receptor e na verificação integrada. 
Tabela 5.1: Quantidade de Componentes de Cada Testbench

\begin{tabular}{|l|c|c|c|c|c|}
\hline \multicolumn{1}{|c|}{ Bloco } & Mon. & BFM & Agentes & Checker & Modo de Operação \\
\hline Window & 2 & 1 & 2 & 1 & Ativo/Passivo \\
\hline FFT & 3 & 1 & 3 & 1 & Passivo \\
\hline Magnitude & 2 & 1 & 2 & 1 & Passivo \\
\hline Average & 2 & 1 & 2 & 1 & Passivo \\
\hline Manchester Decoder & 8 & 1 & 2 & 1 & Ativo/Passivo \\
\hline Packet Banck CtrI & 8 & 1 & 2 & 1 & Passivo \\
\hline Control & 2 & 1 & 2 & 1 & Passivo \\
\hline Manchester Encoder & 8 & 1 & 2 & 1 & Passivo \\
\hline Phase Modulator & 2 & 1 & 2 & 1 & Passivo \\
\hline IQ Pre-distortion & 2 & 1 & 2 & 1 & Passivo \\
\hline
\end{tabular}

Fonte: Desenvolvido pelo autor

No Apêndice A pode-se encontrar um exemplo de testbench construído seguindo a metodologia eRM, utilizando-se a e Language objetivando garantir o correto funcionamento do bloco Manchester Decoder.

Como resultado do processo de verificação, a Tabela 5.2 apresenta na coluna 1 o nome do componente verificado, na coluna 2 é apresentado a quantidade de vetores de teste utilizados durante o processo de verificação para cada um dos blocos, na coluna 3 e 4 a porcentagem de cobertura funcional e de código respectivamente e na coluna 5 a cobertura total alcançada.

Tabela 5.2: Resultados da Verificação por Bloco Digital

\begin{tabular}{|l|c|c|c|c|}
\hline \multirow{2}{*}{ Bloco } & \multirow{2}{*}{$\begin{array}{c}\text { Vetores } \\
\text { de Teste }\end{array}$} & \multicolumn{2}{c|}{ Cobertura } & \multirow{2}{*}{$\begin{array}{c}\text { Cobertura } \\
\text { Total }\end{array}$} \\
\cline { 3 - 4 } & & Funcional & Código & \\
\hline Window & 3000 & $92,62 \%$ & $91,62 \%$ & $92,12 \%$ \\
\hline FFT & 2000 & $100 \%$ & $86,27 \%$ & $93,14 \%$ \\
\hline Magnitude & 3000 & $100 \%$ & $100 \%$ & $100 \%$ \\
\hline Average & 3000 & $100 \%$ & $100 \%$ & $100 \%$ \\
\hline Manchester Decoder & 1500 & $100 \%$ & $95,8 \%$ & $97,9 \%$ \\
\hline
\end{tabular}




\begin{tabular}{|l|c|c|c|c|}
\hline \multirow{2}{*}{ Bloco } & \multirow{2}{*}{$\begin{array}{c}\text { Vetores } \\
\text { de Teste }\end{array}$} & \multicolumn{2}{|c|}{ Cobertura } & \multirow{2}{*}{$\begin{array}{c}\text { Cobertura } \\
\text { Total }\end{array}$} \\
\cline { 3 - 4 } & & Funcional & Código & \\
\hline Packet Banck Ctrl & 2200 & $100 \%$ & $83,31 \%$ & $91,66 \%$ \\
\hline Control & 1500 & $100 \%$ & - & $100 \%$ \\
\hline Manchester Encoder & 1500 & $100 \%$ & $98,65 \%$ & $99,32 \%$ \\
\hline Phase Modulator & 2500 & $98,61 \%$ & $91,29 \%$ & $94,95 \%$ \\
\hline IQ Pre-distortion & 2500 & $98,44 \%$ & $97,3 \%$ & $97,87 \%$ \\
\hline
\end{tabular}

Fonte: Desenvolvido pelo autor

Na Tabela 5.2, a cobertura código expressa o quão eficiente é o testbench na sua função de exercitar as várias áreas do código; a cobertura apresenta níveis satisfatórios, apesar de não atingir 100\% na maioria dos casos; isto é, devido à forma de criação do código (defensiva), existem partes do código inacessíveis independente do estímulo gerado pelo testbench. Já a cobertura funcional, focada na funcionalidade de cada bloco apresenta uma cobertura mais elevada, garantindo que a especificação de cada um dos blocos está sendo atendida.

Um caso especial é o bloco Control, onde não foi coletado a cobertura de código, focando-se apenas na cobertura funcional. Sabia-se de antemão que este bloco, caso fosse coletado a cobertura de código, iria apresentar uma cobertura baixa, pois todos os casos de testes foram criados focando-se em suas funcionalidades e não para atingir uma cobertura de código elevada.

\subsubsection{Verificação dos Blocos Digitais Transmissor e Receptor}

Os testbenches desenvolvidos para verificar a integração dos blocos digitais de transmissão e recepção seguem a estrutura descrita na seção 4.2.3. O processo de verificação foi realizado com objetivo de garantir a integração de todos os blocos digitais no transmissor e no receptor, bem como a validação do protocolo de comunicação estabelecido entre eles.

Assim como cada um dos blocos do IP Transponder, o transmissor e o receptor foram desenvolvidos e integrados por terceiros, durante várias etapas do curso de treinamento do Programa $\mathrm{Cl}$-Brasil. Já os testbenches para estimular e garantir o correto funcionamento da integração foram desenvolvidos pelo presente autor, 
reutilizando os ambientes criados para verificar cada bloco individualmente em modo passivo. A única exceção ocorre no primeiro ambiente que deve estar operando no modo ativo, ou seja, produzindo estímulos para o transmissor e para o receptor.

Em particular, na produção de dados para o transmissor, deve-se observar as características do Manchester Encoder. Já na produção de dados para o receptor, deve-se observar as características de operação do bloco Window do Demodulator e o número máximo de canais possíveis de serem tratados, sendo oito para este projeto. A Tabela 5.3, mostra os resultados obtidos durante a verificação do bloco digital integrado do transmissor e do receptor, onde a coluna 1 identifica qual bloco individual está sendo avaliado, as colunas 2 e 3 apresentam as coberturas funcional de código obtidas respectivamente e a coluna 4 apresenta a cobertura total atingida.

Tabela 5.3: Verificação Integrada do Transmissor e do Receptor

\begin{tabular}{|l|c|c|c|c|}
\hline \multirow{2}{*}{ Bloco } & \multirow{2}{*}{$\begin{array}{c}\text { Vetores } \\
\text { de Teste }\end{array}$} & \multicolumn{2}{|c|}{ Cobertura } & \multirow{2}{*}{$\begin{array}{c}\text { Cobertura } \\
\text { Total }\end{array}$} \\
\cline { 3 - 4 } & & Funcional & Código & \\
\hline Transmissor Digital & 2800 & $100 \%$ & $88,12 \%$ & $88,93 \%$ \\
\hline Receptor Digital & 3000 & $100 \%$ & $76,23 \%$ & $75,82 \%$ \\
\hline
\end{tabular}

Fonte: Desenvolvido pelo autor

Na Tabela 5.3, a cobertura de código expressa o quão eficiente é o testbench na sua função de exercitar as várias áreas do código, não atingindo 100\% na maioria dos casos devido à forma de criação do código (defensiva), como já explicado para os resultados da Tabela 5.2. Apesar disto, apresenta níveis satisfatórios de cobertura de código. Já a cobertura funcional, focada na funcionalidade de cada bloco apresenta uma cobertura de $100 \%$, de forma a garantir a funcionalidade do transmissor e do receptor.

\subsubsection{Verificação do IP Transponder}

Os testbenches desenvolvidos para verificar a integração do módulo-topo digital em uma única simulação seguem a estrutura descrita na seção 4.3. O módulo-topo inclui os sub-blocos receptor digital, Control, Packet Bank Ctrl e transmissor digital, sendo possível verificar o comportamento do sistema digital completo, assim como validar o protocolo de comunicação definido entre os blocos internos. 
Assim como cada um dos blocos do IP Transponder, a integração de toda a estrutura do IP Transponder foi desenvolvida por terceiros, durante a segunda fase do Programa de Treinamento Cl-Brasil. Já o testbench que foi utilizado para estimular e garantir o correto funcionamento da integração de todos os macroblocos digitais foi desenvolvido pelo presente autor, reutilizando os testbenchs criados para verificar cada bloco individualmente em modo passivo exceto pelo testbench que estimula o bloco Control e o testbench que estimula o bloco Window que estavam operando em modo passivo.

O testbench responsável por estimular o bloco Control possui a função de definir o modo de operação do IP Transponder como modo direto assim como definir e trocar o valor de variáveis de controle essenciais para o correto funcionamento do IP Transponder. Já o testbench responsável por estimular o bloco Window possui a função de gerar estímulos capazes de exercitar toda a estrutura digital.

Os resultados obtidos durante o processo de verificação da integração do IP Transponder atingiram $82,21 \%$ de cobertura de código e 87,19\% de cobertura funcional. Acreditamos que os níveis de cobertura atingidos para a verificação da integração do IP Transponder são suficientes uma vez que os blocos foram previamente verificados. Nesta etapa da verificação, o autor visou garantir a correta interação entre os blocos digitais, validando os protocolos de comunicação existente entre eles.

Durante a etapa de integração, foi possível detectar a presença de um erro no bloco Manchester Decoder, que ao ser integrado ao Packet Bank Ctrl não estava atendendo corretamente os protocolos estabelecidos, fazendo-se necessário realizar correções em sua estrutura funcional. Para atingir as coberturas de código e funcional citadas, foram aplicados cerca de 2400 vetores de teste.

\subsection{Verificação da Comunicação entre Interfaces}

No que tange a verificação de protocolos de comunicação entre blocos digitais e entre blocos digitais e analógicos, as estruturas definidas na linguagem e language foram adotadas devido ao fato de o autor possuir conhecimento prévio delas, adquirido em trabalhos passados de verificação de interfaces. Os expects são estruturas responsáveis por garantir que um DUV esteja respeitando o protocolo de comunicação com outros blocos. Quando uma regra de protocolo é violada, os expects interrompem 
instantaneamente a simulação, informando ao engenheiro de verificação que ocorreu uma violação do protocolo de comunicação em determinada interface. Uma vez interrompida a simulação, o engenheiro de verificação tem a possibilidade de descobrir o que causou a violação do protocolo através da análise de formas de onda.

Para o IP Transponder, a verificação de protocolo está focada no sinal que valida o fluxo de dados entre os blocos digitais e entre blocos digitais e analógicos, e também no chaveamento da informação que não pode ocorrer no momento em que o sinal de válido está informando ao próximo bloco que o dado é valido, mantendo o sinal estável por um tempo. Outro ponto presente na verificação de protocolo é em relação entre dependência do sinal de válido da interface de entrada e o sinal de válido da interface de saída, ou seja, o tempo gasto pelo bloco em ciclos de relógio para processar as informações recebidas e produzir uma saída, garantindo que o bloco está respeitando o tempo, em ciclos de relógio, para produzir uma saída válida.

A Figura 5.2 ilustra parte do código utilizado para garantir o protocolo de comunicação estabelecido entre o ADC e Window e entre o Window e FFT, que são blocos que compõem o IP Transponder. A validação é baseada em eventos, que são disparados quando uma determinada condição é atingida. Nas linhas de 2 a 4 e de 9 a 12 são definidos os eventos que são emitidos quando ocorre a subida de um sinal, a descida de um sinal ou a mudança de valor de um sinal. $E$ nas linhas de 5 a 7 e de 13 a 15 são definidos os expects em função dos eventos para garantir o protocolo de comunicação. Para o expect definido na linha 5 , irá ocorrer violação do protocolo sempre que a duração do sinal de válido for superior a um ciclo de relógio, ou seja, quando for emitido - evento adc_data_vld_rise, um ciclo após deverá ser emitido o evento adc_data_vld_fall, caso contrário a simulação irá ser interrompida indicando um erro de protocolo de comunicação.

Ainda relacionado à Figura 5.2, foi estabelecido pela equipe de projetistas uma relação entre receber uma entrada válida e produzir uma saída válida pelo bloco Window, componente do IP Transponder, condição que deve ser respeitada e é validada através do expect definido na linha 15, ou seja, ao receber um dado válido, o bloco Window deve produzir uma saída válida exatamente no próximo ciclo de relógio, caso contrário o bloco Window estará violando o protocolo de comunicação. Ao mesmo tempo, a linha 7 define a distância em ciclos de relógios que deve existir entre dois sinais de válido 
consecutivos, ou seja, ao receber um sinal de válido, o bloco Window deve esperar por um novo sinal de válido em exatamente 64 ciclos de relógio, caso contrário o bloco ADC estará violando o protocolo de comunicação estabelecido com o bloco Window.

Figura 5.2: Expects Utilizado na Checagem de Protocolo do Bloco Window

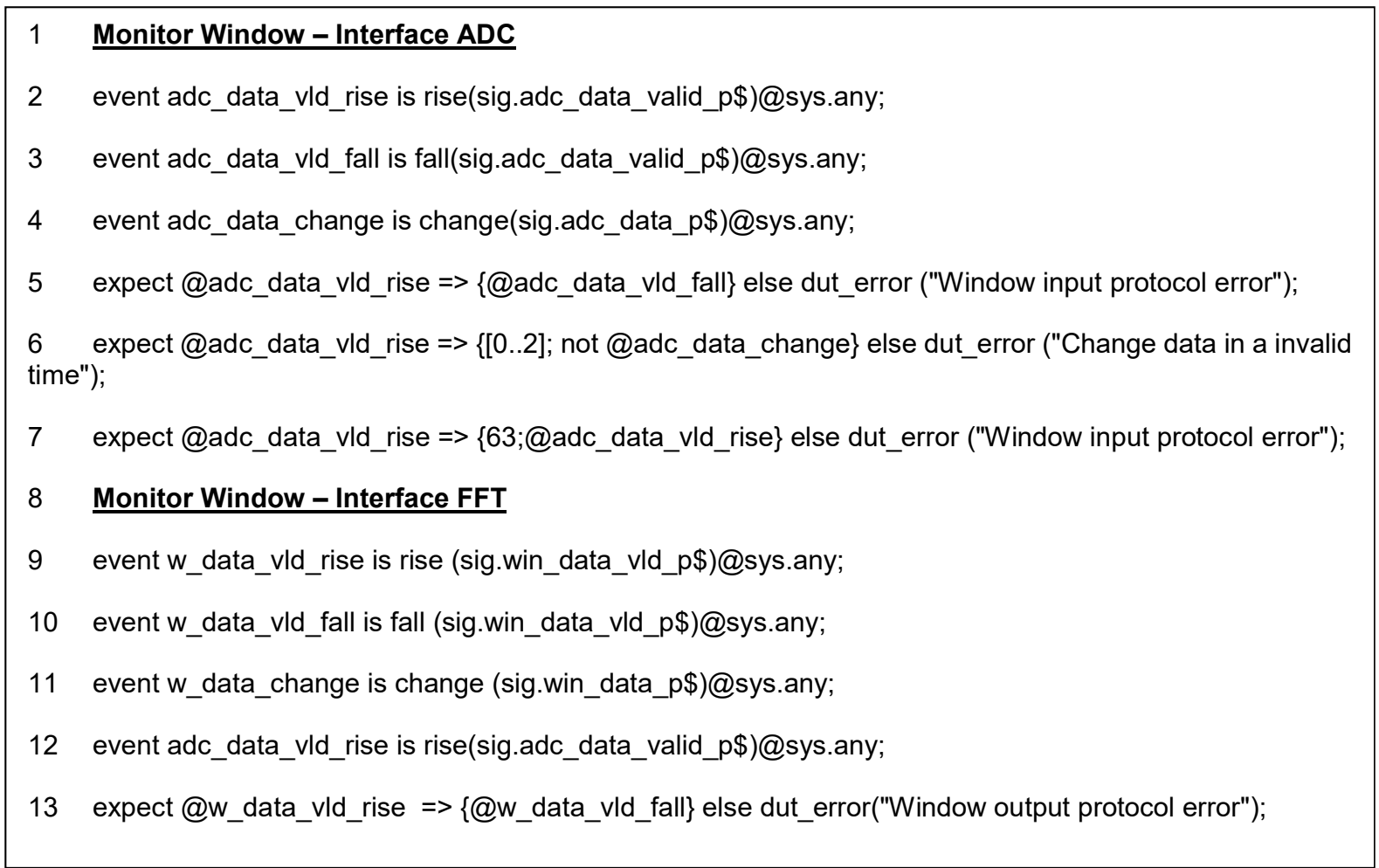

Fonte: Desenvolvido pelo autor

A Figura 5.3 ilustra o protocolo de comunicação entre os blocos ADC e Window utilizando-se formas de onda extraídas da ferramenta Incisive Simulator da Cadence $^{\mathrm{TM}}$. Todas as checagens de protocolos são realizas dentro dos monitores.

Ainda relacionado à Figura 5.3, o sinal adc_data_valid tem a duração de apenas um ciclo de relógio e é validado pelo expect descrito na Figura 5.2 linha 5; ao detectar uma subida do sinal de adc_data_valid, o sinal adc_data não poderá ter o seu valor alterado nos próximos dois ciclos de relógio, assim esta característica é validada pelo expect descrito na Figura 5.2 linha 6; a distância entre duas subidas do sinal adc_data_valid é de 64 ciclos de relógio e é validado pelo expect descrito na Figura 5.2 linha 7; o sinal win_data_valid tem a duração de apenas um ciclo de relógio e é validado pelo expect descrito na Figura 5.2 linha 13; ao emitir um sinal de subida em win_data_valid, o bloco window não poderá alterar o valor do sinal win_data nos 
próximos dois ciclos de relógio, assim esta características é validada pelo expect descrito na Figura 5.2 linha 14; e quando um dado de entrada é detectado, ou seja, quando ocorre uma subida do sinal de adc_data_valid, no próximo ciclo de relógio deverá ocorrer a emissão do win_data_valid, protocolo que é validado pelo expect descrito na Figura 5.2 linha 15.

Figura 5.3: Verificação do Protocolo da Interface ADC-Window

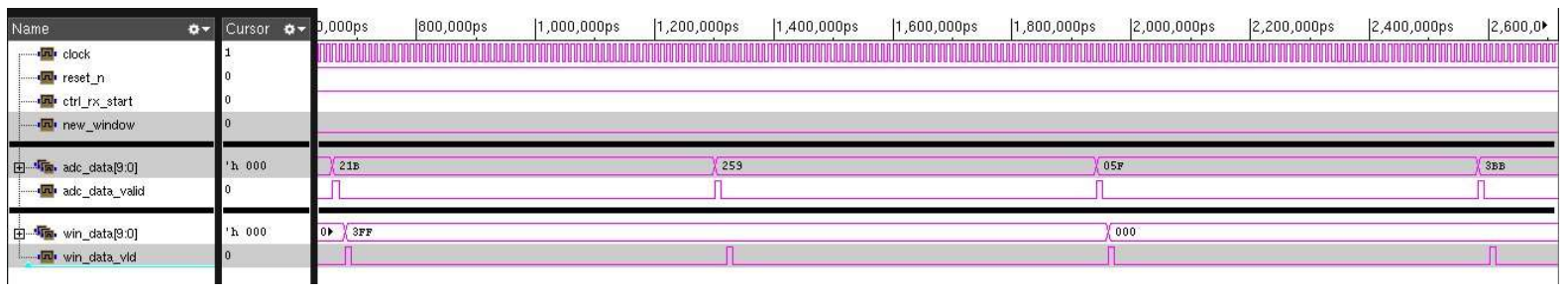

Fonte: Desenvolvido pelo autor

Além dos protocolos presentes entre blocos digitas do IP Transponder visto na Figura 4.2, o bloco FFT possui uma memória interna que, para ser acessada, precisa que um protocolo dependente da natureza da operação a ser realizada seja respeitado (leitura ou escrita). Além da comunicação entre blocos internos ao transponder, devese garantir que o protocolo de comunicação utilizado pelas interfaces APB na comunicação com o processador ARM, seja seguido. Apesar de não ser o foco desta verificação, a interface APB possui um protocolo de acesso à registradores do bloco Control e do bloco Packet Bank Ctrl.

\subsection{Verificação Analógica}

As verificações dos blocos analógicos bem com sua integração foram realizadas pelos projetistas de circuitos analógico dos Centros de Treinamento I e III. O transmissor analógico foi verificado pela equipe de projetistas analógicos do Centro de Treinamento I, onde a sua estrutura e integração foram avaliadas através de formas de onda com objetivo de garantir o seu correto funcionamento. Já o receptor analógico, apesar do autor ter realizado inúmeras análises e simulações, foi basicamente verificado pelo conjunto de instrutores do Centro de Treinamento III.

Nas simulações e análises realizadas pelo autor, foi possível detectar um problema na integração do receptor, problema relacionado ao bloco CGA. O mesmo não produzia resultados conforme o esperado, aplicando ao sinal de entrada um ganho e um deslocamento do valor médio do seu sinal de saída, o que provocava o não 
funcionamento do ADC. Após os ajustes na estrutura do bloco CGA, foi observada, através de formas de onda, a operação conforme a especificação.

\subsection{Verificação do IP Transponder Integrado}

A verificação do IP Transponder integrado foi realizada com objetivo de garantir a integração de todos os blocos digitais e analógicos bem como a validação do protocolo de comunicação estabelecido entre eles. Nesta simulação foi introduzido o modelo de ambiente descrito na seção 4.5 .2 e verificado conforme a seção 5.6. Baseado na propriedade de reutilização das estruturas de testes digitais, todos os testbenches desenvolvidos pelo presente autor foram novamente alocados, porém em modo de operação passivo, exceto para o ambiente de verificação do Packet Bank Ctrl, que foi utilizado para estimular toda a estrutura do IP Transponder (em um único testbench).

Seguindo a Figura 4.12, os estímulos enviados ao DUV exercitaram inicialmente o Packet Bank Ctrl, onde as suas saídas estimularam indiretamente o transmissor digital, passando pelo transmissor analógico, pelo modelo do ambiente, pelo receptor analógico e finalizando no receptor digital.

\subsubsection{Geração dos Pacotes para Verificação Integrada}

Em função da estratégia adotada para realizar a verificação do IP Transponder, os pacotes utilizados para estimular o DUV precisam ter as mesmas características dos dados enviados pela PCD, emulando-se o seu ambiente de operação. Devido à familiaridade com a e language na sua aplicação em outros projetos, ela foi utilizada pelo autor para criar os estímulos que foram enviados para o DUV.

Com objetivo de gerar os estímulos para a verificação integrada, uma série de restrições (constraints) e tipos enumerados foram utilizados com a finalidade de restringir a geração de dados como ilustrado na Figura 5.4, onde a criação de estímulos está de acordo com a especificação do bloco Packet Bank Ctrl. Tomando como base a estrutura de pacotes descrita na seção 4.1.2.2 e que deve ser enviada para estimular o IP Transponder, foi desenvolvido uma estrutura para gerar cada um dos campos. O uso da estrutura keep da e linguagem é responsável por fazer a restrição da geração dos campos. 
Ainda relacionado à Figura 5.4, a linha 2 define os tipos enumerados que serão utilizados para auxiliar na geração dos pacotes, enquanto as linhas de 5 a 10 definem os campos que serão utilizados para gerar os estímulos que serão enviados ao DUV. As linhas de 11 a 14 restringem a geração dos campos, bit_sync,wrd_sync, msg_init e block_num, para valores válidos para o IP Transponder, mas devido ao uso do parâmetro soft juntamente com o keep, os valores destes campos podem ser sobrescritos. As linhas 15 a 35 restringem a geração dos campos baseado no tipo enumerado, como por exemplo, caso o tipo enumerado sorteado seja MAX, automaticamente será acrescentado à estrutura do pacote o campo CRC e o tamanho dos dados úteis enviados neste pacote será máximo, ou seja, o que define o tamanho dos dados úteis, block_num, será igual a 8.

Figura 5.4: Geração de Estímulos para Verificação Integrada

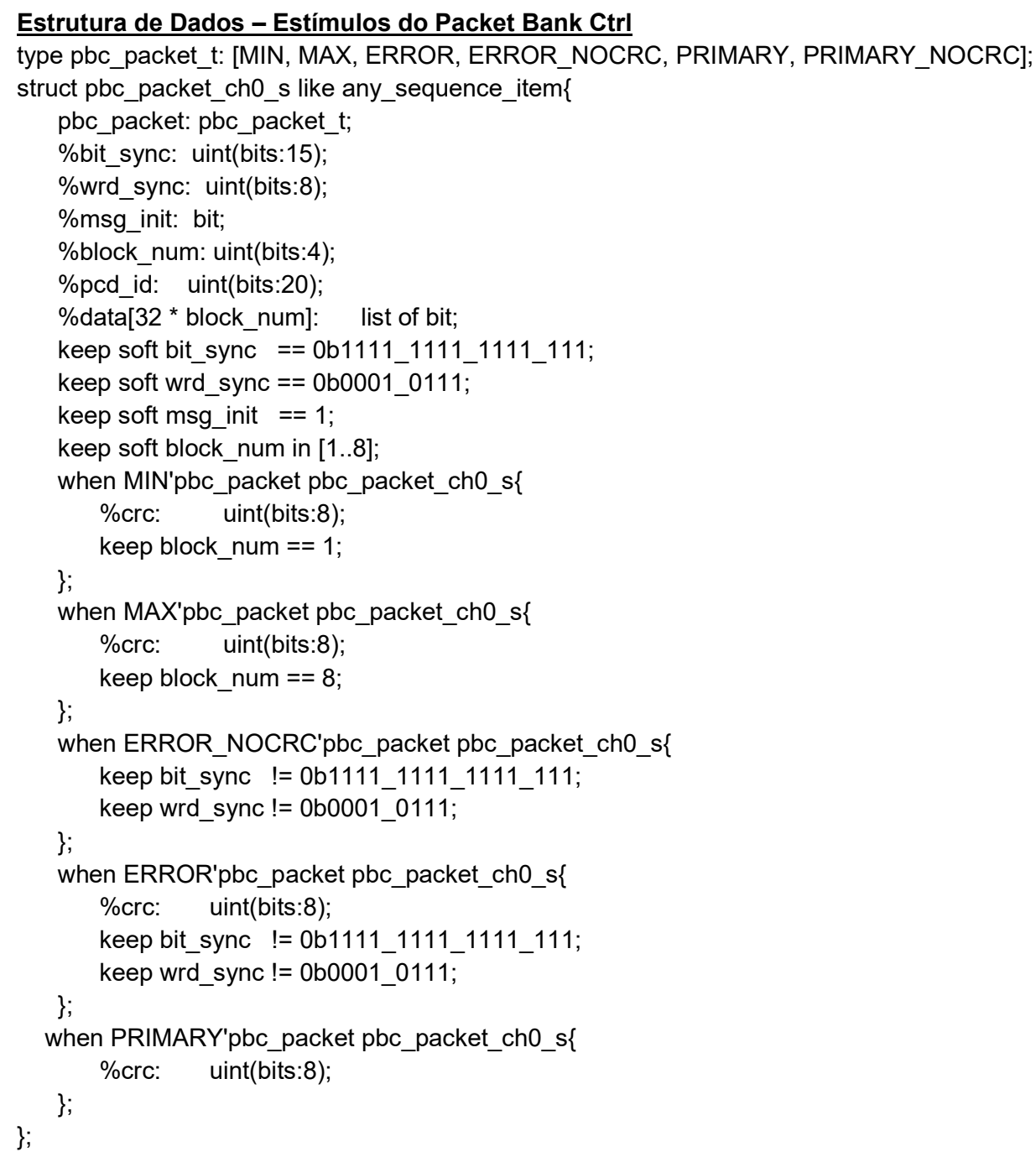


As linhas de 15 a 34 da Figura 5.4 correspondem à restrição dos campos referentes a tamanho de pacotes, inclusão ou não do campo CRC, campo de palavra de sincronismo correta ou não, e campo de bit de sincronismo correto ou não. O pacote é organizado de acordo com a Figura 5.5, onde os pacotes gerados apresentam variações no campo referente ao tamanho dos dados capturados pelos sensores (Campo F da Tabela 4.2), no uso ou não do campo CRC (Campo G da Tabela 4.2), no campo de sincronização de bits (Campo A da Tabela 4.2) e no campo de sincronização de palavra (Campo B da Tabela 4.2). Os demais campos foram gerados aleatoriamente, respeitando apenas a características de número de bits de cada campo.

Figura 5.5: Características dos Pacotes Gerados

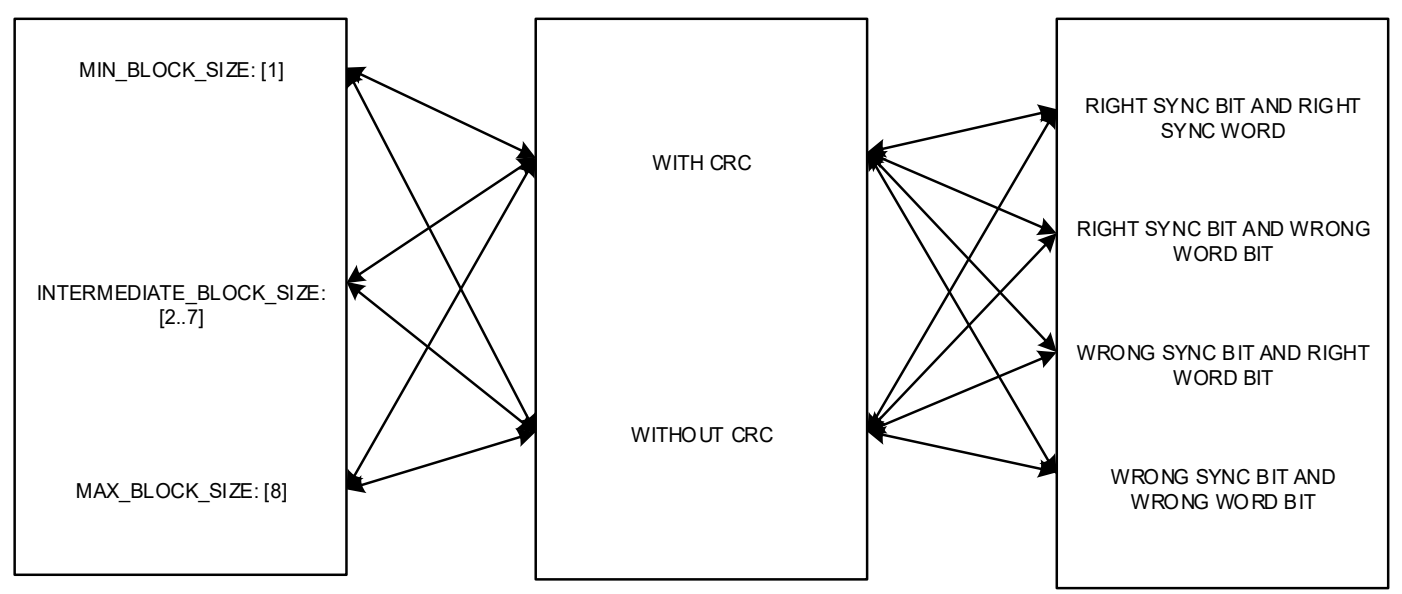

Fonte: Desenvolvido pelo autor

Os estímulos gerados devem seguir uma determinada ordem, pois a geração de alguns campos depende diretamente de algum outro campo, como por exemplo, o campo que define o tamanho do dado deve ser gerado antes do campo de dados dos sensores, estabelecendo uma relação de dependência entre eles.

\subsubsection{Simulação e Detecção de Erros}

Para garantir o correto funcionamento do IP Transponder, o presente autor iniciou a simulação gerando estímulos para o bloco Control, que é responsável por selecionar o modo de operação do IP Transponder, definindo o modo de operação com "direto" de acordo com o descrito na seção 4.1.4. Após selecionar o modo de operação do IP Transponder, estímulos foram enviado para o Packet Bank Ctrl. 
Durante o processo de verificação da integração do IP Transponder foram identificados três erros:

- Erro no protocolo de comunicação entre o Manchester Decoder e o Packet Bank Ctrl.

- Erro na recepção do Packet Bank Ctrl ao formar a estrutura do pacote.

- Erro no sinal de ativação do transmissor analógico.

- Erro no CGA com ganho elevado e offset no sinal de entrada.

Como métricas do processo de verificação, foram coletadas as coberturas funcionais e de código que atingiram 90,71\% e 95,6\%, respectivamente. Os níveis de cobertura atingidos para a verificação da integração entre os blocos digitais, analógicos e de radiofrequência do IP Transponder são suficientes uma vez que os blocos foram previamente verificados em duas outras etapas. Nesta etapa da verificação, o autor visou garantir a correta interação entre os blocos digitais e analógicos, validando os protocolos de comunicação existente entre eles. Além disso, os casos de teste gerados foram suficientes para detectar a presença de erros durante a fase de integração de todo o SoC.

\subsection{Modelo do Ambiente}

O modelo do ambiente, descrito na seção 4.5.2, é utilizado para conectar o Transmissor do IP Transponder ao Receptor do IP Transponder. O modelo contempla a utilização de dois tipos de ruídos que são inseridos separadamente, o Ruído de Cintilação (Flicker Noise) e o Ruído Branco (White Noise). De acordo com Lundberg et.al (LUNDBERG, 2002), o Ruído de Cintilação domina o espectro de ruído em baixa frequência, tendo sido observado em dispositivos eletrônicos, incluindo os semicondutores. O Ruído Branco, em conformidade com (CARTER, 2009), é um sinal aleatório que apresenta uma intensidade igual em diferentes frequências, com uma densidade espectral de potência constante.

A Figura 5.6 ilustra o código utilizado no modelo do ambiente em Verilog-AMS. As linhas 3 e 4 são utilizadas para carregar informações referentes às bibliotecas de blocos analógicos que são pré-determinadas; as linhas de 6 a 18 são utilizadas para definição de entradas, saídas e parâmetros utilizados; a linha 20 realiza a multiplicação do sinal de entrada por um sinal senoidal com uma determinada 
frequência, o que resulta em um sinal deslocado para mais e para menos na frequência do sinal senoidal; a linha 22 corresponde à filtragem do sinal, eliminandose o componente de frequência superior gerada pelo passo anterior; e as linhas 24 e 25 corresponde à inserção de ruídos cintilante e branco respectivamente.

Figura 5.6: Verilog-AMS do Modelo do Ambiente

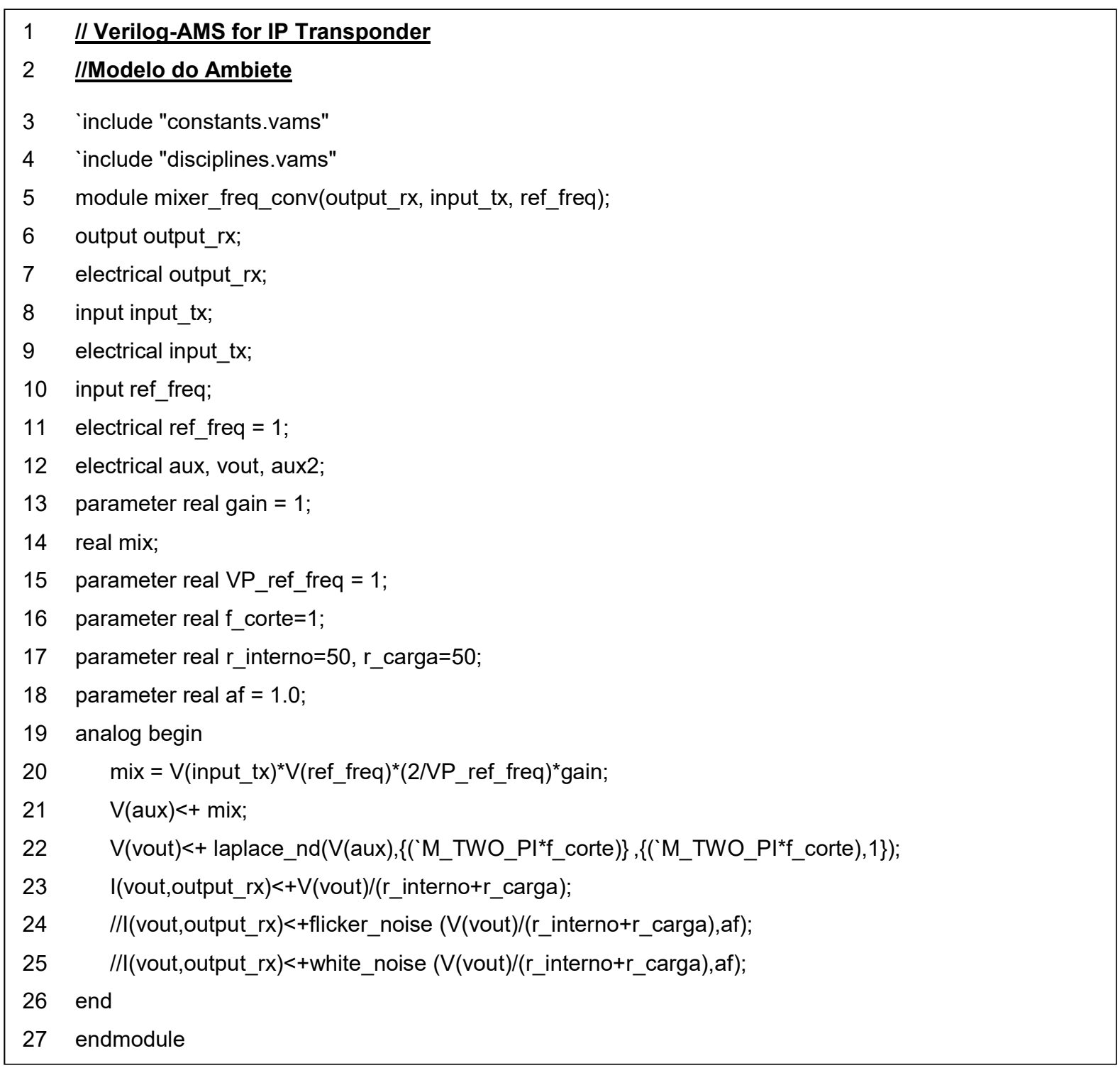

Fonte: Desenvolvido pelo autor

O modelo de referência, após ser simulado, realiza as funções conforme o esperado, transladando o sinal de alta frequência para baixa frequência e atenuando componentes de alta frequência, como pode ser observado na Figura 5.7. O sinal de entrada, envolto por uma linha tracejada Figura 5.7, presente na frequência de 2,4 $\mathrm{GHz}$, é transladado para frequência de saída em 401,65 MHz, envolto por uma linha 
traço-ponto; Figura 5.7 as componentes com frequência acima de $500 \mathrm{MHz}$ foram atenuadas, incluindo o sinal de entrada.

Figura 5.7: Sinais de Entrada e Saída do Modelo de Ambiente
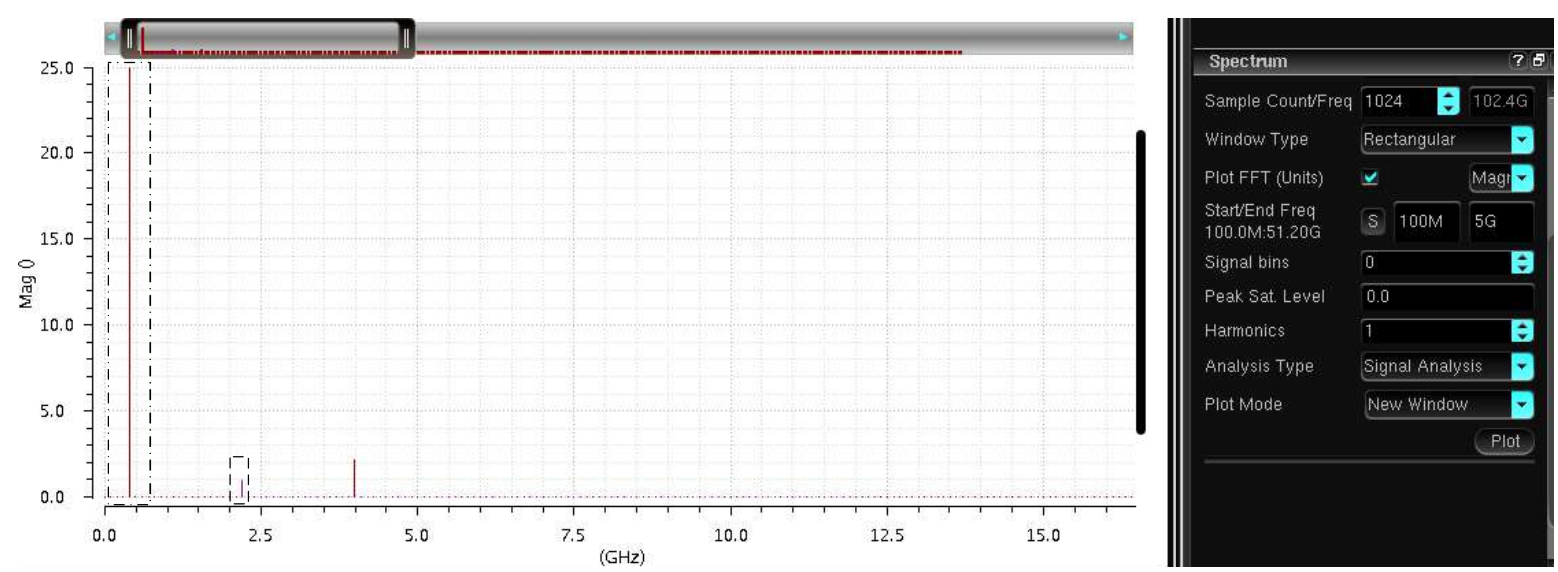

Fonte: Desenvolvido pelo autor

\subsection{Considerações Finais}

Este capítulo foi dedicado à apresentação de resultados experimentais obtidos pela aplicação da metodologia de verificação de circuitos integrados desenvolvida pelo autor que visa garantir a correta integração e o funcionamento de um circuito integrado de sinais mistos.

A metodologia de verificação de circuitos de sinais mistos inicia-se na verificação de cada bloco individualmente. Após a verificação individual, realiza-se a verificação integrada do topo do receptor digital, do topo do transmissor analógico, do topo do DSP digital. Em seguida, é feita a verificação do modelo de ambiente e da integração dos blocos analógicos. Na última etapa, é realizada a verificação integrada de blocos analógicos e digitais visando a certificação da integração entre eles e dos protocolos de comunicação entre os blocos; esta última mostrou-se ser uma metodologia eficiente, pois permitiu identificar quatro erros que não tinham sido identificados em etapas prévias do processo de verificação. 


\section{Conclusões}

Dados os fatos apresentados na pesquisa bibliográfica e, nos resultados e discussões obtidos, pode-se extrair as seguintes conclusões:

- Foram desenvolvidas alternativas integradas dos domínios analógico-digital e transmissão-recepção para melhorar a eficiência do processo de verificação, particularmente para sistemas de comunicação envolvendo transmissor e receptor, criando um modelo de ambiente capaz de conectar o transmissor analógico ao receptor analógico estabelecendo um fluxo fechado para o sinal.

- Foi desenvolvida a verificação de um circuito de sinais mistos da área de comunicação como estudo de caso: estabeleceu-se um plano de verificação, criouse o testbench e validou-se os circuitos de sinais mistos através de verificações funcionais utilizando-se os testbenches desenvolvidos para operar no modo passivo e ativo.

- Foi possível realizar a simulação do circuito, garantindo-se a funcionalidade de todo o IP Transponder em um único ambiente de simulação, onde foi possível detectar quatro erros, não detectados em etapas prévias.

- Foi realizada a verificação da interface existente entre o domínio analógico e o domínio digital utilizando-se de estruturas (expects) que são capazes de validar o protocolo de comunicação entre os blocos.

- Obtiveram-se resultados de cobertura funcional e de código, que evidenciaram a eficiência da metodologia adotada na verificação do IP Transponder. As coberturas de código foram coletadas pelas ferramentas de simulação da Cadence ${ }^{\mathrm{TM}}$.

- Foi possível criar uma estratégia para verificação e validação da interface analógico digital, focando-se principalmente na comunicação existente entre os dois domínios utilizando a estrutura expect da e language.

\subsection{Trabalhos Futuros}

A partir de reflexões realizadas durante o desenvolvimento deste trabalho, foi possível vislumbrar questões inacabadas que podem ser alvo de trabalhos futuros, com foco em: 
- Desenvolvimento de estratégias de verificação e estruturas de verificação para validação de circuitos de comunicação que operam em modo full-duplex e halfduplex.

- Desenvolvimento de uma estratégia de verificação com objetivos de garantir a correta operação do modo indireto, ou seja, incorporando o desenvolvimento de software, que deve ser compilado e salvo em memória do SoC, para realizar a correção do pacote, caso este apresente algum erro.

- Planejamento e desenvolvimento de estratégias de verificação para outras aplicações, como, por exemplo, adaptadores de rede, adotando o desenvolvendo de outros modelos de ambientes capazes de realizar a conexão de dois blocos analógicos e representar o meio de transmissão. 


\section{REFERÊNCIAS BIBLIOGRÁFICAS}

ACELLERA. Verilog-AMS Language Reference Manual. Disponível em: <http://accellera.org/images/downloads/standards/v-ams/VAMS-LRM-2-4.pdf>, p. 292, 2014. Acesso em: Novembro 2016.

AGGARWAL, P. AVM Tutorial. Disponível em: $<$ http://www.asicguru.com/methodologies/avm-tutorial/56/>, 2012. Acesso em: Novembro 2016.

AISOLA, R. et al. Verilog-A Language Reference Manual. Open Verilog International, v. 1, p. $170,1996$.

ARM. AMBA ${ }^{\mathrm{TM}}$ Specification. Disponível em: <https://www.arm.com/>, 1999. Acesso em: Novembro 2016.

. AMBA® APB Protocol. Disponível em: <https://www.arm.com/>, 2003. Acesso em: Novembro 2016.

BALASUBRAMANIAN, S.; HARDEE, P.; SYSTEMS, C. D. Solutions for Mixed-Signal SoC Verification Using Real Number Models. 2013.

BERGERON, J. Writing Testbenches: Functional Verification of HDL Models. 2nd Edition. Kluwer Academic Publishers, 2006. ISBN 978-1402074011.

BERNAL, V. B. Codificação e transmissão de sinais digitais em banda básica. Disponível em: $<$ http://www.lsi.usp.br/ volnys/courses/redes/pdf/08codif-col.pdf >, 2013 . Acesso em: Novembro 2016.

BHATNAGAR, H. Advanced ASIC Chip Synthesis. 2nd Edition. New York: Kluwer Academic Publishers, 2002.

BONFINI, G. et al. A Mixed-Signal Verification Kit for Verification of Analogue-Digital Circuits. Proceedings of the Design Automation \& Test in Europe Conference, 2006, 6-10 March 2006. p.1-6.

CADENCE. Virtuoso ADE Explorer. Disponível em: $<$ https://www.cadence.com/content/dam/cadencewww/global/en US/documents/tools/custom-ic-analog-rf-design/virtuoso-ade-explorerds.pdf $>$, 2015. Acesso em: Novembro 2016.

. Cadence's Specman tool. Disponível em: <https://www.cadence.com/>, 2016. Acesso em: Novembro 2016. 
CARTER, B. Op Amps for Everyone. Elsevier Science, 2009.

CARVALHO, P. R. B. D. Projeto de circuito Oscilador Controlado Numericamente implementado em CMOS com otimização de área. 2016. (Mestrado). Engenharia de Sistemas Eletrônicos, Universidade de São Paulo

CEITEC. CEITEC-SA Semiconductors. Disponível em: <http://www.ceitecsa.com/SitePages/home.aspx>, 2014. Acesso em: Outubro 2016.

CHAO, L. Mixed-signal verification methods for multi-power mixed-signal System-on-Chip (SoC) design. 2013 IEEE 10th International Conference on ASIC, 2013, 28-31 Oct. 2013. p.14.

CHIPUS. Chipus Microelectronics. Disponível em: <http://www.chipus-ip.com/>, 2008. Acesso em: Dezembro 2016.

COSTA, H. J. B. D. Modelagem em SystemC-AMS de uma plataforma compatível com o Sistema Brasileiro de Coleta de Dados 2009. 88 (Mestrado). Universade Federal do Rio Grande do Norte

DAS, A. M. J. Modern Verification Introduction to System Verilog and UVM 2016.

DAVID HARRIS, N. W. CMOS VLSI Design: A Circuits and Systems Perspective. 3th Edition. San Francisco: CA: Pearson, 2005.

DELORME, N. Mixed-signal verification challenges. Ph.D. Research in Microelectronics and Electronics (PRIME), 2014 10th Conference on, 2014, June 30 2014-July 3 2014. p.1-1.

ELDORADO. Instituto de Pesquisas Eldorado. Disponível em: <http://www.eldorado.org.br/>, 1999. Acesso em: Janeiro 2017.

FERREIRA, S. et al. Analog Design Methodology adopted in Training Center 1. XXVI SIM South Symposium on Microelectronics 2011.

FONSECA, A. L. T. B. D. Metodologia de Verificação Funcional para Circuitos Analógicos. 2009. 119 (Mestre). PROGRAMA DE PÓS-GRADUAÇÃO EM ENGENHARIA ELÉTRICA, UNIVERSIDADE FEDERAL DO RIO GRANDE DO NORTE

FOSTER, H. D. Trends in functional verification: A 2014 industry study. 2015 52nd ACM/EDAC/IEEE Design Automation Conference (DAC), 2015, 8-12 June 2015. p.1-6.

GLASSER, M. Open Verification Methodology Cookbook. First Edition. 2009. 
GOERING, R. Webinar Report: New Methodology Revs Up Code Coverage Analysis. https://community.cadence.com/cadence_blogs_8/b/ii/archive/2012/02/06/webinar-reportnew-methodology-revs-up-code-coverage-analysis, 2012.

HEATON, N. Maximizing Verification Effectiveness Using MDV. Disponível em: $<$ https://www.design-reuse.com/articles/4617/maximizing-verification-productivity-evc-reusemethodology-erm.html>, 2014. Acesso em: Outubro 2016.

IEEE. IEEE Standard for Verilog Hardware Description Language. IEEE Std 1364-2005 (Revision of IEEE Std 1364-2001), p. 0_1-560, 2006.

IEEE Standard VHDL Analog and Mixed-Signal Extensions. IEEE Std 1076.1-2007 (Revision of IEEE Std 1076.1-1999), p. 1-328, 2007.

IEEE Standard VHDL Language Reference Manual - Redline. IEEE Std 1076-2008 (Revision of IEEE Std 1076-2002) - Redline, p. 1-620, 2009.

IEEE Draft Standard for System Verilog--Unified Hardware Design, Specification, and Verification Language. IEEE P1800/D5, February 2012, p. 1-1304, 2012a.

. IEEE Standard for Standard SystemC Language Reference Manual - Redline. IEEE Std 1666-2011 (Revision of IEEE Std 1666-2005) - Redline, p. 1-1163, 2012b.

IEEE Draft Standard for System, Software and Hardware Verification and Validation. IEEE P1012/D17, August 2015, p. 1-262, 2015.

IEEE Approved Draft Standard for the Functional Verification Language e. IEEE 1647/D3, April 2016, p. 1-562, 2016.

ILIUŢĂ, I.; TEPUŞ, C. Constraint random stimuli and functional coverage on mixed signal verification. 2014 International Semiconductor Conference (CAS), 2014, 13-15 Oct. 2014. p.237-240.

INITIATIVE, A. S. Universal Verification Methodology (UVM) 1.2 Class Reference. Disponível em:

<http://accellera.org/images/downloads/standards/uvm/UVM Class Reference Manual 1.2. pdf>, 2014. Acesso em: Novembro 2016.

KHAN, N.; KASHAI, Y.; FANG, H. Metric Driven Verification of Mixed-Signal Designs. 2011.

LUNDBERG, K. H. Noise Sources in Bulk CMOS. Disponível em: <http://web.mit.edu/klund/www/papers/UNP noise.pdf>, 2002. Acesso em: Novembro 2016.

MAMMANA, C. I. Z. Introdução ao Projeto de Circuitos Integrados. p. 11-19, 1987. 
MARTINS, V.; CHAU, W. J.; GUEX, J. P. Mixed Signal Verification to Avoid Integration Mismatch in Complex SoCs. LATS, v. 1, p. 6, March, 20172017.

MARTINS, V. et al. Study Case of Mixed Verification Flow to cope Analog Mixed Signal Mismatch Integration SBMICRO - WCAS, v. 1, p. 4, August, 20162016.

MEALE, K. A.; ROSENBERG, S. A Practical Guide to Adopting the Universal Verification Methodology (UVM). Second Edition. 2013.

MENTORGRAPHICS. Ovm world: Open verification methodology. Disponível em: $<$ http://www.ovmworld.org/>, 2009.

MOTOROLA. SPI Block Guide. Disponível em: <https://web.archive.org/web/20150413003534/http://www.ee.nmt.edu/ teare/ee308I/datash eets/S12SPIV3.pdf>, 2000. Acesso em: Novembro 2016.

MUHAMMAD, K.; MURPHY, T.; STASZEWSKI, R. B. Verification of Digital RF Processors: RF, Analog, Baseband, and Software. IEEE Journal of Solid-State Circuits, v. 42, n. 5, p. 992-1002, 2007. ISSN 0018-9200.

NAHIR, A. Introduction to Specman and the e programming language. Disponível em: $<$ https://webcourse.cs.technion.ac.il/236605/Spring2008/ho/WCFiles/IntroToSpecmanE_4pe rPage.PDF>, 2007. Acesso em: Outubro 2016.

NEGREIROS, M. et al. System-Level Analysis for a New SBCD Transponder SoC. WCAS, Agosto 2015.

NIZIC, M. Mixed-Signal Design Trends and Challenges Disponível em: $<$ http://www.soccentral.com/results.asp?EntrylD=38597>, 2014. Acesso em: Outubro 2016.

NXP. I ${ }^{2}$ C-bus specification and user manual. Disponível em: $<$ http://www.nxp.com/documents/user manual/UM10204.pdf $>$, 2014. Acesso em: Novembro 2016.

RAE, J. C. P. Detector de Sinais para os Satelites do Sistema Brasileiro de Coleta de Dados usando Análise Espectral Digital. 2005. (Master's thesis). Technological Institute of Aeronautics (ITA), ITA, http://www.bdita.bibl.ita.br/tesesdigitais/lista resumo.php? num_tese $=000534752$.

RASHMI, V. S.; SOMAYAJI, G.; BHAMIDIPATHI, S. A methodology to reuse random IP stimuli in an SoC functional verification environment. VLSI Design and Test (VDAT), 2015 19th International Symposium on, 2015, 26-29 June 2015. p.1-5.

RODDY, D. Satellite Communications. New York: McGraw Hill: 2001. 
RODRIGUES, C. L. Análise de Cobertura Funcional na Fase de Integração de Blocos de Circuitos Digitais. 2010. (Doutorado). Coordenação de Pós-Graduação em Ciência da Computação, Universidade Federal de Campina Grande

SHETTY, A.; MAHMOODI, D. H. System Verilog Verification Methodology Manual. 2012.

SHVARTZ, A. Maximizing Verification Productivity: eVC Reuse Methodology (eRM). Disponível em: <http://www.design-reuse.com/articles/4617/maximizing-verificationproductivity-evc-reuse-methodology-erm.html>, 2014. Acesso em: Outubro 2016.

SILVA, K. R. G. D. Uma Metodologia de Verificação Funcional para Circuitos Digitais. 2007. 133 (Doutor). Processamento da Informação, Universidade Federal de Campina Grande

SIMON, S. et al. Safety-oriented mixed-signal verification of automotive power devices in a UVM environment. 2016 13th International Conference on Synthesis, Modeling, Analysis and Simulation Methods and Applications to Circuit Design (SMACD), 2016, 27-30 June 2016. p.14.

SYNOPSYS. The Industry's Widely-used and Proven Verification Methodology. Disponível em: <https://www.synopsys.com/community/interoperability/pages/vmm.aspx>, 2016. Acesso em: Novembro 2016.

TANENBAUM, A. S. Computer Networks. 2002.

Cumputer Networks. Quinta edição. 2010.

UNITEC. Unitec Semicondutores Disponível em: <http://www.unitecgroup.net/Paginas/unitec.aspx>, 2014. Acesso em: Outubro 2016.

VASUDEVAN, S. Effective Functional Verification: Principles and Processes. Springer, 2006. ISBN 978-1588298683.

VMMCENTRAL. VMM Central. Disponível em: <https://www.vmmcentral.org/>, 2013. Acesso em: Novembro 2016.

WEST, N. H. E.; HARRIS, D. CMOS VLSI Design: A circuits and systems perspective San Francisco, CA: Pearson, 2005. 


\section{Apêndice A}

\section{Código em e language para o Testbench do Manchester Decoder}

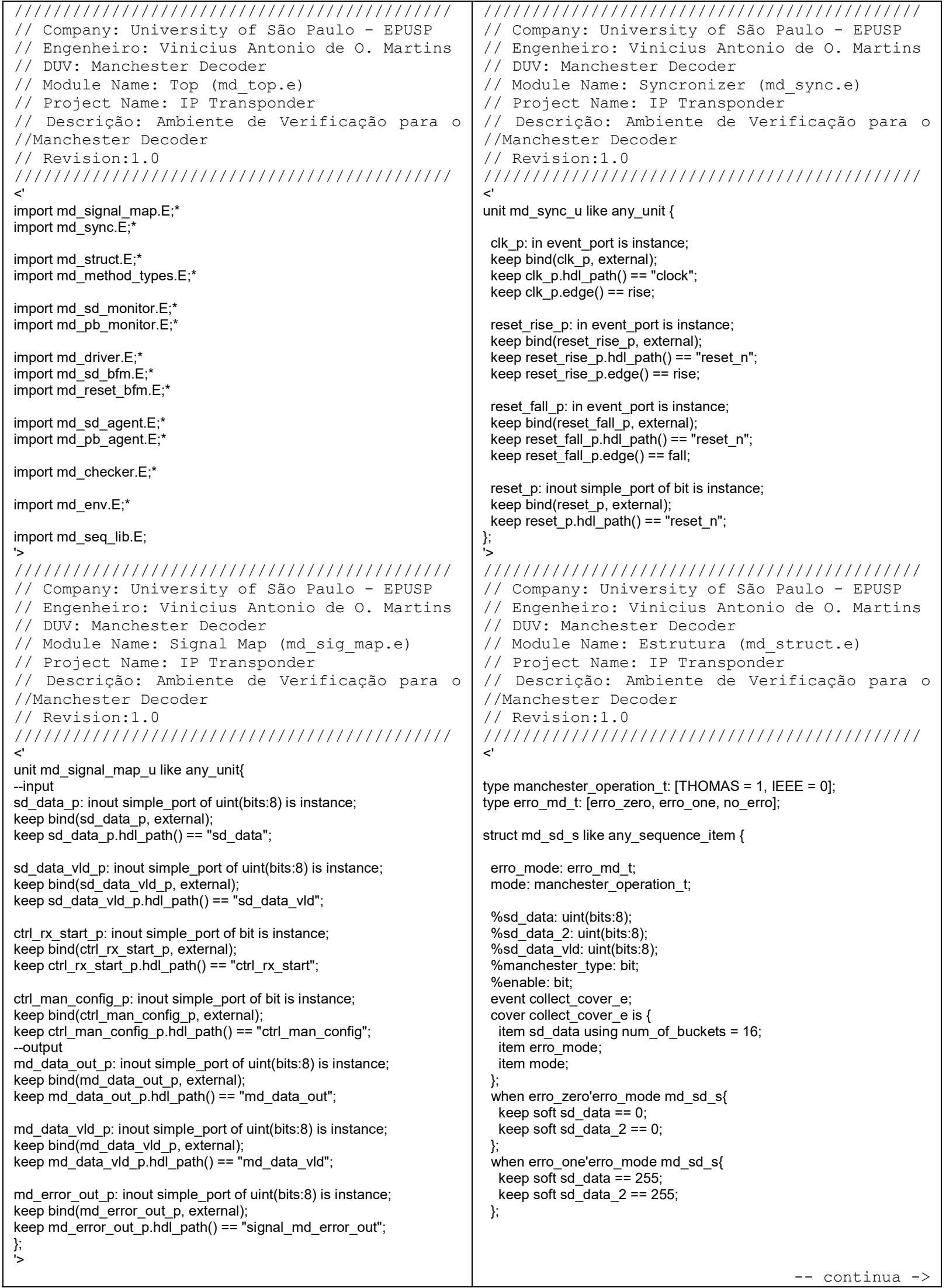




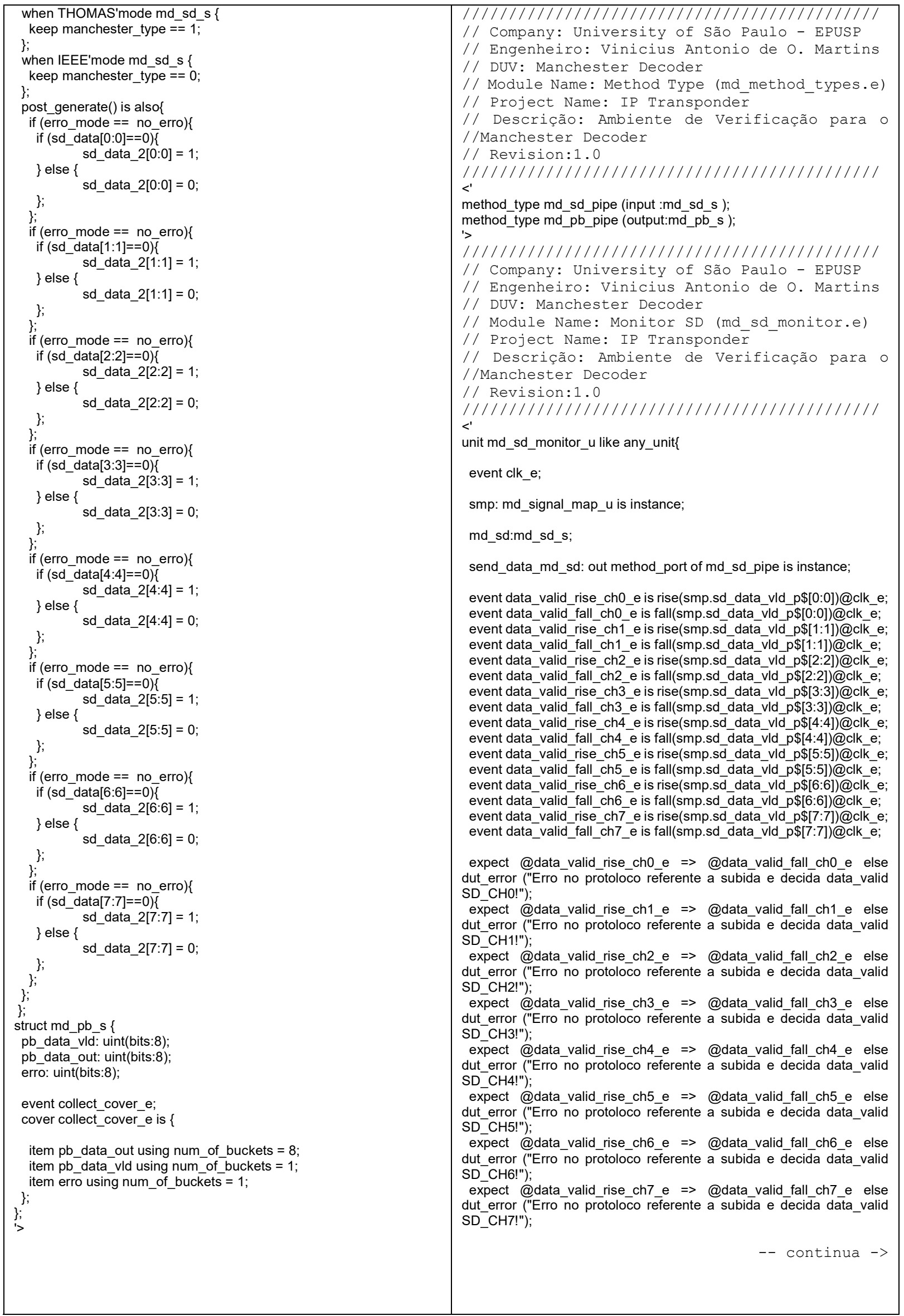




\section{md_sd_watch_bus()@clk_e is \{ \\ while TRUE\{}

wait true(smp.sd_data_vld_p $\$[0: 0]==1$ or smp.sd_data_vld_p $\$[1: 1]==1$ or smp.sd data vld $p \$[2: 2]==1$ or smp.sd data vld $p \overline{\$}[3: 3]==1$ or smp.sd_data_vld_p $\$[4: 4]==1$ or smp.sd_data_vld_p $\$[5: 5]==1$ or smp.sd_data_vld_p $\$[6: 6]==1$ or smp.sd_data_vld_p $\$[\overline{7}: 7]==1)$;

md_sd.sd_data $=$ smp.sd_data_p\$;

md sd.sd_data_vld = smp.sd_data_vld_p $\$$;

md_sd.manchester_type = smp.ctrl_man_config_p\$;

md_sd.enable $=$ smp.ctrl_rx_start_p $\$$;

wait [1];

send_data_md_sd $\$\left(m d \_s d\right)$;

\}

run() is also

start md_sd_watch_bus();

\}

\}

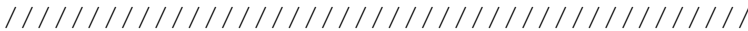

// Company: University of São Paulo - EPUSP

// Engenheiro: Vinicius Antonio de O. Martins

// DUV: Manchester Decoder

// Module Name: Monitor PB (md_pb_monitor.e)

// Project Name: IP Transponder

// Descrição: Ambiente de Verificação para o

//Manchester Decoder

// Revision:1.0

////////////////////////////////////// $<$

unit md_pb_monitor_u like any_unit \{

event clk_e;

smp: md_signal_map_u is instance;

md_pb:md_pb_s;

send_data_md_pb: out method_port of md_pb_pipe is instance;

event

data_valid_rise_ch0_e

rise(smp.md_data_vld_p\$[0:0])@clk_e;

event data_valid_fall_ch0_e is fall(smp.md_data_vld_p\$[0:0])@clk_e

event

data valid rise ch1 e

rise(smp.md data vld p\$[1:1])@clk_e;

event data_valid_fall_ch1_e is fall(smp.md_data_vld_p\$[1:1])@clk_e;

event data_valid_rise_ch2_e

ise(smp.md data vld p\$[2:2])@clk_e;

event data_valid_fall_ch2_e is fall(smp.md_data_vld_p\$[2:2])@clk_e;

event data_valid_rise_ch3_e

rise(smp.md_data_vld_p\$[3:3])@clk_e;

event data_valid_fall_ch3_e is fall(smp.md_data_vld_p\$[3:3])@clke;

event data valid rise ch4 e

rise(smp.md_data_vld_p\$[4:4])@clk_e;

event data_valid_fall_ch4_e is fall(smp.md_data_vld_p\$[4:4])@clk_e; event data_valid_rise_ch5_e

rise(smp.md data vld p\$[5:5])@clk e;

event data_valid_fall_ch5_e is fall(smp.md_data_vld_p\$[5:5])@clk_e;

event data_valid_rise_ch6_e

rise(smp.md_data_vld_p\$[6:6])@clk_e;

event data_valid_fall_ch6_e is fall(smp.md_data_vld_p\$[6:6])@clk_e;

event data_valid_rise_ch7_e

rise(smp.md_data_vld_p\$[7:7])@clk_e;

event data_valid_fall_ch7_e is fall(smp.md_data_vld_p\$[7:7])@clk_e;

expect @data_valid_rise_ch0_e => @data valid fall ch0 e else dut error ("Erro no protoloco referente a subida e decida data valid PB_CHO!");

expect @data_valid_rise_ch1_e => @data_valid_fall_ch1_e else dut_error ("Erro no protoloco referente a subida e decida data_valid PB_CH1!");

expect @data valid rise ch2 e => @data valid fall ch2 e else dut_error ("Erro no protoloco referente a subida e decida data_valid $\mathrm{PB} \_\mathrm{CH} 2$ !");

expect @data valid rise_ch3_e => @data valid fall ch3 e else dut error ("Erro no protoloco referente a subida e decida data valid PB_CH3!"); expect @data valid rise ch4 e => @data valid fall ch4 e else dut_error ("Erro no protoloco referente a subida e decida data_valid PB_CH4!");

expect @data_valid_rise_ch5_e => @data_valid fall ch5 e else dut error ("Erro no protoloco referente a subida e decida data valid PB_CH5!");

expect @data_valid_rise_ch6_e => @data_valid_fall_ch6_e else dut_error ("Erro no protoloco referente a subida e decida data_valid PB_CH6!");

expect @data valid rise ch7 e => @data valid fall ch7 e else dut_error ("Erro no protoloco referente a subida e decida data_valid PB_CH7!");

event data error_rise_ch0_e

rise(smp.md error out p\$[0:0])@clk e;

event data_error_fall_ch0_e is fall(smp.md_error_out_p\$[0:0])@clk_e; event data_error_rise_ch1_e

rise(smp.md_error_out_p\$[1:1])@clk_e;

event data_error_fall_ch1_e is fall(smp.md_error_out_p\$[1:1])@clk_e; event data_error rise ch2 e

rise(smp.md_error_out_p\$[2:2])@clk_e;

event data_error_fall_ch2_e is fall(smp.md_error_out_p\$[2:2])@clk_e; data error rise ch3 e

rise(smp.md error_out_p\$[3:3])@clk e;

event data_error_fall_ch3_e is fall(smp.md_error_out_p\$[3:3])@clk_e; event data_error_rise_ch4_e

rise(smp.md_error_out_p\$[4:4])@clk_e;

event data_error_fall_ch4_e

fall(smp.md_error_out_p\$[4:4])@clk_e;

event data_error_rise_ch5_e

rise(smp.md_error_out_p\$[5:5])@clk_e;

event data error fall_ch5_e is fall(smp.md error_out_p\$[5:5])@clk_e;

event data error rise ch6 e

rise(smp.md_error_out_p\$[6:6])@clk_e:

event data_error_fall_ch6_e is fall(smp.md_error_out_p\$[6:6])@clk_e; event data_error_rise_ch7_e

rise(smp.md error out p\$[7:7])@clk e;

event data_error_fall_ch7_e is fall(smp.md_error_out_p\$[7:7])@clk_e; expect @data_error_rise_ch0_e => @data_error_fall_ch0_e else dut_error ("Erro no protoloco referente a subida e descida do sinal de erro $\mathrm{CHO}$ !");

expect @data error rise ch1 e => @data error fall ch1 e else dut_error ("Erro no protoloco referente a subida e descida do sinal de erro $\mathrm{CH} 1$ !");

expect @data_error_rise_ch2_e => @data_error_fall_ch2 e else dut error ("Erro no protoloco referente a subida e descida do sinal de erro $\mathrm{CH} 2$ !");

expect @data_error_rise_ch3_e => @data_error_fall_ch3_e else dut_error ("Erro no protoloco referente a subida e descida do sinal de erro $\mathrm{CH} 3$ !");

expect @data_error_rise_ch4_e => @data error fall ch4 e else dut_error ("Erro no protoloco referente a subida e descida do sinal de erro $\mathrm{CH} 4$ !");

expect @data_error_rise_ch5_e => @data_error_fall_ch5_e else dut error ("Erro no protoloco referente a subida e descida do sinal de erro $\mathrm{CH} 5$ !");

expect @data_error_rise_ch6_e => @data_error_fall_ch6_e else dut_error ("Erro no protoloco referente a subida e descida do sinal de erro $\mathrm{CH} 6$ !");

expect @data_error rise_ch7_e => @data_error fall ch7_e else dut_error ("Erro no protoloco referente a subida e descida do sinal de erro $\mathrm{CH} 7$ !");

md_pb_watch_bus()@clk_e is \{

while $\bar{T} R U E\{$

wait true(smp.md_data_vld_p\$[0:0] == 1 or smp.md_data_vld_p $\$[1: 1]==1$ or $\mathrm{smp} . \mathrm{md}$ ddata_vld_p$\$[2: 2]==1$ or smp.md_data_vld_p $\$[3: 3]==1$ or

smp.md_data_vld_p $\$[4: 4]==1$ or smp.md_data_vld_p $\$[5: 5]==\overline{1}$ or smp.md_data_vld_p $\$[6: 6]==1$ or smp.md_data_vld_p $\$[7: 7]==1$ );

md_pb.pb_data_out $=$ smp.md_data_out_p $\$$;

$\mathrm{md}$ pb.pb data vld $=$ smp.md data vld $\mathrm{p} \$$;

wait [1]; md_pb.erro = smp.md_error_out_p\$;

send_data_md_pb $\$\left(m d \_p b\right)$;

\}

run() is also

\};

-- continua -> \}; 


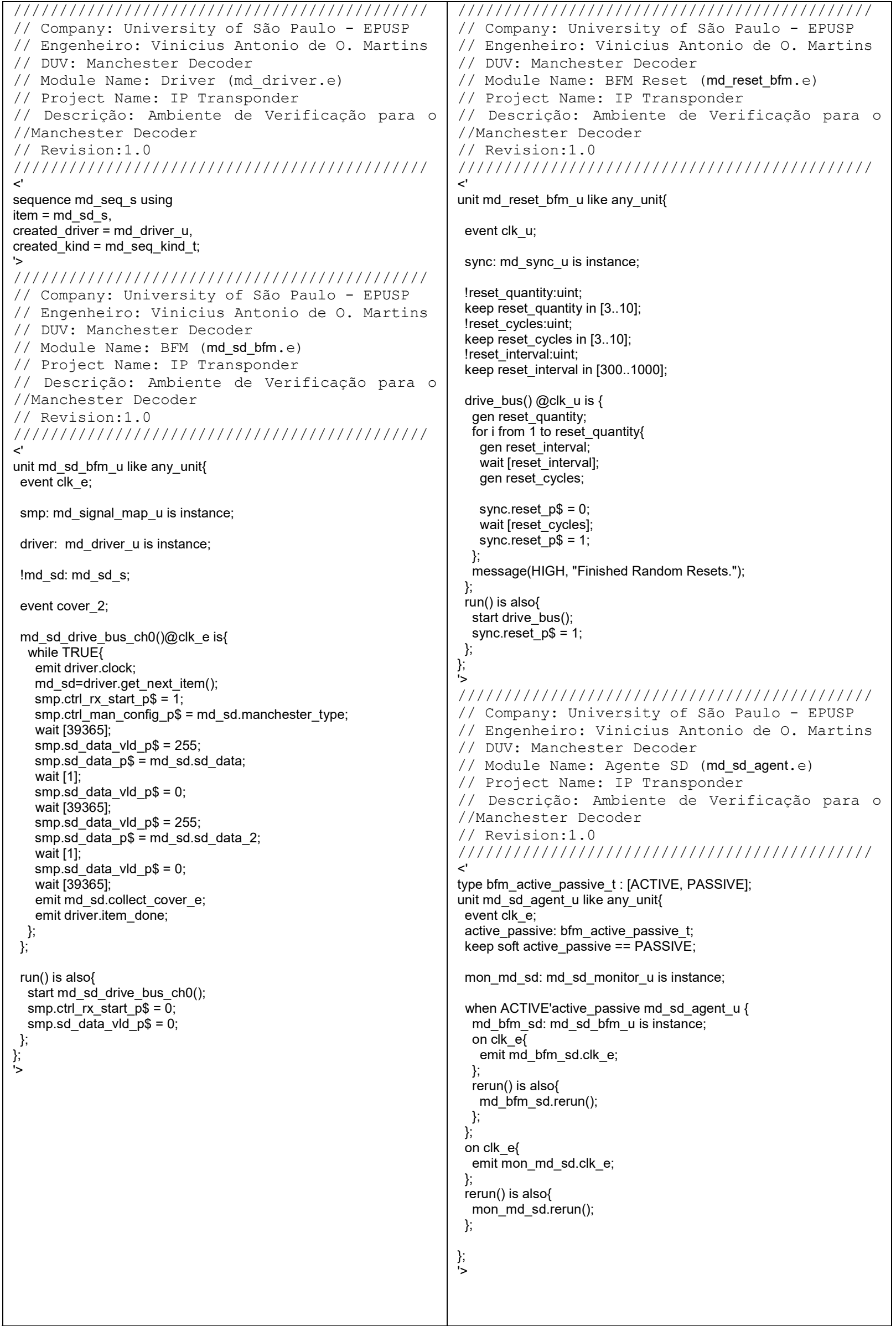




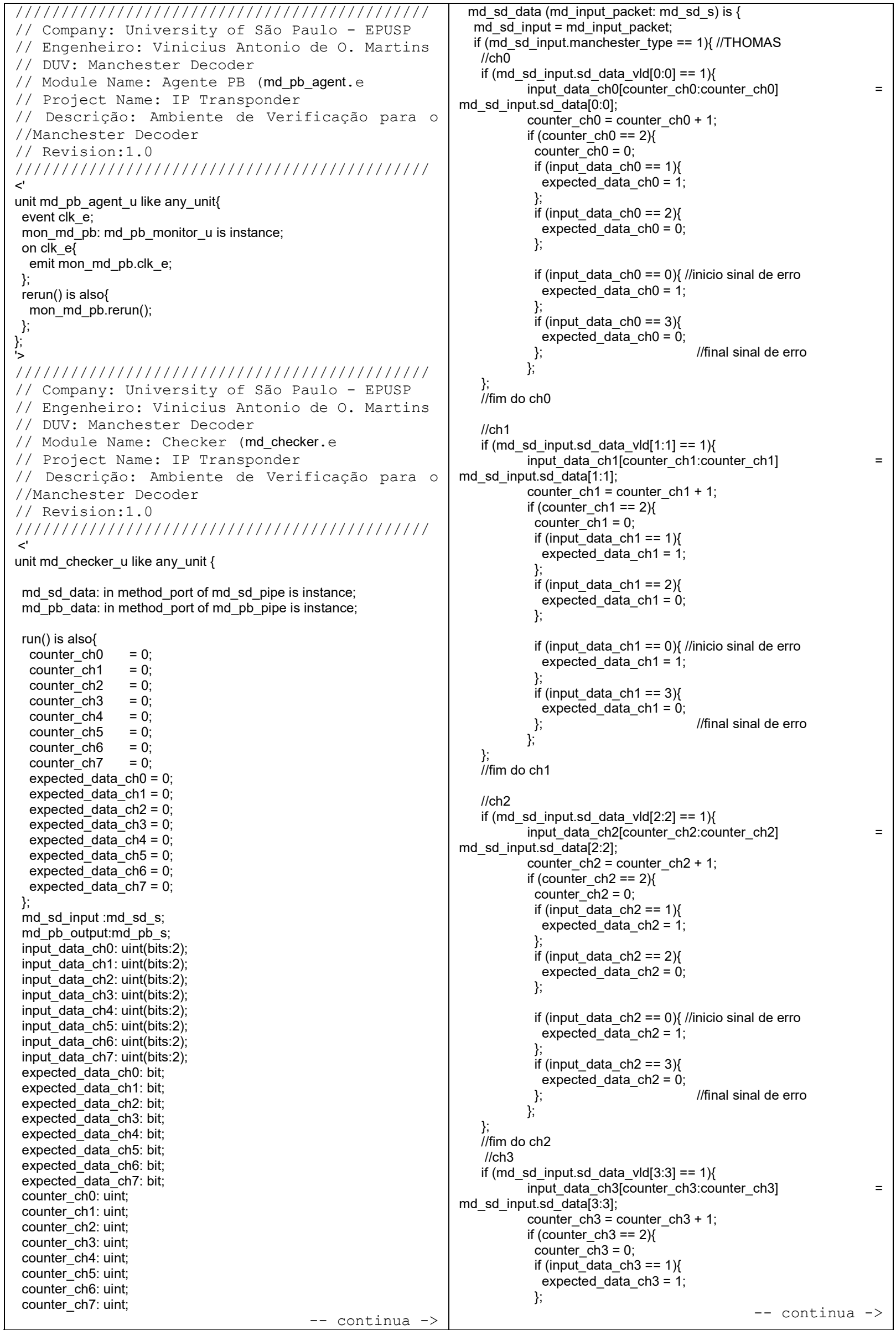




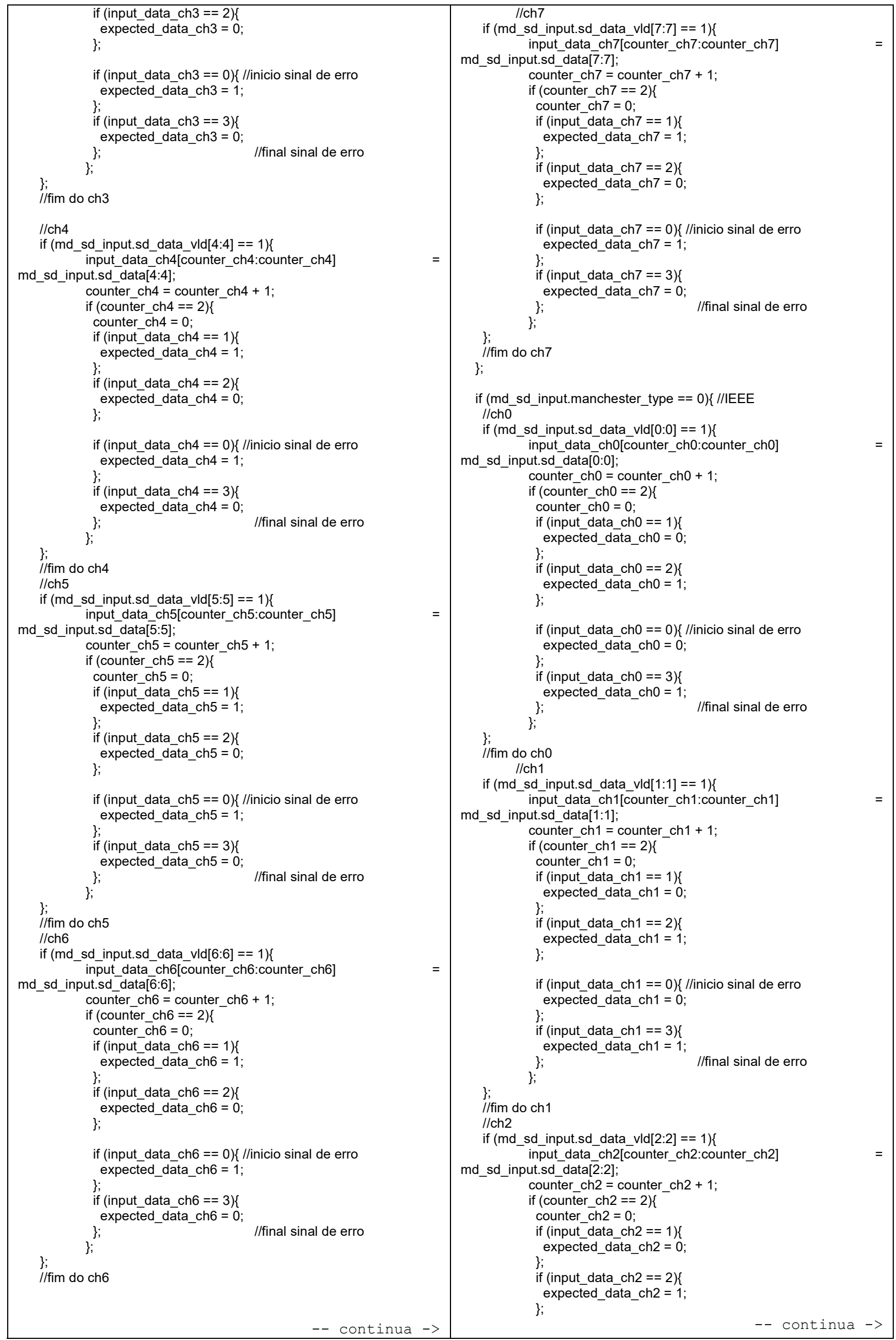




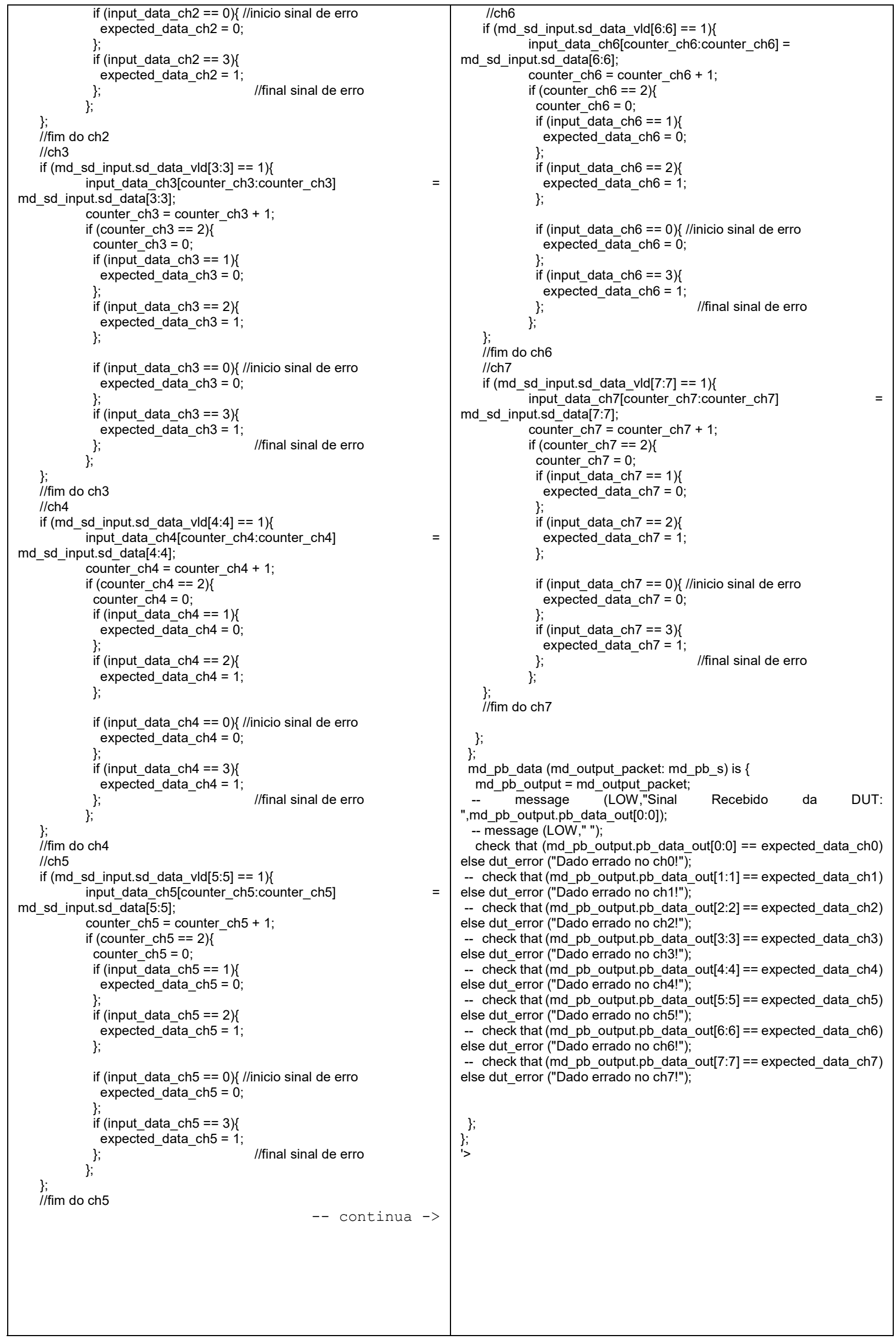


$1 / 1 / 1 / 1 / 1 / 1 / 1 / 1 / 1 / 1 / 1 / 1 / 1 / 1 / 1 / 1 / 1 / 1 / 1 / 11$

// Company: University of São Paulo - EPUSP

// Engenheiro: Vinicius Antonio de O. Martins

// DUV: Manchester Decoder

// Module Name: Environment (md_env.e)

// Project Name: IP Transponder

// Descrição: Ambiente de Verificação para o //Manchester Decoder

// Revision:1.0

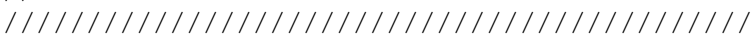

type active_passive_reset_md_t:[ACTIVE_RESET, PASSIVE_RESET];

unit md_env_u like any_env\{

sync: md_sync_u is instance;

!reset on: bool

keep soft reset_on == FALSE;

event clk_u is @sync.clk_p\$;

event clk e is true(reset on ==FALSE)@sync.clk_p\$

event reset_start_e is fall(sync.reset_p\$)@sim;

event reset_stop_e is rise(sync.reset_p\$)@sim;

md sd agent: md sd agent $u$ is instance;

md_pb_agent: md_pb_agent_u is instance;

md_checker : md_checker_u is instance;

reset_md_type:active_passive_reset_md_t;

when ACTIVE_RESET md_env_u \{

bfm_reset : md_reset_bfm_u is instance;

on clk $\mathrm{u}\{$

emit bfm_reset.clk_u;

;

\}

connect ports () is also

do_bind(md_sd_agent.mon_md_sd.send_data_md_sd,

md_checker.md_sd_data);

do_bind(md_pb_agent.mon_md_pb.send_data_md_pb, md_checker.md_pb_data);

\}

on clk_e\{

emit md_sd_agent.clk_e;

on reset_start_e\{

reset on=TRUE;

md_sd_agent.rerun();

md_pb_agent.rerun();

md_chēcker.rerun();

on reset_stop_e \{

reset_on=FALSE;

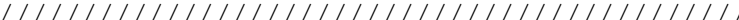

// Company: University of São Paulo - EPUSP

// Engenheiro: Vinicius Antonio de O. Martins

// DUV: Manchester Decoder

// Module Name: Sequencer Library (md_seq_lib.e)

// Project Name: IP Transponder

// Descrição: Ambiente de Verificação para o //Manchester Decoder

// Revision:1.0

/////////////////////////////////////

extend md seq kind t: [MANCHESTER NO ERRO THOMAS,

MANCHESTER NO ERRO IEEE

MANCHESTER_ERRO_ZERO_THOMAS

MANCHESTER ERRO ZERO IEEE,

MANCHESTER ERRO ONE THOMAS,

MANCHESTER ERRO-ONE IEEE, INCREASE COVER]

extend MANCHESTER_NO_ERRO_THOMAS md_seq_s \{

!a_paket:md_sd_s;

body() @driver.clock is only \{

do a paket keeping \{

it.mode $==$ THOMAS

it.erro_mode $==$ no_erro;

extend MANCHESTER_NO_ERRO_IEEE md_seq_s \{

!a paket:md_sd_s;

body()@driver.clock is only \{

do a paket keeping \{

it.mode $==$ IEEE

it.erro_mode $==$ no_erro;

extend MANCHESTER_ERRO_ZERO_THOMAS md_seq_s \{

!a_paket:md_sd_s;

body() @driver.clock is only \{

do a paket keeping \{

it. mode $==$ THOMAS;

it.erro_mode ==erro_zero;

\}

extend MANCHESTER_ERRO_ZERO_IEEE md_seq_s \{

!a_paket:md_sd_s;

body() @driver.clock is only \{

do a paket keeping \{

it.mode == IEEE;

it.erro_mode ==erro_zero;

extend MANCHESTER_ERRO_ONE_THOMAS md_seq_s \{

la_paket:md_sd_s;

body() @driver.clock is only \{

do a paket keeping \{

it.mode $==$ THOMAS

it.erro_mode == erro_one;

extend MANCHESTER_ERRO_ONE_IEEE md_seq_s \{

!a_paket:md_sd_s;

body() @driver.clock is only \{

do a_paket keeping \{

it.mode == IEEE;

it.erro mode == erro one;

extend INCREASE_COVER md_seq_s \{

!a_paket:md_sd_s;

body() @driver.clock is only \{

for i from 0 to 255 do

do a_paket keeping \{

it.sd_data $==\mathrm{i}$;

;

\}; 


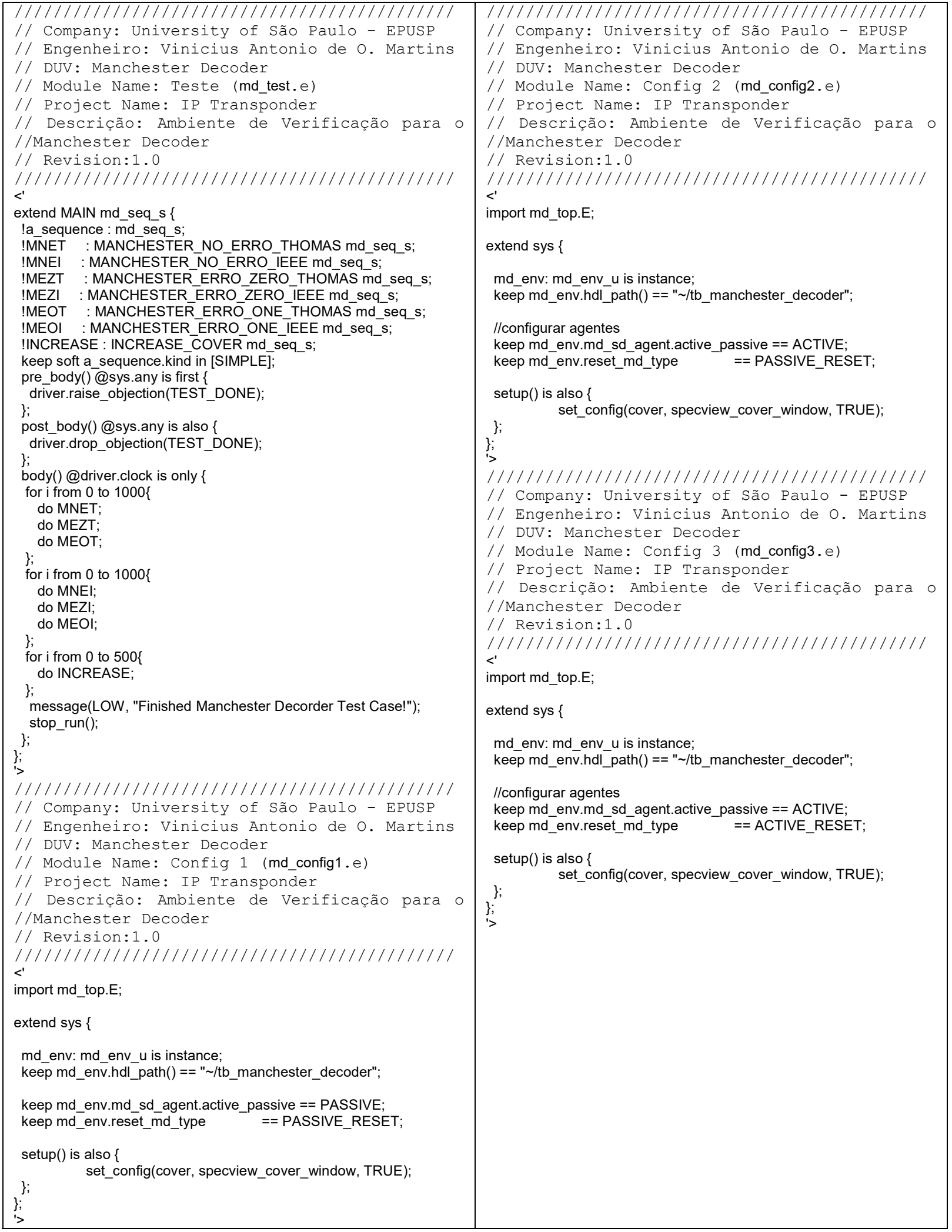

